Portland State University

PDXScholar

$1-1-1975$

\title{
Toward a theory of child abuse: a review of the literature
}

Marc F. Maden

Portland State University

Follow this and additional works at: https://pdxscholar.library.pdx.edu/open_access_etds Let us know how access to this document benefits you.

\section{Recommended Citation}

Maden, Marc F., "Toward a theory of child abuse: a review of the literature" (1975). Dissertations and Theses. Paper 748.

https://doi.org/10.15760/etd.748

This Thesis is brought to you for free and open access. It has been accepted for inclusion in Dissertations and Theses by an authorized administrator of PDXScholar. Please contact us if we can make this document more accessible: pdxscholar@pdx.edu. 


\title{
TOWARD A THEORY OF CHILD ABUSE:
}

A REVIEW OF THE LITERATURE

\author{
by \\ MARC F. MADEN
}

A thesis submitted in partial fulfillment of the requirements for the degree of

MASTER OF SCIENCE

in

PSYCHOLOGY

Portland State University

1975

(1) Marc F. Maden 1975 


\section{TO THE OFFICE OF GRADUATE STUDIES AND RESEARCH:}

The members of the Committee approve the thesis of

Marc F. Maden presented May 20, 1975
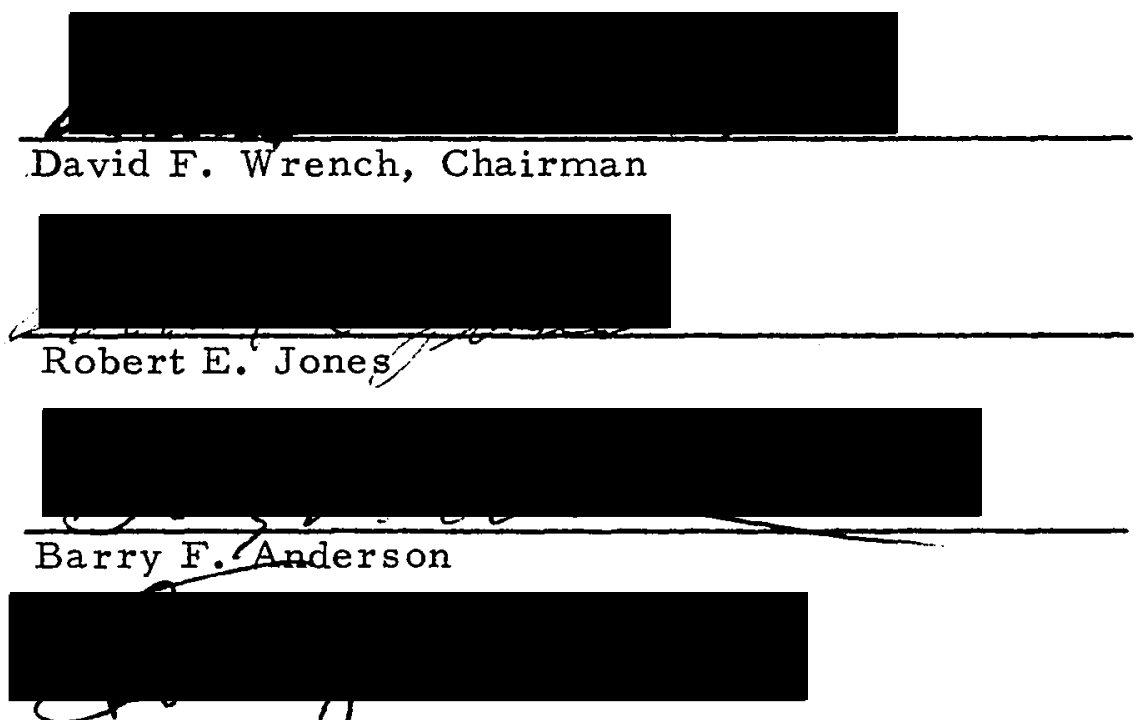

Stanley N. Cohen

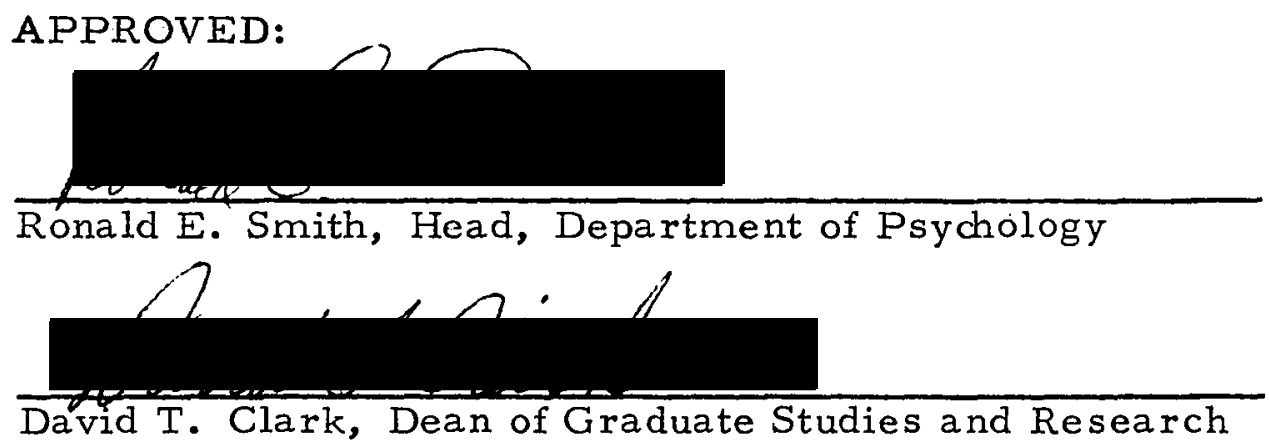

May 23, 1975 
AN ABSTRACT OF THE THESIS OF Marc F. Maden for the Master of Science in Psychology presented May 20, 1975.

Title: Toward a Theory of Child Abuse: A Review of the Literature APPROVED BY MEMBERS OF THE THESIS COMMITTEE

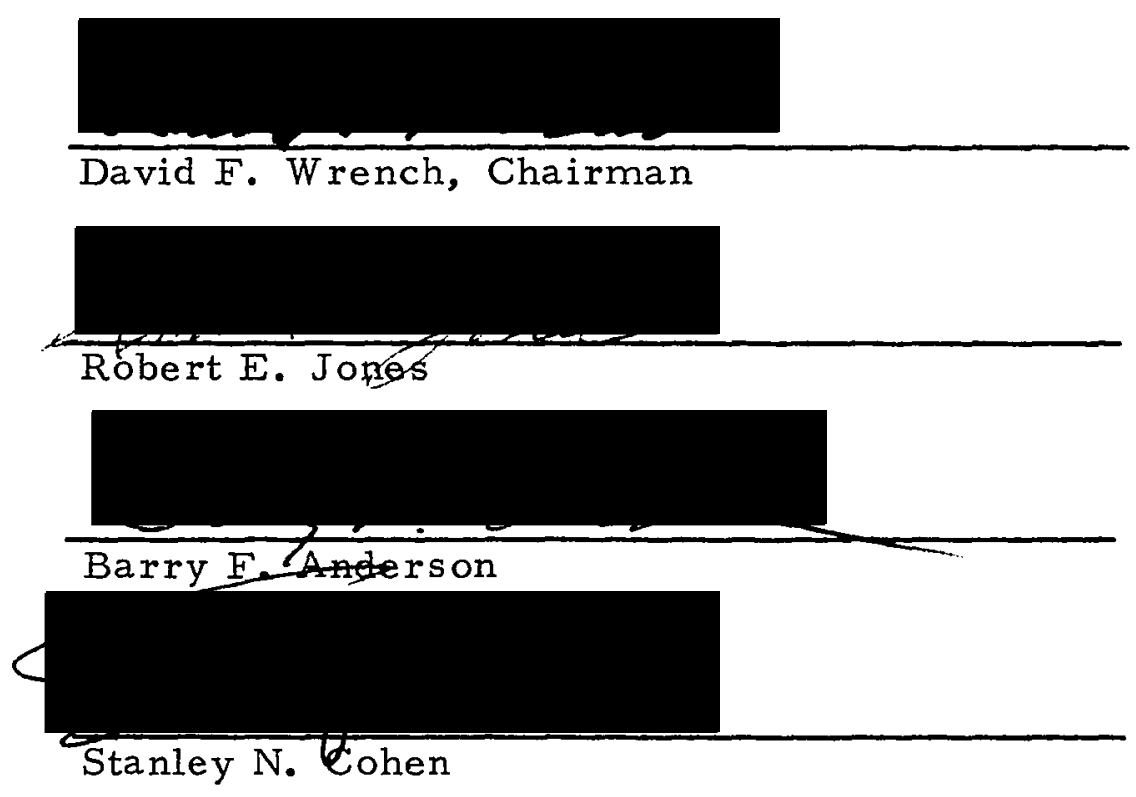

Currently, there exists no conclusive etiology of child abuse although there are two major and contrasting theories which attempt to impart a systematic interpretation to the data. The purpose of this study was to determine what are the significant factors in child abuse and to what extent the respective theories render a coherent and comprehensive explanation of these factors.

This study aggregated the data on the demographic, social, economic, and psychological features of the child abuse victim and 
perpetrator. Each study was analyzed according to a methodology of review which considered the problems involved in eliciting meaningful data from a group of studies grounded on different assumptions and conducted according to disparate research designs. The studies were compared and contrasted to determine what factors were significantly related to child abuse. Thereafter, both major theories of child abuse were tested against the findings of the literature review to determine to what extent the respective theories successfully predicted and related significant factors in child abuse.

The review of the literature clearly established a demographic profile of the child abuse victim and his family. The abused child is usually very young, typically below the age of three. Neither race nor gender are specifically related to the age of the victim. Abusing families tend to have more than the average number of children, but usually select only one child - frequently, the eldest or the youngest - as the target for abuse. The child is likely to have been born prematurely and to have had more than the usual number of serious physical illnesses or disabilities throughout his life. In addition, a significant number of abused children display intellectual, social, and psychological dysfunction which may have resulted from injuries sustained from previous abuse. Most injuries stemming from child abuse fall into the general category of superficial bruises anc' welts although compared with accidental childhood injuries, there is a higher frequency of fractures and 
head injuries. The pattern that emerges from the somewhat limited data is that abused children are unusually impaired in intellectual, social, and psychological functioning.

Nearly all child abuse is committed by parental figures most of whom are the natural mothers and fathers of abused children. Most abusing parents are around twenty-five years old reflecting the fact that the majority of abuse victims are infants and younger children. Mothers are the most frequent child abusers. Although only one parent actually attacks the abuse victim, generally speaking, the other parent is overtly, or at least covertiy involved in abusing the child. Abusing parents are characterized by a history of anti-social behavior and psychological problems. A general atmosphere of instability and disruption surrounds the child abusing family indicated by frequent discord among married parents, as well as separations and divorces. On all measures of socioeconomic status, child abusing families have low achievement and face the stresses of poverty and its associated conditions. However, neither race nor socioeconomic status distinguish the abusing family when compared with the social, racial, and economic groups to which they belong. Abusing families are distinguished by their transience and inability to maintain social contact with the com munity or affiliation with social organizations.

Neither a sociocultural or a psychodynamic theory of child abuse effectively relates and explains all the significant findings of the 
literature review. While the former predicts the several environmental factors significantly related to child abuse and the latter explains the significant findings associated with the perpetrator, neither theory provides an explanation of the role of the child abuse victim. This review suggests that an alternative theoretical framework which incorporates environmental factors and relates significant factors about the child abuse victim and perpetrator will produce the most comprehensive explanation of child abuse. 
In memory of my mother 


\section{ACKNOW LEDGMENTS}

It is a great pleasure to recall and thank the individuals who made contributions to this thesis from its inception to its completion. My deepest appreciation goes to Dr. David Wrench who originally introduced me to the study of child abuse and who, with characteristic energy, perseverance, and care, guided me expertly to completion. During the drafting and re-drafting of the manuscript, each member of my thesis committee offered constructive criticism, good counse?, and strong encouragement. I give much thanks to Dr. Barry Anderson, Dr. Robert Jones, and Dr. Stan Cohen for their help and support.

This thesis developed out of a project sponsored by the Western Interstate Commission for Higher Education and the University of Oregon Health Sciences Center, Child Psychiatry Program under the direction of Dr. Harold Boverman. I gratefully acknowledge his assistance and the cooperation of the entire staff of the Rosenfeld Center for the Study and Treatment of Child Abuse.

I extend thanks to Katie Juhl, Kristen Kotka, and Steve Farris for their assistance in revising the original manuscript and pay special thanks to Susan Teeter for her superb and expeditious rendering of the final draft. Final thanks goes to Patricia Leighton.

Finally, I express my warm appreciation to Mel Goldstein and Morris Tiktin for their best wishes. 
TABLE OF CONTENTS

PAGE

ACKNOWLEDGMENTS. • • • • • • • • • • • • • • .

CHAPTER

I. THEORIES OF CHILD ABUSE • • • • • • • . 1

The Sociocultural Theory . . . . . . . . 2

The Psychodynamic Theory . . . . . . . 10

Chapter Summary • • . . . . . . . . 18

II. THE METHODOLOGY OF REVIEWING THE CHILD ABUSE LITERATURE • • • • . • • • . 24

Definition . . . . . . . . . . . . . 24

Child . . . . . . . . . . . . . 30

Physical Abuse . . . . . . . . . 31

Sexual Abuse . . • . . . . . . . . 31

Infanticide . . . . . . . . . . . 33

Neglect . . . . . . . . . . . . 35

Intentionality . . . . . . . . . . 38

Study Design and Sampling . . . . . . . 40

Sources . . . . . . . . . . . . . . 40

Sampling . . . . . . . . . . . 45

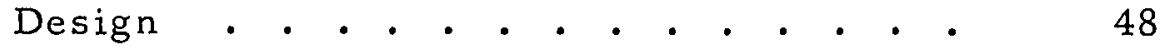

Chapter Summary . . . . . . . . . 50

III. THE CHILD ABUSE VICTIM . . . . . . . 52 
Incidence . . . • . . . . . . . . . •

Age. • • • • • • . • • . . • . • • . 56

Gender . . . . . . . . . . . . 62

Birth History . . . . . . . . . . . 67

Sibship . . . . . . . . . . . . . . 71

Race . . . . . . . . . . . . . . 77

Injuries . . . . . . . . . . . . . . 84

Previous and Subsequent Abuse . • . . . . 96

Past and Present Functioning . . . . . . . 98

Physical Functioning. • . . . . . . . . 99

Intellectual Functioning . . . . . . . . 102

Social and Psychological Functioning . . . 103

Chapter Summary • . . . • . . . . . 105

IV. CHILD ABUSERS • . . . . . . . . . . 107

Age • • . . • . . . . . . . . . . 107

Identity of Abuser • • • • • • • • • • • 109

Family Environment . . . . . . . . . 116

Socioeconomic Status . . . . . . . . . 120

Employment . . • . . . . . . . . . 121

Income . . . . . . . . . . . . 123

Occupation . . . . . . . . . . . . 125

Education . . . . . . . . . . . 127

Religion . . . . . . . . . . . . 128

Mobility . . . . . . . . . . • . . . 129

Housing • • • • • • • • • • • • • • • 130

Section Summary . • . . . . . . . . 132 
Intellectual, Social and Psychiatric Functioning . . 132

Intellectual Functioning . . . . . . . . . 134

Social Functioning . . . . . . . . . 136

Psychiatric Functioning . . . . . . . . 140

Section Summary • • • . • . • • . • 145

Chapter Summary . . . . . . . . . . 146

V. EVALUATION OF CHILD ABUSE THEORIES • • . 147

Evaluation of Theories According to Significant

Factors About the Child Abuse Victim . . . . 148

Incidence . . • • . . . . . . . . . . 148

Age . . . . . . . . . . . . . . . 148

Gender . . . . . . . . . . . 149

Birth History . . . . . . . . . . . . 149

Sibship . • . . . . . . . . • . 150

Injuries . • . . . . • • • . . • • . 151

Past and Present Functioning . . . . . 152

Evaluation of Theories According to Significant

Factors About the Child Abuse Perpetrator . . 152

Age • • • . . • . • . . . . . • . . 152

Identity of the Abuser . . . . . . . . . 152

Family Environment . • . . . . . 153

Socioeconomic Status . . . . . . . 153

Past and Present Functioning . . . . . 154

Chapter Summary and Conclusion . . . . . 155

BIBLIOGRAPHY • • • • • • • • • • • • . • • . 158 


\section{LIST OF TABLES}

I Survey: Definitional Elements of Child abuse . .

II Significant Proportion of Abused Children by Age Range Among Representative Studies . . . .

III-A Comparison of Age Distributions Among Five Selected Studies . . . . . . . . . . .

III-B Rate of Abuse by Age . . . . . . . . . . 60

IV Sex of Child Abuse Victim . . . . . . . 63

V Premature Abused Children . . . . . . 69

VI Number of Children in Abusing Families . . . 73

VII Child Abuse Victims by Race . . . . . . . 79

VIII Most Frequent Means of Attack . . . . . . 86

IX Type and Distribution of Physical Injuries Sustained by Abused Children . . . . . . . 88

$\mathrm{X}$ Comparison of Injuries Sustained by Abused and Nonabused Children . . . . . . . 90

XI Fatalities Resulting from Child Abuse . . . . 92

XII Severity of Child Abuse Injuries 94

XIII Hospitalized Child Abuse Victims . . . . . . 94

XIV Previously Abused Children . . . . . . . 96

XV-A Age Distribution of Abusing Mothers . . . . 107

XV-B Age Distribution of Abusing Fathers . . . . 108 
TABLES

PAGE

\begin{tabular}{|c|c|c|c|c|c|c|c|}
\hline $\mathrm{XVI}$ & Mean Age of Abusing Parents . . & & • & . & & & 109 \\
\hline XVII & Identity of the Child Abuser... & & & & & & 111 \\
\hline XVIII & Income Distribution of Abusing Fami & & & & & & 125 \\
\hline XIX & Occupations of Abusing Parents. & & 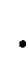 & & & • & 26 \\
\hline $\mathrm{XX}$ & Educational Achievement of Abusing & & & & & & 28 \\
\hline $\mathrm{XXT}$ & Religious Affiliation of Child Abuser & & & & & & \\
\hline
\end{tabular}


CHAPTER I

\section{THEORIES OF CHILD ABUSE}

The contemporary study of child abuse commenced with

Caffey's (1946) observation of the relationship between severe head injuries and fractures in the long bones of children. Following Silverman's (1953) positive identification of the traumatic origin of these injuries, Wooley and Evans (1955) concluded that many of these injuries were willfully inflicted. In 1962 Kempe et al. (1962) proposed the term "battered child syndrome" to describe children who had sustained serious physical injury in circumstances which indicated that the injury was intentionally caused.

In the ensuing years, research efforts have generated a considerable amount of data about. the victims and perpetrators of child abuse. Currently, there exists no conclusive etiology of child abuse although there are several theories that impart a systematic interpretation to the data. The purpose of this chapter is to compare and contrast the two major explanatory paradigms of child abuse as a way of establishing the theoretical context for the research data presented in Chapters III and IV.

David Gil, professor of social welfare, not unexpectedly offers a sociocultural theory that identifies cultural conditions and 
environmental circumstances as the most significant set of factors in child abuse. $^{1}$ Psychiatrists Brandt Steele and Carl Pollock not inconsistently present a psychodynamic theory that relates child abuse to the personality and personal history of the perpetrator. ${ }^{2}$ Throughout the discussion that follows, the basic theme that distinguishes the two theories is the extent to which the respective theorists consider that child abuse is a situation or personality generated phenomenon.

\section{THE SOCIOCULTURAL THEORY}

Gil (1970) presents a complex conceptual framework which employs a set of forces, dimensions, and circumstances to explain child abuse. In response to the question, "why and under what conditions do some persons go beyond a culturally sanctioned level of physical violence against children," he lists five forces:

1. environmental chance factors;

2. environmental stress factors;

3. deviance or pathology in areas of physical, social, inte]lectual, and emotional functioning on the part of caretakers and/or the abused children themselves;

4. disturbed intrafamily relationships involving conflicts between spouses and/or rejection of individual children;

${ }^{1}$ David G. Gil, Violence Against Children (Cambridge, Mass.: Harvard Univ. Press, 1970).

${ }^{2}$ Brandt F. Steele and Carl B. Pollock, "A Psychiatric Study of Parents Who Abuse Infants and Small Children, " in The Battered Child, ed. Ray E. Helfer and C. Henry Kempe, 2nd ed. (Chicago: Univ. of Chicago Press, 1974). 
5. combinations of these sets of forces (p.135). Having concluded that the phenomenon of child abuse is multidimensional, Gil recasts his forces into a hierarchy of five dimensions. The basic dimension upon which all others rest is "the general, culturally determined permissive attitude toward the use of a measure of physical force in the caretaker-child interaction, and the related absence of clear-cut legal prohibitions and sanctions against this particular form of interpersonal violence" (p. 135). For Gil, "a key element to understanding physical abuse of children in the United States seems to be that the context of child-rearing does not exclude the use of physical force toward children by parents and others responsible for their socialization" (p. 134). The second dimension is the specific child-rearing traditions, practices, and attitudes among different social classes and ethnic or racial groups. According to Gil, the evidence collected from his nationwide survey supports the generalization that families that are nonwhite and/or of low socioeconomic status use corporal punishment more frequently. Chance environmental factors constitute the third dimension. A child flung across the room who accidentally collides with a radiator causing burns and bruises is an example how chance may "transform an otherwise acceptable disciplinary measure into an unacceptable outcome $^{\prime \prime}$ (p. 136). Environmental stress factors including and combining poverty, inadequate housing, unemployment, etc comprise the fourth dimension. Gil explains that these factors may "weaken a 
person's psychological mechanisms of self-control, and may contribute thus to the uninhibited discharge of aggressive and destructive impulses toward physically powerless children, perceived to be of stress for real or imaginary reasons" (p. 136). The last dimension embraces the various forms of deviance. in physical, social, intellectual, and emotional functioning in both the perpetrator and victim as well as the family to which they belong.

Finally, Gil perceives a simple structure which identifies the most frequent contexts in which child abuse occurs according to a factor analysis of 1,380 incidents. His typology of precipitating circumstances includes:

1. Psychological rejection leading to repeated abuse and battering;

2. Disciplinary measures taken in uncontrolled anger;

3. Male babysitter acting out sadistic and sexual impulses in the mother's temporary absence, at times under the influence of alcohol;

4. Mentally or emotionally disturbed caretaker acting under mounting environmental stress;

5. Misconduct and persistent behavioral atypicality of a child leading to his own abuse;

6. Female babysitter abusing child during mother's temporary absence;

7. Quarrel between caretakers, at times under the influence of alcohol (pp. 140-141).

At this juncture, it is appropriate to translate Gil's conceptual frameword into a coherent theory and to identify the assump- 
tions upon which it is grounded.

The essential theorem in Gil's paradigm is that "culturally determined permissive attitudes toward the use of physical force in child-rearing seem to constitute the core of all physical abuse of children in American society" (p. 141). Gil concurs in the general observation that violence is endemic to American society as evidenced by the number of homocides, assassinations, rapes, and armed

robberies. American society accepts a high level of violence in general, and in particular, condones a measure of physical force in its child-rearing philosophy and practices. This sanction is communicated to and thereby perpetuated in the culture through the popular and professional media.

Gil presumes that what generates violence in America is the "uninhibited pursuit of self-interest" and the unequal distribution of wealth and resources that result from it. Moreover, racial discrimination serves to create additional inequality within the society with the consequence that nonwhites are frequently confined to the lowest socioeconomic classes. The violence that underlies racial discrimination is internalized within racial minorities which then intensifies the general level of cultural violence for these specific groups. It has been suggested, moreover, that law enforcement within discriminated groups is often disregarded by the policing agencies who find it easier and safer to avoid intervention. This gives license to unlawful 
activities which contribute to a culture of violence within groups, typically nonwhite, who are discriminated against by the social majority. Poverty compounded by racial discrimination imposes harsh environmental stresses on its victims and accentuates stresses which confront any individual. Finally poverty conditions are closely associated with a range of intellectual, social, and psychological deviance.

Given this body of general assumptions, Gil's paradigm of child abuse reduces to the following theory from which is derived a set of actions predicted to eliminate or reduce child abuse:

Child abuse is a multidimensioned phenomenon caused by forces operating on a hierarchy of three environmental levels. The substratum upon which the other forces operate is the permissive attitude about the use of physical force in socializing children in America. Gil speculates that corporal punishment is consonant with American social values and serves the function of instilling children with those values as a means of surviving in the society. Subcultures i. e. nonwhites particularly subject to social violence respond with an intensified violence that permeates those cultures and sanctions the use of physical force in the preparing their children to deal with social realities.

Operating upon the predisposition toward violence are a set of socioeconomic factors - themselves, derivatives of violence - that 
place financial and emotional burdens on potential child abusing families. These relevant conditions include: 1) unemployment or underemployment that places the livelihood of the family in jeopardy and alters the traditional roles of its members; 2) substandard housing that creates an inherently unsafe physical environment for children and aggravates by close physical proximity, tensions that inevitably arise; 3) insufficient education that ill prepares parents to plan family size and care for their children; 4) inadequate and expensive medical care that neither prevents nor remedies illness and often drains families of already scarce resources.

These conditions in association with a set of chance factors create situations that precipitate a child abuse incidents. For example, a fatherless household ruptured by an unstable marriage where a male babysitter is substituting for the mother and under the influence of alcohol are a set of circumstances sufficient to generate an abusive act against a misbehaving child. The fact that the same child under the care of his mother and/or a competent babysitter would not have received a physical injury illustrates the unique interplay of circumstances that precipitates a child abuse incident.

Gil's agenda of social actions is designed to attack the causes of child abuse at the three levels at which they operate. Gil proposes a comprehensive community program of family planning, counseling, and educational services, day care facilities, and child protection 
agencies to eliminate or ameliorate circumstances which forge a child abusing situation. In addressing the role of poverty conditions in generating child abuse, Gil recommends simple and complete elimination of poverty by means of a guaranteed income maintenance supplemented by a national health service, decent public housing, and cultural and recreational facilities. At the core of abuse is the American culture of violence and racial discrimination. Gil advocates the transvaluation of American social values in the direction which emphasizes nonviolence and cooperation. More specifically, he calls for the symbolization of rejecting violence against children by establishing legal prohibitions against the use of physical force against a child by any individual.

In conclusion it is worthwhile to consider Gil's approach in developing his theory since it is well known that an individual's predispositions - personal and academic - help select the paradigm with which he will organize the data relevant to phenomena that want explanation. More subtly, an individual's paradigmatic disposition will - consciously or unconsciously - influence what phenomena need explanation as well as what kinds of information are considered significant and sufficiently related to formulate those explanations. During the years 1967-68, Gil conducted a nationwide survey of all 12, 610 legally reported incidents of physical child abuse in the United States and its territories. These incidents were analyzed 
along a number of demographic, socioeconomic, and situational factors according to a schedule of multiple choice questions. It is interesting to note that spaces for written responses were provided only for a description of the child abuse event and the occupations of the parents. Moreover, none of the subjects were directly interviewed by Gil and all data, generally speaking, relied on the reports from social welfare agencies. The point to be made is that the data elicited about the child abuse incident were modified by the subjects themselves for obvious reasons and/or abbreviated by the interviewers translating the information into their schedule. Moreover, the abstracted information was subject to a factor analysis which re-related the pieces of information into a pattern that may or may not conform to reality. In other words the logic of inquiry may itself operate from a paradigm that selects only the kinds of data that fall into its pattern.

To expose the difficult and subtle problem of predetermined theories is a way of introducing Steele and Pollock's (1968) theory of child abuse. Their approach to formulating an explanation of this phenomenon is distinctive and no less clearly reflects a certain predisposition. Consider that their empirical data pool comprises only sixty cases of abusing families they treated over a period of five and one half years at the University of Colorado psychiatric clinic. It is significant that, in stark contrast to Gil, they present no precise and uniform demographic or socioeconomic information on their subjects. 
Rather, the data consisted of a set of lengthy and in depth descriptions of the subjects' personal appearance and behavior; histories of their childhood and marriages; and reports about their fantasies and dreams (Note that Gil designates no category in his schedule for either dreams or fantasies). The point to be made is that clearly Steele and Pollock operate with a paradigm that explains behavior according to the way in which an individual manipulates his environment, not how the environment influences that individual.

\section{THE PSYCHODYNAMIC THEORY}

A theory of child abuse that interprets this behavior as psychodynamically determined rests on several assumptions. Like Gil, Steele and Pollock observe that "yelling, scolding, slapping, punching, hitting, and yanking acted out by parents on very small children" indicate "a pattern or style of child rearing quite prevalent in our culture" (p. 90). What distinguishes the child abuser from the nonabuser is that the former implements the culturally sanctioned use of physical force in child rearing with an exaggerated intensity and at an inappropriately early age. In other words, the psychodynamic paradigm presumes that the perpetrator is acting out of context with his environment. Paradoxically, what explains the act of abuse is the observation that the perpetrator is not sufficiently influenced by his environment and therefore not acting in accordance with it. Why an individual loses his sense of reality requires another explanation. 
The psychodynamic theory of behavior in general assumes that to a very great extent, each individual is a product of his early childhood experiences. (The fact that child abuse involves young children accentuates the applicability of the psychodynamic theory according to its adherents.) Parallel to Gil, Steele and Pollock recognize that an individual is shaped by the culture in which he is nourished although the focus of their attention is the family milieu. Since the dominant members in the family are typically the parents, it is the relationship between a young child and his parents that largely establishes the pattern of relating with other significant figures in subsequent micro and macro societies.

Represented in the mechanisms of psychoanalytic theory, behavior results from the product of instinctual patterns of survival (id) and acquired ideals of functioning (superego) mediated by an agency that relates these intrapsychic forces with the environment (ego). The relative strengths of these agencies, determined for the most part by the extent of their development in early childhood, decides the particular pattern of response to a situation. For example, if the superego is overdeveloped in an individual, its pattern of response incorporated into a set of behaviors will dominate in acting and reacting.

The superego is the intrapsychic agency whose origin and operating is most relevant to the phenomenon of child abuse. The superego is basically defined as the system of personality that repre- 
sents the values and traditions of society as interpreted to the child by, primarily, his parental figures. It is at this juncture that the sociocultural or environmental theory of behavior coincides with the psychodynamic or psychoanalytic explanation. It is important to note that what is internalized in the child is not purely the sociocultural parameters but the parental interpretation of those parameters themselves mediated by the child's perception of those parents. In other words the child's emotional relationship with his parents will color the transmission of cultural norms from one generation to another. There are a number of significant behavioral patterns that comprise a relationship between parent and child, not the least of which is the initial caretaking of the infant. Steele and Pollock distinguish two basic functions of this caretaking process, "mothering and motherliness." Mothering describes those activities most typically performed by the maternal figure which sustain the life of a thoroughly dependent individual at infancy. These practical or technical activities include feeding, clothing, cleaning, etc. Without these provisions, a human infant will not survive. Motherliness, on the other hand, describes an attitude, approach, and sense of responsibility that are represented in a tender awareness of the emotional as well as physical needs of an infant. Without these provisions, an infant would survive but not grow and develop to its potential.

The major assumptions underlying the psychodynamic paradigm now having been explicated, it remains to describe the intra- 
psychic forces and the psychological processes that comprise Steele and Pollock's theory of child abuse.

The theory rests on the central theorem that there is a direct relationship between the behavior of the child abuse perpetrator and that individual's experience as a child. More particularly, the theorem states a congruence between the pattern of parenting practiced in adult life - mothering, but especially motherliness - and the pattern of parenting that individual himself received as a child. It is important to note that the term "motherliness" does not attribute the attitude and feelings it describes exclusively to biological mothers. However, since maternal figures almost always provide the initial care for and establish the primary relationship with their children, the original and most sustaining impressions of caretaking are associated with the mother. Significantly, child abuse victims recall that even in the instance where the father figure was the actual attacker, they experienced the inability of the mother figure to protect them as more devestating. Essentially, it is the mother's pattern of early parenting that gets incorporated into the superego. Note that Steele and Pollock place strong emphasis on "the significance of this early experience in the development of recognizable superego rudiments. . 3

${ }^{3}$ Steele and Pollock (1968, p. 107) quote Rene Spitz who finds that although the superego takes its final form after the resolution of the Oedipal conflict around age five as posited by Freud, "there are significant superego precusors and rudiments existing as early as the first year of life." Spitz suggests that these early rudiments of the 
The mature superego contains two components whose foundation is the internalized representation of the earliest caretaking experiences, namely: the ego ideal that represents the need fulfilling and the pleasure-giving mother; and the conscience that incorporates the need-frustrating and pain-producing mother. This basic pattern is supplemented and reinforced with later childhood experiences. Steele and Pollock suspect that "in the abusing parent there has been a marked imbalance between the two mother images with the frustrating mother being much more powerful than the empathetic, caring mothe $r^{\prime \prime}$ (p. 101).

The emphasis on the frustrating mother stems directly from earliest situations in which the mother placed unusual or excessive demands on the child and allowed his needs to go unfulfilled. Frustration stimulates the infant's aggression and directs it to the formulation of the image of the punitive mother. Anger at the mother figure will occupy a larger part in the child's superego and consequently, "when there is significant environmental and intrapsychic stress, with a contest between ego ideal and superego, the punitive superego wins out" (p. 109).

superego come from "the perceptual sector of the tactile and visual impressions, such as restraining the child physically on the hand, the facial expression, as well as the tone of voice which accompanies such prohibiting interference on the other." Steele and Pollock place stronger emphasis on these earliest experiences in light of their observations in the course of their studies eg. parents dealing aggressively and violently in the feeding, diapering, bathing and general caring of infants beginning shortly after birth. 
The influence of the punitive superego is manifested in several psychological processes which motivate destructive behavior toward a child. Identification is a fundamental process in which a person incorporates features of another person in the pursuit of need gratification. Since a child abuser's earliest and most enduring identification model is the punitive mother, the repertoire of behaviors available to deal with his own child is skewed toward destructive ones. Moreover, the self-conception of'badness'that stems from the identification with the punitive mother generates a sense of personal inadequacy. The punitive superego has redirected anger against the mother to anger against the self and by projection, what is an extension of self, namely, one's child. Consequently anger against mother and self is transferred to the infant. Any behavior on the part of the child that stirs personal inadequacy receives a destructive response that can result in abuse.

One sub-process of identification - the so-called role reversal - is especially pertinent to a psychodynamic explanation of child abuse. The overdevelopment of the superego creates dual and conflicting self-concepts of who one is and who one should be. Steele and Pollock find that child abusers lack a "continuity of personal characte $r^{\prime \prime}$ reflected in a "loose collection of unintegrated, disparate, concepts of self" (p.109). In particular, there is a "lack of useful integration of the two experiences of being a child and being parented" 
(p. 109). In other words, the internalized demands and punishments from the superego rob child abusers of their own childhood, and this deficiency of experience is highlighted in their relationship with their children. On one hand, the lack of experience as a child prevents a realistic perception of what the capabilities of an infant are. More subtly, the infant stimulates the frustrated desire of the child abuser to become an infant. In some instances the self-concept of what should be and what is desired get reversed in the relationship between parent and child. In essence the parent reverts to a childish posture complete with primitive modes of expressing frustration while the child is perceived as the individual responsible for giving care to the parent. The inherent incapacity of a young child to perform caretaking and need satisfying functions invariably results in the disappointment of the parent that gets expressed in the primitive act of a violent assault against the child.

Essentially, the misinterpretation of the parental role and the capacity of the young child which stems from an original identification with the punitive mother serves as the basic psychodynamic explanation of a child abuse. The theory, however, does not entirely explain, for example, why a particular child in a family is subject to abuse. Steele and Pollock allow that other, secondary factors are involved in an act of aggression against a particular child.

They affirm that "the infant, innocently and unwittingly, may contribute to the attack which is unleashed upon him" (p. 114). Unwanted 
or premaritally conceived pregnancies, constitutionally difficult, congentitally defective, and premature infants, are cited as special factors that may select a particular child for abuse. In addition, psychodynamic considerations involving unresolved sibling rivalry, or Qedipal-like conflicts may be played out on a particular child who, perhaps, resembles the original figures in the conflict. Finally, Steele and Pollock acknowledge the effect of environmental circumstances, gleaned from their own case studies, that include abandonment, unemployment, and even the Kennedy assassination. But, they unequivocally conclude that these circumstances and secondary factors are neither necessary nor sufficient to cause child abuse.

Represented schematically, the psychodynamic theory of child abuse offered by Steele and Pollock includes:

1. The child abuser was invariably abused physically or emotionally by his own parents.

2. In particular, the maternal figure displayed a lack motherliness perceived as lack of caretaking and an abundance of punishment.

3. The image of the punitive mother was introjected as a major component of the superego and reinforced by subsequent relationships.

4. The predominance of the superego imposes unrealistic demands upon the child abuser represented by chronic feelings of inadequacy and lack of integrated identity.

5. Encountering environmental stress in general, the superego, dominated by the image of punition, prevails by responding with destructive aggression. 
6. In particular, the child is perceived as a source of major stress in the environment and the superego, through the basic process of identification, motivates a pattern of responses that culminates in violent attacks against children.

Amelioration of child abuse, according to the psychodynamic theory principally involves an alteration in patterns of relating. Steele and Pollock employ the relationship between the rapist and client as a means of establishing a secure, non-threatening, caring milieu. Essentially, the client gets an opportunity to relate successfully with a nother individual who has suspended judgment and maintained neutrality about the previous history of the client. The capacity to relate generously and appropriately with another individual is transferred to the relationship between the parent and child. More intensive therapy assumes the traditional psychoanalytic model. Analysis is employed to reveal the primary relationship with the punitive mother and to recreate an identification that either partakes of the more positive qualities of that individual or redirects the identificatory process to more constructive persons. In sum, Steele and Pollock's resolution of the child abuse phenomenon mainly rests on alterations in individual relationships and de-emphasizes action on the sociocultural level.

\section{CHAPTER SUMMARY}

As way of summarizing the child abuse theories of Gil and Steele and Pollock and of introducing the child abuse data presented in Chapters III and IV, what findings predicted by respective theories are 
outlined as follows.

Given Gil's sociocultural orientation to child abuse, his theory in general would predict a set of social and economic factors that are specifically related to violence against children. Since the core theorem in Gil's explanation of child abuse is the culturally sanctioned attitude toward the use of physical force in the care and discipline of children, findings in support of his theory should include evidence of this general attitude. For example, the data should indicate that corporal punishment is pervasive throughout American society and that child abusers, in particular, use corporal discipline more often and impose more severe physical punishment involving the use of weapons. Since Gil theorizes that minority groups are subject to general violence against them in the form of social and economic discrimination and that this aggression is internalized and self-inflicted, the evidence should show that minority groups i.e. nonwhites are more often child abusers. Gil also explains child abuse in part by chance environmental factors which would predict a relatively random and evenly distributed incidence of child abuse among families. However, since environmental factors associated with poverty and racial discrimination eg. inadequate housing, unemployment, generate stresses which Gil considers are significant precipitating factors in child abuse, the data should point to a disproportionate number of poverty-stricken families as child abusers. Given these sociocultural conditions, individuals prone to violence will, according to Gil, dis- 
charge destructive impulses toward children in the form of physical assault. Consequently, the evidence should identify a significant number of child abusers as exhibiting behavior that is maladaptive and/or violent.

Ironically, Steele and Pollock's psychodynamic theory of child abuse begins where Gil's theory leaves off, namely with the individual perpetrator. Since they suggest that child abuse is fundamentally explained by a pathological relationship between perpetrator and child produced primarily by a previously inadequate relationship between the perpetrator as a child and his parent, their theory should predict a pattern of findings that show a general and consistently disturbed childhood of the perpetrator. In particular, the data should indicate that a majority of child abusers had inadequate parenting and were subject to harsh and often emotionally or physically abusive child-rearing practices which they themselves incorporated into their own parenting behavior. In contrast to Gil's theory which predicts generalized social and psychological dysfunction of child abusers, Steele and Pollock's theory predicts evidence of pathology specific to parenting and childrearing and related activities. Since the basic process underlying the child abusing relationship is identification of the perpetrator with the child, any defect in the child's behavior or appearance that elicits memories of the perpetrator's own feelings of "badness" as a child will cause the perpetrator to strike out against the'bad"child as was 
done to him. The data should, therefore, indicate that the abused child is often dysfunctional although this is a condition secondary to the perpetrator's own parenting dysfunction. Since the focus of attention is almost exclusively on the perpetrator, Steele and Pollock's theory does not predict any one or set of social and economic factors that are specifically related to child abuse. However, their theory rejoins Gil's theory of child abuse when they explain the perpetrator's abusing relationship within the context of a general cultural attitude of violence against children.

In fact, the sociocultural and psychodynamic theories of child abuse are not mutually exclusive. Framed in different terms reflecting different focuses of attention, both predict evidence of violence in the child-rearing practices in society in general and, in particular, the inappropriate and unusually severe use of physical force in child abusing families. Both theories will be supported by data indicating that the perpetrator suffers maladaptive behavior expressed as violence although Steele and Pollock's theory predicts that pathologic behavior is child-specific whereas Gil's theory predicts more generalized pathology. Both theories will rest on evidence showing early and continual dysfunction of the child although Gil's theory will consider these as chance environmental factors which place real stress on the time and money of the child abusing family whereas Steele and Pollock's theory will consider these factors as overdetermined i.e. the dysfunction is stressful but the perpetrator perceives the difficulties as not 
only burdensome but anxiety-provoking.

Gil's theory predicts that the race of the child but not his age are significant and Steele and Pollock's theory predicts the reverse; neither predicts a significant relationship between gender and child abuse but for different reasons. Whereas the former consistently relates minority status and the socioeconomic conditions associated with it to child abuse, Steele and Pollock's theory places no relevance on race and/or socioeconomic status because they explain abuse in terms of a specific type of relationship and not as an expression of frustration at external stresses. They, however, consider that the age of the child is significant since the specific parenting relationship that explains child abuse, according to Steele and Pollock, is imprinted within the perpetrator at a very early age and that relationship is reproduced when the abuse victim is still very young. Since Gil conceives child abuse as culturally sanctioned outlet for real world frustrations, the target of frustration need only be an individual who can be legally assaulted and will not return the assault i.e. the perpetrator's own child or children. Note that Gil's theory attaches no significance to ordinal position of the child nor does it predict any limitation on the number of abused children in a family. In contrast, Steele and Pollock's theory predicts that a particular child in the family who can be most easily identified with the perpetrator will be selected for abuse. Both theories posit no relationship between the 
gender of the child and abuse. The chance environmental element in Gil's theory predicts a random distribution of abuse victims by sex and, incidentally, by age. Steele and Pollock's theory attaches no importance to gender because the explanation involves a relationship that evolves prior to the formation of sexual roles according to psychoanalytic theory.

In sum, Gil's sociocultural theory and Steele and Pollock's psychodynamic theory predict somewhat different findings although their predictions coincide in several areas where, naturally, the theories themselves coincide. As will be illustrated in Chapters III and IV and discussed in Chapter V, the re are some significant factors in child abuse predicted by neither theory. 
CHAPTER II

\section{THE METHODOLOGY OF REVIEWING THE CHILD ABUSE LITERATURE}

Reviewing the literature for the purpose of identifying significant factors in child abuse requires a consideration of the problems encountered in collating and analyzing the data. Following is a general statement and explanation of the methodology applied to the child abuse studies incorporated in this review. In the subsequent chapters the specific methödological problems connected with individual factors in child abuse will be discussed in evaluating the evidence and establishing a conclusion. This chapter is divided into two parts to resolve two fundamental questions: 1) what is the definition of child abuse imposed on the data generated from the literature?; and 2) what are the limitations of the studies that generated the data in this review of the literature?

\section{DEFINITION}

The fundamental problem in the study of physical child abuse is determination of its definition. Originally, the meaning of physical child abuse was restricted to a medical diagnosis initially designated by Kempe et al. (1962) as the "battered child syndrome." The syndrome 
described children who suffered serious physical injury in circumstances which indicated that the injury was caused willfully rather than by accident. According to Simons et al. (1966), the classic features of the battered child syndrome included subdural hematoma i.e. swelling or bleeding under the skull between the brain and its protective membrane, long bone fractures and lesions, and soft-tissue swellings in combination or alone. Although Paulsen (1969) reported that about $90 \%$ of his cases $(\underline{N}=96)$ fitted into this definition of physical child abuse, many authors find along with Rycroft (1968) cited in Fergusson et al. (1972) that the battered child syndrome inappropriately groups all forms of child abuse under a single and misleading term. For example, Gil (1970) discovered that only $14 \%$ of all the legally reported cases of physical child abuse in the United States conformed to the battered child syndrome. Further more, Elmer (1966) argues that conceptually, the term "battered child" connotes "willful assault, sadism, and cruelty and leaves no room for the exploration of other etiological possibilities" (p. 29). Zalba (1966) adds that the etiological problems he identified in "families with childabusing adults" i.e. the "psychosocial dynamics and problems of the parents and the family that result in the battering of the child" were not covered by the term (p. 14). Both he and Pfundt (1964) agree that "the term 'battered child' does not refer to a disease, is hardly a syndrome, is at best a poorly defined entity. . " (p. 62).

Steele and Pollock (1968) realized that the original definition of physical child abuse excluded a more widespread phenomenon "in which 
the infant was moderately bruised by severe hitting, shaking, yanking, choking, or being thrown about" (p. 90). Gil(1970) replaced "battered child syndrome" with the most popular term, "child abuse" which he defined as:

the intentional, non-accidental use of physical force, or intentional, nonaccidental acts of omission, on the part of the parent or other caretaker interacting with a child in his care, aimed at hurting, injuring, or destroying the child (p. 6).

Essentially, Gil now included any and all deliberate acts of physical force and acts of omission as well, irrespective of the severity or nature of the injury. He specifically excluded sexual abuse unless it accompanied physical force and unintentional acts of omission under which he included injuries stemming from neglect, poverty, or ignorance. Fontana (1973b) offers the broadest definition in substituting his "maltreatment syndrome" for Gil's "child abuse" which embraced "any treatment by which a child's potential development is retarded" (p. 780). In so doing Fontana joined with Kempe and Schmidt (1974) in attaching nutritional and medical neglect as well as sexual and emotional abuse to the primary component of physical injury in conceptualizing child abuse. Note that this conceptualization does not distinguish between intentional and accidental causes of maltreatment to children but simply considers the consequences of action and/or non-action on the part of the caretaker as evidence for establishing abuse. Moreover, both Fontana (1973a) and Kempe and Schmidt (1974) incorporate the 
element of potentiality in their conceptualization of abuse as, for instance, in the case of failure to thrive. Van Stolk (1972) reports that a significant number of cases of caloric inadequacy and dehydration are due to deficiencies in mothering that subsequently result in physical child abuse.

A survey of the literature (TABLE I) reveals that authors differ widely in incorporating none, some, or all of these additional components as well as others in their respective definitions of child abuse. 


\section{TABLE I}

\section{SURVEY: DEFINITIONAL ELEMENTS OF CHILD ABUSE}

\section{VICTIM}

Age (years)

Physical injury

Psychological impairment

Sexual Molestation

Infanticide

Neglect

Potential harm

Exploitation

Abandonment

Failure to thrive

\section{PERPETRATOR}

Parents

Adults

Caretakers

Intentionality

Omission

Non-accidental
Gil Galdston Paulson Elmer Birrell Silver Lauer Delsordo Morse

\begin{tabular}{|c|c|c|c|c|c|c|c|c|}
\hline 18 & $3-1 / 2$ & & & & & 10 & & \\
\hline Yes & Yes & $\overline{\text { Yes }}$ & $\overline{\text { Yes }}$ & $\overline{\text { Yes }}$ & $\overline{\text { Yes }}$ & Yes & $\overline{\text { Yes }}$ & $\overline{\text { Yes }}$ \\
\hline No & No & No & & & $?$ & $?$ & No & - \\
\hline No & & & & & & & No & - \\
\hline & & & & & & & & - \\
\hline No & No & & Yes & Yes & Yes & No & No & Yes \\
\hline No & & No & & & & & No & Yes \\
\hline No & & & & & & & No & - \\
\hline No & & & & E & & & No & - \\
\hline
\end{tabular}

Yes Yes
Yes
Yes
Yes
Yes
Yes 
TABLE I (continued)

SURVEY: DEFINITIONAL ELEMENTS OF CHILD ABUSE

\section{VICTIM}

Age

Physical injury

Psychological impairment

Sexual molestation

Infanticide

Neglect

Potential harm

Exploitation

Abandonment

Failure to thrive

\section{PERPETRATOR}

Parents

Adults

Caretakers

Intentionality

Omission

Non-accidental

\begin{tabular}{|c|c|c|c|c|c|}
\hline Wertham & Kempe & Fontana & Simpson & Nomura & Delane \\
\hline & & & 3 & & \\
\hline & $\overline{\text { Yes }}$ & Yes & Yes & $\overline{\text { Yes }}$ & Yes \\
\hline$\overline{\text { No }}$ & Yes & Yes & No & Yes & Yes \\
\hline No & Yes & & & Yes & \\
\hline \multirow[t]{3}{*}{ No } & No & & No & Yes & \\
\hline & Yes & Yes & No & Yes & Yes \\
\hline & & Yes & $N T$ & & Yes \\
\hline \multirow[t]{2}{*}{$\overline{\text { No }}$} & Yes & Yes & No & $\begin{array}{l}\text { Yes } \\
\text { Yes }\end{array}$ & Yes \\
\hline & Yes & & & & \\
\hline
\end{tabular}

$\begin{array}{ll}\square & \text { Yes } \\ \square & \text { Yes } \\ \square & \text { Yes } \\ \square & \text { Yes } \\ \square & \text { Yes } \\ & \text { Yes }\end{array}$

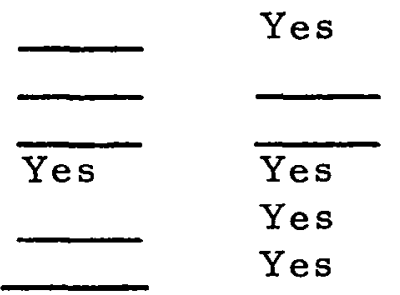


In an effort to establish a definition of child abuse for the purposes of this review, an analysis of the definitional components of child abuse that appear in the literature are analyzed for consistency and relevancy as follows:

Child

Unfortunately there exists no consistency about the meaning of "child" operationally defined by age in years. Gil (1970) accepts the legal definition of eighteen years in his nationwide survey of all reported cases of physical child abuse although individual state laws governing central registries from which these cases were obtained have different age limits. According to De Francis (1970) the upper age limit of children covered by abuse laws range from twelve in Oregon and Georgia to twenty-one in Washington. Although eighteen states and the Virgin Island use sixteen as the top limit, twenty-nine other states, the District of Columbia, and Guam use ranges above sixteen. Likewise, clinical studies establish different age limits for their subjects. For example Gregg (1969) restricted her study to children below fourteen; Lauer et al. (1974) excluded children over ten; and Melnick and Hurley (1969) only considered children three years old or less. Since most clinical studies employ populations obtained from cases admitted to pediatric wards which typically exclude adolescents, the re is difficulty in evaluating their findings because their samples are skewed. Some authors a rgue, however, that injury to adolescent children is etiologically 
different, suggesting that physical injury stems from sexual conflicts during the puberty period of development. Since there exists no consensus on meaning of child defined by age in years, this review will consider all child abuse studies irrespective of age limits but carefully noting and discussing when and if age limitations substantively affect conclusions.

Physical Abuse

As stated above, physical child abuse was originally conceived exclusively as the "battered child syndrome." Since unexplained physical injury constitutes the sine qua non of child abuse, there is universal agreement that physical abuse is the primary component of child abuse. With the exception of Elmer (1967) whose study considered only subjects with multiple bone fractures, all other studies accept any and all nonaccidental physical injuries that require medical attention as evidence of child abuse. With no argument to the contrary, this review follows that definition.

Sexual Abuse

Kempe et al. (1962), Normura (1966) and Fontana(1973b) and others regard sexual molestation as an element of child abuse and at lease one study (Virginia, 1972) includes sexual abuse cases. In contrast, Gil (1970) and Steele (1970) separate out sexual abuse on the assumption that it is etiologically and dynamically different from physical 
child abuse. Gil suggests that where sexual molestation occurs in the absence of resistance from the child, the perpetrator is motivated by self-gratification rather than by an intent to hurt the child.

Steele and Pollock (1968) hypothesize that physical injury against children much over four years is motivated by unresolved Oedipal conflicts. Consequently, they operationalize the distinction between physical child abuse and sexual molestation by restricting the former designation to children less than five. Gil, on the other hand, includes sexual abuse where it is accompanied by physical abuse. Since Gil extends the age of child abuse to eighteen years, he probably confuses the meaning of child abuse by including cases in which physical attack masquerades sexual conflicts that particularly arise at puberty. Wertham (1972) concludes that extending the age past puberty in the definition of child abuse and/or including sexual molestation is misleading.

De Francis cited in Fontana (1973a) conducted a three year study of sexual abuse in children in New York City whose results help resolve controversy over the appropriateness of including sexual molestation in the definition of child abuse. Unlike the vast majority of child abuse cases, only $27 \%$ of the offenders were members of the child's own immediate household; a nother $11 \%$ we re closely related though not living in the household. Fully $38 \%$ of the offenders were persons unrelated to the child or his family including neighbors, 
visitors, acquaintances, etc; $27 \%$ were identified as complete strangers. In other words, sexual abuse in contrast to physical child abuse is not strictly or predominantly a family affair. In those cases of immediate family involvement, the father is identified as the principal offender who frequently abuses more than one child. Moreover, while some victims were infants, the mean age of the sexual abuse victim is eleven and a half, (range: 0-16 years old). Finally, while $79 \%$ of the cases were accompanied by emotional and physical neglect, only $11 \%$ involved concurrent physical abuse. In sum, the common features of physical child abuse (discussed in detail in subsequent chapters) - victim is infant or, young child, perpetrator is natural parent, mother is most frequent abuser - are not present in cases of sexual abuse. Consequently, this review separates out sexual abuse from child abuse based on the general assumption that they are etiologically distinct as manifested by major differences in factors associated with the respective phenomena.

$\underline{\text { Infanticide }}$

While Adelson (1963) and Solomon (1973) place homocide on the child abuse spectrum, most authors join with Kempe (1973) in affirming that child abusing parents do not willfully mean to murder their children. It is generally acknowledged that a percentage of abused children eventually die from injuries sustained from repeated and increasingly severe attacks, but the research supports Wertham's 
(1972) conclusion that there are special circumstances "in which infants or children may be killed which should not be confused with the battered child syndrome (p. 890). Steele and Pollock (1968) observe that "direct murder of children is an entirely different phenomenon and is instigated during a single impulsive act by people who are clearly psychotic" (p. 104).

Although Adelson (1963) considers infanticide to be a variant of child abuse he found that psychosis was the most common denominator in parents who murdered their children. Myers (1970) found that $71 \%$ of filicidal mothers in his study $(\underline{N}=35)$ were overtly psychotic. Similarly, Resnick (1969) found that previous to their filicides, three fourths of the parents manifested psychistric symptoms. Yet, according to Spinetta and Rigler (1972) a review of the literature seemed to support the view that few child abusing parents showed severe psychotic tendencies. Both Myers (1970) and Makeover quoted in Gil (1970) reported that those few non-psychotic filicides were frequently mothers who matter-of-factly disposed of a child who represented a social or economic burden.

Finally, both Resnick (1969) and Myers (1970) show that the

${ }^{4}$ It should be recalled that there is a long tradition in Western society that sanctions infanticide as a legitimate mode of relief when the survival of the family was in jeopardy. For an historical account of infanticide see Samuel X. Radbill, 'A History of Child Abuse and Infanticide" in Helfer and Kempe, The Battered Child, pp. 3-19. 
most common modes for infanticide were suffocation by drowning, strangulation, and head wounds indicating that death was caused by a single, direct attack. In contrast, most injuries stemming from child abuse are bruises, welts, and long bone fractures although a significant number of children sustain head trauma (See INJURIES, Chapter III). However, most authors agree with O'Neill (1973) that head injury is typically a late manifestation of child abuse $i . e$. the culmination of a series of escalating injuries over a period of time.

Generally speaking those relatively infrequent fatalities stemming from physical child abuse typically occur after episodic and progressively severe assaults. In sum the consensus excludes infanticide as part of the definition of child abuse. The context of the attack, the mode of assault, and the type of injury inflicted support the hypothesis that they are etiological ly different.

Neglect

Several authors conclude with Silver (1969) that neglect and physical abuse are ends of the child abuse spectrum and not mutually exclusive phenomena. Gil (1968), for example, reported the simultaneous occurrence of abuse and neglect in $32.5 \%$ of his survey cases. While Currie (1970) recognizes considerable overlap between abuse and neglect, he and others believe they are etiologically and symptomatologically distinguishable. Galdston (1965) observes a basic difference in reporting that many abused children are well-fed and cared for. 
He gives the example of a "young child, covered with welts and bruises, all decked out in a fresh pinafore" (p. 440).

Chesser (1952) cited in Paulsen and Blake (1967) maintains that neglect is associated with poverty and ignorance, while cruelty is related to deep-seated characterological or psychological causes. Kent (1973) cited in Light (1973) partially substantiates Chesser's hypothetical relationship between neglect and poverty conditions. He found, comparing neglecting, abusing and sexually molesting families $(\underline{N}=500)$ that neglecting families were much larger, much poorer, and lived in more frequently inadequate housing. In her study of 300 neglecting and abusing families Young (1964) determined three groups of factors that statistically differentiated between the two: parental behavior toward children, marital roles of perpetrators, and family standards of behavior.

Steele and Pollock (1968) identify a basic difference in the caretaking function of neglecting and abusing parents. The former display inadequate mothering skills eg. feeding, bathing, clothing whereas the latter typically perform these activities well but fail to establish an emotional relationship with their children characterized as need-fulfilling and described by Steele and Pollock (1968) as motherliness. This basic difference between inadequate mothering and lack of motherliness fundamentally distinguishes the neglecting from the abusing parents although their respective responses, according to 
Steele and Pollock (1968) emanate from common excessive needs and unrealistic demands from their children. The concurrence of abuse and neglect in some cases of child abuse may find explanation in similar etiology although, they note, "there is a striking/sic $\bar{l}$ differences in these two forms of caretaker-infant interaction" (p. 99). The neglecting parent meets with a perceived failure of their children to respond satisfactorily by withdrawing from and "abandoning efforts to even mechanically care for the child" (p. 99). In contrast, the abusing parent responds to disappointment over a child by overacting and 'moves in to punish it for its failure and to make it 'shape up' and perform better" (p. 99). This over-investment in the life of the abused child is corroborated by Young cited in Zalba (1966). She observed "the general willingness of neglectful parents to allow social workers to come to their home, form relationships with the children, and even remove the children to foster care. In contrast, abusive parents tend to resist efforts at intervention, whether it comes in the form of casework services in the home, taking a child on an outing, or removing him for protective placement" (p. 5).

Another factor that appears to separate abusing from neglecting families is the fact that the latter provide inadequate care for all the member children. For instance, Togut et al. (1969) found that almost all the siblings $(\underline{N}=32)$ of the patients $(\underline{N}=18)$ in their study of non-organic failure-to-thrive displayed abnormal health, and/or 
inadequate care. Siblings in only one family had received adequate immunization; one-third were of low birthweight. This general lack of adequate medical care often stemming from insufficient nutrition is consistent with the general observation noted above that neglect is very often a function of a poverty environment. Physical child abuse is not concommitant with poverty conditions and is typically perpetrated against only one member of the family sibship.

In sum, while physical abuse and neglect belong on the same spectrum of mistreatment of children and may, in fact, share a similar etiology, the pattern of neglect is significantly different from the pattern of abuse. Whereas neglect is most closely associated, as Giovannoni (1971) points out, with stresses emanating from poverty conditions, "the existence of abuse is generally conceded to be more randomly distributed with respect to a socioeconomic status" (p. 650). Moreover, neglect typically involves all children in the family whereas physical abuse is restricted to one child prompting Giovannoni (1971) and others to conclude that abuse stems from interpersonal and intrapsychic stresses. Finally, neglecting parents and abusing parents contrast in their caretaker-infant interaction. Consequently, this review excludes consideration of neglect.

Intentionality

Although Gil (1970) recognizes the "difficulty of ascertaining the presence of elements of intentionality" he considers volition to 
"constitute a sine qua non of child abuse"(p. 6). For Young (1964) repetition of injury represents evidence of intentionality although Elmer (1966) questions whether chronicity of mistreatment is a necessary condition for establishing abuse. Holter and Friedman (1968) have attempted to operationalize intentionality by empirically observing that certain injuries are significantly more likely to characterize abuse than accidents (See INJURIES, Chapte $r$ III).

Whereas Gil (1970) defines "intentionality" to include nonaccidental acts of commission and omission, he does not establish, as Fergusson et al. (1972) note, what exactly constitutes "nonaccidental." Kempe et al. (1974) enlarges the meaning of nonaccidental to include both conscious and unconscious acts. Court (1969) lends substantiation to this definition in observing that a parent's unconscious hostility can place the child in a perilous situation in which he is likely to be accidentally injured. Elmer (1967) refers to households in which dangerous physical environments present unusual opportunities for injury to small children eg. inadequately secured cribs, insufficiently protected heating elements, etc. While no doubt equally serious physical injury results where parents display negligence in caring for their children, the pattern of child abuse characterizes those incidents where a parent deliberately attacks his child - for a reason imagined or real with severity that is not appropriate for the age of the child and/or is an inappropriate response to the child's perceived misbehavior. 
Consequently, this review excludes consideration of negligence including mistreatment of children resulting from inadequate response to medical emergencies or chronic illness, inability to take minimum percautions for proper supervision of a child's health or welfare, and cases of failure to thrive. In sum, child abuse will be defined as a deliberate attack against any child resulting in physical injury, perpetrated by any person exercising his responsibility as a caretaker.

\section{STUDY DESIGN AND SAMPLING}

Child abuse studies are generally divided into two categories. Clinical studies, frequently conducted in a public hospital setting, typically collect and analyze demographic and medical data about the child abuse victim and psychiatric and demographic data about the perpetrator. These studies rely on hospital files and/or records of interviews or therapy sessions. Child abuse surveys or sample surveys usually employ case records from law enforcement or social welfare agencies. Most of the information analyzed in these studies refer to demographic characteristics of the abused child and his abuser and their respective social histories reflected in their agency contacts. In any case, all child abuse studies suffer some general sampling and design problems as follows:

\section{Sources}

All child abuse studies draw their sample population from 
those cases which have come to the attention of the hospital or agency that records them. Even where a study considers all physical child abuse cases eg. Gil (1970), Fergusson et al. (1972), it is obvious that not all cases of child abuse are reported and therefore included in the sample. Silver , (1968) identifies several reasons for incomplete reporting of child abuse cases in presenting the results of his survey of 450 physicians. He found that: 1) One in five physicians reported they rarely or never considered child abuse when seeing an injured child; 2) almost one of every four physicians stated that he would not report a case of suspected child abuse even if he were protected against legal action by parents. In other words, there is considerable variation in the ability to distinguish child abuse from other pediatric trauma and there is a reluctance, particularly among private physicians, to meport cases to public registries even where the diagnosis of child abuse is established. Solomon (1973) substantiates this fact in finding that of 2,600 cases of child abuse registered in New York in 1969, only $0.42 \%$ were reported by a private medical doctor. Other studies listing reporting rates for private physicians corroborate Solomon's findings as follows: Gil (1970), 2.8\% (N=1,380); Glazier (1971), 4.9\% $(\underline{N}=376)$; Simons et al. (1966), 2.4\% ( $\underline{N}=293)$.

Moreover, reporting laws among the states vary considerably, according to De Francis (1970), in regard to legal definitions of child abuse, persons mandated to report, and immunities conferred on 
persons who may or must report. Some states eg. Colorado, Alabama, Vi rginia, and Washington, include sexual molestation in the definition of child abuse. Some state laws regard infanticide as part of legal child abuse and at least one state considers exploitation and overworking to be legal child abuse. Consequently, there exists no consistency in reporting laws about what constitutes child abuse and therefore the data is not uniform. Moreover, the administration of the reporting laws vary so that, for instance, Gil (1970) reports an incidence of 31.2 per 100,000 in Texas and 1.4 per 100,000 in neighboring Oklahoma. Since geography is not a significant factor in child abuse it is very likely that such discrepancies reflect different levels of administrative competence in identifying child abuse. For instance, only twenty-eight states maintain central registries on child abuse. Moreover, only twenty-nine states impose criminal penalties for failure to report; thirty-one states have suspended the privileged status between husband and wife, doctor and patient while there are some states that do not grant full immunity to those making reports. Finally, categories of persons required by law to report child abuse vary among the states. In Oregon, physicians, elementary school teachers, and nurses, public health nurses, police officers and state welfare workers must report whereas in Oklahoma only physicians, dentists and nurses are required to file. In sum, nationwide surveys which purport to consider all cases of child abuse in their study sample fail to include a proportion of 
cases which go undetected and/or officially unreported. Moreover, that percentage of cases which do receive official attention are subject to a number of reporting biases which make evaluation of studies that employ these cases problematical.

Gil, (1970), for example, drew his comprehensive sample $(\underline{N}=1,380)$ of all legally reported cases of child abuse from primarily metropolitan areas. He found, however, that Standard Metropolitan Statistical Areas (SMSA's) reported significantly higher concentrations of child abuse than a reas outside the SMSA's. Although only $67 \%$ of the national population lived in SMSA's in $1967,78.6 \%$ of the 1967 and $81.90 \%$ of the 1968 child abuse reports originated from communities in SMSA's. Young (1967) found similarly that urban areas were overrepresented in her study of child abuse and neglect which she attributed to the impersonality and anonymity of the urban environment. However, she did not consider that urban areas have better developed and more sophisticated bureaucracies with greater administrative and reporting competence. Moreover, urban areas typically rely to a much greater extent on public social welfare and law enforcement agencies and medical facilities. All are more likely to report cases of child abuse. Personnel are usually exposed to a wider range of pathology and maintain a higher index of suspicion for unexplained trauma to children. Physicians, for example, have less personal relationships with their public patients and probably feel less obligation to maintain privacy 
and not comply with the reporting law. In fact Gil (1970) reports that the vast majority of cases a re reported by predominantly public hospitals and clinics $(49.0 \%)$, police $(23.2 \%)$, public schools and child care facilities $(12.4 \%)$ or public social agencies $(7.9 \%)$.

Moreover, since lower socioeconomic classes tend to locate in urban core areas and therefore use public facilities more frequently, Gil (1969) acknowledges that families from the middle and upper classes who abuse children are more likely to go unreported than economically deprived families. Because historically, the socioeconomic classes include an overrepresentation of racial minorities, the incidence of child abuse among nonwhite populations may be distorted. As an example consider that in New York, California, Michigan, and Pennsylvania, $27.3 \%$ of abuse cases involved white children in contrast to Kentucky, Tennesse, Georgia, and Texas where $72.9 \%$ of the abused children were white. Light (1973) suggests that the disparity has less to do with radically different ethnic patterns than with the historical fact that few public services for children are yet presently available to nonwhites in the South whereas they constitute the major clientele of public social services in the North. As Light (1973) points out, even studies which include large sample populations eg. Gil's epidemiological survey of all legally reported abuse cases in the United States in 1967 $(\underline{N}=5,993)$ and $1968(\underline{N}=6,617)$ are nonrandom. 
Sampling

Clinical studies typically drawing from hospital populations usually pediatric and/or emergency room patients - also employ nonrandom samples and encounter problems in addition to the ones discussed above in connection with survey studies. Plainly, many clinical studies suffer from statistically inadequate sample size and/or insufficient number of cases analyzed for a specific factor. In the former instance, studies by Terr (1970), Bennie and Sclare (1969), and Melnick and Hurley (1969) considered only ten cases respectively. Cohen (1966) studied twelve cases; Silver et al. $(1969,1971)$ included thirty-four cases; (1967), employed thirty-three cases. In the latter instance, Paulsen (1969), for example, recorded $29 \%$ of the perpetrators as unknown $(\underline{N}=96)$; Simons et al. (1966) listed 38\% as unknown ( $\underline{N}=293$ ); Gregg and Elmer (1969) found $40 \%$ were unknown $(\underline{N}=30)$; and Schloesser (1964) reported $27 \%$ as unknown or not stated $(\underline{N}=54)$. Moreover, since most hospital samples serve particularly lower socioeconomic populations, subjects are not randomly selected. In addition, Gil (1970) notes that more severe cases of child abuse receive the attention of hospitals and clinics where emergency facilities and medical care are available. Also, the typical organization of a hospital that separates pre- and post-adolescent children into pediatric and adult wards may place an artificial limitation on the age limit of the study subjects. For example, Steele and Pollock (1968) assembled part of their sample from families referred by the pediatric services while their children were in the hospital. Thus, their sample consisted 
of a nonrandom selection of infants and young children with injuries serious enough to warrant hospitalization.

The most conspicuous problem in the study of child abuse is the general absence of controlled studies which match and compare child abusing families with nonabusing families. Studies which discriminate child abusing families on the basis of, most usually, social and economic factors may be equivocal when the subject families are compared with families from the same pool. Elmer (1967), Young (1967), and O'Neill (1973) all concur that for instance, the racial distribution of their child abusing subjects mirrored the general population in their respective localities. Melnick and Hurley (1969) found that the ten control subjects recruited from the locale of their clinic achieved almost perfect match with abusing mothers on socioeconomic and demographic indices including: age, weekly income, and the Hollingshead - Redlich social class index. Lenoski (1974) matched 674 child abusing families with 500 control families randomly drawn from the same pediatric emergency room population and found that abusing families were not distinguishable by race or financial status. Generally, studies employ general census data with which to compare research data on child abuse. For example. Gil (1970), having defined the poverty level at 8,000 dollars, compared the general census population with hample of all legally reported child abuse for income level. When he found that half the general population, but a full $69 \%$ of 
the abuse study population fell below the poverty level, he concluded that there was a direct connection between poverty and child abuse. However, whereas the census data gives a very accurate distribution of income, the child abuse sample is admittedly skewed toward the lower socioeconomic classes. Consequently comparisons between the general population and child abuse study subjects are not altogether valid. This is not to suggest that relationships between, for instance, socioeconomic factors and child abuse are not valid, but only that these relationships must always be evaluated with full consideration of the lack of appropriate control populations in most studies.

In general then, all child abuse studies suffer from nonrandom sample populations selected by incomplete or inaccurate reporting, or unreliable and inconsistent reporting procedures and administration thereof, or insufficient size of the sample population, or sample populations biased by geographic or socioeconomic factors, or populations generated from special institutions or organizational idiosyncracies of these institutions. Moreover, almost all studies do not match abusing and nonabusing families on relevant factors to determine to what extent factors, eg. socioeconomic, determined as significant are artifacts of nonrandomly selected sample populations. In addition to sampling problems in the study of child abuse, the re also exist difficulties and disparities in the design of child abuse studies. 
Design

Naturally, an essential activity in the study of child abuse is to compare and contrast the data from previous research to evaluate the significance of factors associated with child abuse. Unfortunately, although not unexpectedly, there exists no uniformity in the design of child abuse studies which make comparisons between them difficult and sometimes not possible.

For example, in an effort to calculate most frequent injuries sustained by child abuse victims consider that Lenoski (1974) separated "lacerations" into "abrasions" and "contusions" whereas Gil (1967) combined both categories. On the other hand Lauer et al. (1974) aggregated lacerations, abrasions and contusions under "bruises and welts" in "abrasions" and "contusions." Additionally, frequencies of injuries were differently determined depending on whether the study established categories that were mutually exclusive or listed multiple injuries.

Compounding this problem is the diversity in the way the data were actually presented. For example Gil (1970) recorded the age dis tribution of abused children as follows: $75 \%$ over two years old; $46 \%$ over six years old; $66 \%$ over three years old. The American Humane Association (1962) reported that $55 \%$ of the children were under four years old, while Paulsen and Blake (1967) showed that $40 \%$ are under ten years old. MeRae (1973) found that $73 \%$ are under three years old 
and the Virginia study (1973) determined that $59.8 \%$ were under five years old.

Finally, nearly all child abuse studies encounter what Spinetta and Rigler (1972) identify as research design inadequacies. Few studies test specific hypotheses generated from the pool of knowledge about child abuse. Consequently, most research presents no unified set of stated assumptions that justify the kinds of data collected nor are the data analyzed according to any methodological rigor imposed on most experimental research. Clearly, the real world conditions and circumstances surrounding the study of child abuse make laboratory precision impossible but many studies suffer from sufficient laxness in the control of bias - personal and professional - as to make their conclusions doubtful. For example, a large number of studies gather information on the race of the child abuse victim and perpetrator. There is an implicit assumption that child abuse is related to race based on statistical associations yet there exists no theory which connects the etiology of child abuse with race. Moreover, statistical relationships between incidence of child abuse and nonwhite groups rely on data that do not control for socioeconomic or geographic factors which may render the associations artifactual.

Gelles (1973) points out that many studies are distorted by what he called expost facto analysis. In other words, conclusions about child abuse are reached after the child abuse incident which may 
result in erroneous explanations. For example, studies frequently establish that perpetrators display psychopathological functioning. Analyzed after the abuse incident "it seems obvious, comments Gelles, (1973) that a parent who beats this child almost to the point of death has poor emotional control and reacts with uncontrolled aggression" (p. 614). That someone who abuses his child is abnormal and therefore abnormality predicts child abuse represents the circularity inherent in ex post facto analysis. Homocide is an indication of aggressive behavior and yet it is not possible to demonstrate that homocides are child abusers. Moreover, as Friedman (1972) observes, few studies which establish a relationship between psychological dysfunction and child abuse compare a matched control population for incidence of psychological problems.

\section{CHAPTER SUMMARY}

A review of the child abuse literature requires consideration and resolution of the problems encountered in collating and analyzing data from many different studies. The fundamental problem is the determination of the definition of child abuse. Although originally conceived as the "battered child syndrome" the definition of child abuse has been expanded to include all instances of intentional physical injury to children as well as neglected, sexual molestation, failure to thrive, infanticide, exploitation, abandonment and psychological abuse. An analysis of these definitional components indicate that they all constitute 
part of a very broad category of mistreatment of children but that intentional physical injury to children is etiologically and/or dynamically disting uishable from these other components and remains the best definition of child abuse and the one employed in this review.

The problems encountered in analyzing child abuse evidence include the incompleteness, invalidity, unreliability, and biases of the studies and the data which they use. For one thing, both surveys that rely primarily on case records of public welfare and law enforcement agencies and clinical studies that employ subjects drawn from hospital admissions use sample populations that are not random. While surveys typically include larger samples less subject to chance error, the information they collect are often inaccurately and/or inconsistently reported and recorded. In contrast, clinical studies usually produce more accurate and refined data based on direct observation and detailed medical records, but suffer from inadequate sample size. Most surveys and clinical studies are not accompanied by appropriate control populations with which to test the validity of the conclusions generated from the results of the studies. Moreover, the variety in research designs and the presentation of the data make comparisions and contrasts between and among studies difficult. All these methodological problems are considered in evaluating each individual factor of child abuse in the subsequent chapters. 


\section{CHAPTER III}

\section{THE CHILD ABUSE VICTIM}

This chapter assembled much of the existing information on the demography and the medical, social, and psychological history of the child abuse victim in an effort to identify those specific factors that are significantly related to child abuse. As a way of introduction, the review of the literature on the abused child is preceded by a discussion of the incidence of child abuse.

\section{INCIDENCE}

Gil (1970) gives the number of legally reported physical child abuse incidents in 1967 as 5,593 and 6,617 incidents in 1968. Between 1967 and 1968 the number of reported incidents grew by $10.41 \%$. Based upon these reports, the national incidence rate of abuse for children eighteen years old or younger in 1967 was estimated at 9.3 per 100,000. The incidence rate among the fifty states that year ranged from 0.0 (Rhode Island) to 24.0 (Texas) per 100,000. In 1968 the range was 0.0 (Rhode Island) to 31.2 (Texas) per 100,000. The coefficient of rank correlation between 1967 and 1968 was .809 .

According to Light (1973) the number of reported cases increased to 11,000 in 1968 and doubled by 1972 . Fontana(1973b) shows in 1968, 965 
cases of abuse were reported in New York City. In 1969 the number increased to 1,600; in 1970 there were approximately 3,000 cases for a total increase of $549 \%$ in reported cases. He concludes that the incidence of child abuse is increasing. Gil (1971), however, comments that "one consequence of the extensive interest in child abuse seems to have been the widely held assumption that its incidence was on the increased" (p. 641). Given the combination of more competent detection of child abuse coupled with stronger and more comprehensive reporting laws and more sophisticated recording procedures it is likely that the increase in the incidence of child abuse simply reflects the fact that a larger proportion of the actual number of abuse cases is reported.

Knowledge about the occurrence of child abuse relies on an accurate determination of the incidence rate $i . e$. the rate of abuse that would be present if all possible cases of abuse were recorded. Gil (1968) distinguishes the incidence rate from the reporting rate i.e. the rate of abused based on the reported number of cases. He recognizes that "legally reported incidents may constitute only a part of the total universe of child abuse incidents, the real size and characteristics of which a re likely to remain unknown" (p. 859). The number of disparate estimates extrapolated from reported rates of incidence reflect the problems of reporting discussed in the previous chapter. For example, Kempe cited in Light (1973) estimated that 60,000 children 
were seriously abused in 1972. Steele (1970) calculated that at least 40, 000 children were injured by their parents or caretakers each year. A Massachusetts survey of physicians, hospitals, institutions, and police departments cited in Light (1973) produced an annual occurrence rate of 200,000 abuse cases when extrapolated for the nation as a whole. Fontana (1973b) estimates an incidence rate of 1.5 million cases. Each of these figures represents estimates calculated from different reported rates with varying degrees of accuracy including abuse cases variantly defined.

In contrast Gil (1970) produced his estimate of the incidence of child abuse by surveying a sample of 1,520 subjects selected to statistically approximate a simple random sample of 1,000 . He found that $3 \%$ of the respondents reported personnel knowledge of a physical child abuse incident as defined by Gil (1970) (see DEFINITION, Chapter II) over the previous 12 months. Extrapolating for an adult population of 110 million he estimated the upper limit of incidence at between 2.53 and 4.07 million. However, since it is possible that more than one respondent had referred to the same incident, Gil's estimate includes some proportion of multiply known cases which inflate the rate of incidence. Light (1973) attempts to control for this problem by injecting values of probability into the calculation to reflect the assumptions that a) "a respondent was more likely to know of a case of actual abuse if it occurred in a family he knew well than if it occurred in a family 
he knew moderately or just a bit; b) the more families with children under eighteen any respondent knew, the less likely he was to know about an actual occurrence of child abuse. . " (p. 564). Applying these corrective values to Gil's original estimate of physically abused children and assuming that each family abuses 1.6 children, Light offers a revised estimate based on the 1970 census data of 500,000 incidents. In view of severe under-reporting and inaccurate reporting of child abuse, incidence rates based on reported cases of child abuse are unreliable. Gil's indirect method of reporting incidence via a sample survey of knowledge about abuse incidents qualified by Light's corrective measures appears to generate the best estimate of real incidence. Nevertheless, even Light's model for estimating incidence retains one basic problem in Gil's original survey design and introduces two other problems which modify his estimate. Both Light and Gil fail to consider the proportion of child abuse incidents that come to the attention of nobody outside the abusing family. It is well established that even many physicians fail to correctly diagnose child abuse and so it is probable that lay persons are still less likely to consider the possibility of child abuse even where visible injuries are sustained by a child with whom they come in contact. Moreover, while Light assumes that the respondent will have knowledge of an abuse incident in families most well known to him, it is also possible that accounts of abuse reaching the respondent will be discounted precisely because he is friendly with 
the family. More significantly, there is enough data about child abusing families to suggest that since they tend to be self-isolated from the community, there must be a number of incidents that simply never receive notice and are not reported about in a survey. The omission of this category of incidents depresses the final estimate of incidence. However, Light may have inflated his estimate by multiplying the approximate number of child abusing families by 1.6 to reflect the average number of children abused by each family. Although he cites several studies that report the frequent abuse of siblings, a large number of studies (see SIBSHIP, below) find that most families select only one child for physical abuse.

In any event, until such time as detection and reporting of child abuse become reliable, estimates of incidence based on reported rates are not useful. Gil's indirect estimate modified by Light's corrections presently represents the best approximation of the incidence of child abuserone million incidents per annum.

\section{II. $\mathrm{AGE}$}

A substantial majority of studies (TABLE II) indicates that most abused children are very young, typically below the age of three. For example, Currie (1970), aggregating Birrell and Birrell (1968), Cohen (1966), Elmer (1967), Holter and Friedman (1968) and Schloesser (1964) found that $83 \%(\underline{N}=208)$ of the total were three years old or less 


\section{TABLE II}

SIGNIFICANT PROPORTION OF ABUSED CHILDREN

BY AGE RANGE AMONG REPRESENTATIVE STUDIES

$\underline{N}$ is greater than 100 - Frequency exceeds $40 \%$

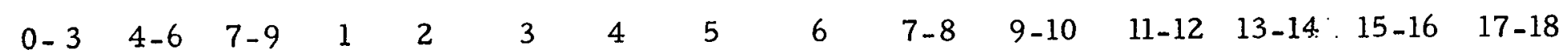

mo. mo. mo. yr. yrs. yrs. yrs. yrs yrs. yrs. yrs. yrs. yrs. yrs. yrs

\begin{tabular}{|c|c|c|c|c|c|c|c|c|c|c|c|c|c|c|c|}
\hline \multirow{2}{*}{\multicolumn{16}{|c|}{$\mathrm{x} \times \mathrm{x} \times \mathrm{x} \times \mathrm{x} \times \mathrm{x} \times \mathrm{x} \times \mathrm{x} \times \mathrm{x}$}} \\
\hline & & & & & & & & & & & & & & & \\
\hline AHA $(44 \%)$ & $\mathrm{XXXX}$ & $x \times x \times$ & $\mathrm{xxxx}$ & $\mathrm{xxxy}$ & $\mathrm{xxx}$ & $\mathrm{xxxx}$ & $x \times x \times$ & & & & & & & & \\
\hline Morse $(50 \%)$ & $\mathrm{xxxx}$ & $\mathrm{x} \times \mathrm{x}$ & $x \times x \times$ & $x \times x \times$ & $\mathrm{xxx}$ & $x x$ & & & & & & & & & \\
\hline Glazier $(50 \%)$ & & & $\mathrm{XxXX}$ & $\mathrm{x} \times \mathrm{x}$ & $\mathrm{xxx}$ & $\mathrm{xxx}$ & $x \times x x$ & $\mid x \times x$ & $\$ x \times x$ & & & & & & \\
\hline Paulsen $(63 \%)$ & $\mathrm{XXXX}$ & $x \times x \times$ & $\times x \times x$ & $\mathrm{xxx}$ & $\mathrm{xxx}$ & $\mathrm{kxx}$ & & & & & & & & & \\
\hline McHenry $(65 \%)$ & XXXes: & $\mathrm{Kxxx}$ & & & & & & & & & & & & & \\
\hline Ore. $(47 \%)$ & XXXXX & $x \times x$ & $x \times x$ & $\mathrm{xxx}$ & $x \times x x$ & $x \times x \times 2$ & $x \times x$ & & & & & & & & \\
\hline Lauer $(63 \%)$ & $\mathrm{XXXX}$ & $\mathrm{xxx} \times$ & $\mathrm{XXXX}$ & $\mathrm{x} \times \mathrm{XX}$ & $\mathrm{xx}$ & & & & & & & & & & \\
\hline Simons $(41 \%)$ & $\mathrm{x} \times \mathrm{xX}$ & $\mathrm{x} \times \mathrm{xx}$ & $x \times x \times$ & $\mathrm{xxx}$ & $\mathrm{xxXX}$ & $\mathrm{xxX}$ & & & & & & & & & \\
\hline McRae $(78 \%)$ & XXXXX & $\mathrm{x} \times \mathrm{x}$ & $x \times x$ & $x x x$ & $x \times x x$ & $x \times x$ & & & & & & & & & \\
\hline 6. $\quad 10201$ & 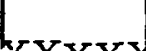 & Y Y & FYY & ty & TYYY & & & & & & & & & & \\
\hline Currie $(83 \%)$ & $x \times x y$ & $\times \times x y$ & $x \times x y$ & & & $x \times \wedge \times$ & & & & & & & & & \\
\hline Ireland $(83 \%)$ & $\mathrm{XXXX}$ & $\mathrm{XxXX}$ & $\mathrm{XXXX}$ & XXX & $\mathrm{xXXX}$ & $x \times x \times$ & $x \times x x$ & $\$ \mathrm{XXX}$ & & & & & & & \\
\hline
\end{tabular}


while $36 \%$ were less than six months old. However, Gil (1970) contradicts the consensus in establishing that $66.8 \%$ of his sample population were more than three years old. He concludes that "physical abuse of children is not limited to very young children as has been suggested by numerous investigators" (p. 105).

Part of the disagreement over the relationship between age and abuse involves the definitional age of child abuse employed by the res pective studies. For example, Skinner and Castle (1969) establish a very strong relationship-with a high level of significance - that the younger the child, the more likely it is to be abused. However, their sample was specifically restricted to case records of children four years old or less whereas Gil's (1970) sample included all children through eighteen years old. While Skinner and Castle reported that $91 \%$ of the children in their study $(\underline{N}=78)$ were three years old or less, only about one-third of Gil's 1968 study cohort ( $N=6,617$ ) fell into that age category. Because the two studies imposed different age ranges on their subjects, they generated different age distributions and different proportions of cases for each age. Note, however, that even in Gil's survey, the first three years represented the single largest proportion of cases and a comparison with other studies which included older children and adolescents (TABLE III A) indicate a similar age distribution. Moreover, Fergusson et al. (1972) have computed the number of abused children for each age level for the entire population and 
TABLE Ш A

COMPARISON OF AGE DISTRIBUTIONS

AMONG FIVE SELECTED STUDIES

Figures in percentages $(\%)$

\begin{tabular}{|c|c|c|c|c|c|}
\hline $\begin{array}{l}\text { Age } \\
\text { (years) }\end{array}$ & Gil & Fergusson & Glazier & Oregon & Skinner/Castle \\
\hline Under 1 & $13.6^{\mathrm{a}}$ & 11.08 & $13.9^{c}$ & 15.0 & 56.0 \\
\hline 1 & 10.8 & 9.4 & 8.5 & 9.0 & 22.0 \\
\hline 2 & 9.4 & 8.6 & 7.85 & $10.0 \mathrm{e}$ & 13.0 \\
\hline 3 & $6.63 \mathrm{~b}$ & 8.2 & 7.85 & 10. & 9.0 \\
\hline 4 & 6.63 & 3.9 & $5.3 d$ & $7.5^{\mathrm{e}}$ & - \\
\hline 5 & 6.63 & 6.7 & 5.3 & 7.5 & - \\
\hline 6 & $5.03 b$ & 6.7 & $6.0^{d}$ & $5.33 \mathrm{e}$ & - \\
\hline 7 & 5.03 & 6.7 & $6.0 \mathrm{~d}$ & 5.33 & - \\
\hline 8 & 5.03 & 5.9 & $5.05^{\mathrm{d}}$ & 5.33 & - \\
\hline 9 & $4.07 \mathrm{~b}$ & 5.5 & 5.05 & $2.67 \mathrm{e}$ & - \\
\hline 10 & 4.07 & 3.9 & $3.9^{d}$ & 2.67 & - \\
\hline 11 & 4.07 & 3.9 & 3.9 & 4.25 & - \\
\hline 12 & $3.60^{\mathrm{b}}$ & 5.1 & 3.9 & 4.25 & - \\
\hline 13 & 3.60 & 5.1 & $5.83^{d}$ & 4.25 & - \\
\hline 14 & 3.60 & 5.5 & 5.83 & 4.25 & - \\
\hline 15 & 2.10 & 3.1 & 5.83 & --- & - \\
\hline 16 & 2.10 & 0.8 & -- & --- & $=$ \\
\hline 17 & 2.10 & -- & - & $\ldots$ & $=$ \\
\hline 18 & 2.10 & $\ldots$ & $\ldots$ & $\ldots$ & - \\
\hline
\end{tabular}

aGil's two categories, "under 6 months (8.1\%) and 6 months to under 1 year $(5.5 \%)$ are aggregated.

bGil's '3 to under 6 years" category (19.9\%) is disaggregated by obtaining the average percentage for one year. His subsequent three year intervals: $6-9$ years $(15.1 \%) ; 9-12$ years $(12.2 \%) ; 12-15$ years $(10.8 \%)$ and 15 and over $(5.6 \%)$ are likewise disaggregated.

cGlazier's two categories, "0-6 months (10.4\%) and "7-12 months" are aggregated

dGlazier's categories: $2-3$ years $(15.7 \%), 4-5$ years $(10.6 \%), 6-7$ years $(12.0 \%), 8-9$ years $(10.1 \%), 10-12$ years $(11.7 \%)$ and $13+$ years $(17.5 \%)$ are disaggregated.

'The same procedure was applied to Oregon's categories: 2-4 years $(20 \%) ; 4-6$ years $(15 \%) ; 6-9$ years $(16 \%) ; 9-11$ years $(8 \%) ; 11-15$ years $(17 \%)$. 
determined that the highest rates were concentrated in the first three years as follows. (TABLE III B).

TABLE III B

RATE OF ABUSED AGE

$\underline{\text { Age }}$

under 1 year

1 year

2 years

3 years

6 years

9 years

12 years

15 years
Rate of Abused Children

4. 50 per 10,000

4. 00 per 10,000

3.76 per 10,000

3.42 per 10,000

2.68 per 10,000

2. 37 per 10,000

2. 36 per 10,000

1.56 per 10,000

In sum, while Gil's survey indicates a broader age distribution of abused children compared with many studies which exclude older children, it is not inconsistent with the consensus that the largest proportion of abused children are infants and young children.

Gil (1970) asserts, however, that most studies are conducted in a clinical setting and employ a biased sample. He argues that since most studies are conducted at a hospital, the cases naturally involve children withmore serious injuries. In fact $65 \%$ of the severely abused children incorporated in Gil's sample cohort $(\underline{N}=1,380)$ were three years old or younger. It is also probable that some proportion of older abused children go undetected or reported. For one thing, older children sustain more accidental injuries which may confound the diagnosis of abuse particularly where there is no known history of unexplained injury. Since infants and younger children are less mobile, 
Helfer (1972) observes that "it is rare to have true accidents occur in infancy" (p. 75). Consequently, injuries stemming from abuse as distinguished from accidents are more positively detectable in younger children and infants. Moreover, physical assaults on older children are more likely to be socially regarded as measures of strong disciplinary action rather than abuse and therefore go unreported. In addition, older children have the capacity to flee from assault and/or defend themselves from attack both physically and verbally which may diminish the severity and frequency of physical injuries. Finally, Fergusson et al. (1972) point out the possibility that some number of younger children are, upon detection, removed from the mistreating family which may "depress the rate of abuse in the older age groups" (p. 148). However, studies which include older children and adolescents $r$ un the risk of incorporating cases of sexual abuse which quite often go reported as physical assault rather than sexual molestation (see GENDER, below).

In sum, while it is likely that most clinical studies are skewed toward the younger age range for reasons cited above, there remain a number of reasons why the reported overrepresentation of younger abused children and infants may nevertheless be an accurate reflection of the phenomenon.

Clearly, preschool children are in greater and closer contact with their caretakers, particularly mothers. It is not unexpected that 
most studies report that mothers are the most frequent perpetrators of child abuse (See IDENTITY OF ABUSERS, Chapter IV). Naturally, younger children, and infants especially, demand almost continuous attention which can and does create heavy burdens on caretaker, moreover, requires constant physical and emotional response from the caretaker although the infant provides no meaningful social interaction in return. Generally speaking, the care of a young child or infant creates greater stress on the parent who, if predisposed, will vent his frustion or disappointment on the source of stress.

Accepting that younger children and infants are more susceptible to injury from physical assault and therefore more easily diagnosed as abused, it nevertheless remains probable that the largest proportion of physically abused children fall into the 0 to 3 years age range. Consequently most authors (Fontana, 1973b; Helfer, 1972; Solomon, 1973; Bennie and Sclare, 1969; and others) agree that the age of the child abuse victim is highly significant and certainly a factor in the diagnosis of child abuse.

\section{GENDER}

While most studies indicate that abused males outnumber females, several studies report opposite results (TABLE IV). Fergusson et al. (1972) attributes these inconsistent findings to "chance sampling variations" which is not unlikely in view of the 
TABLE IV

SEX OF CHILD ABUSE VICTIM

Male (\%) Female (\%) $\quad$ Control (\%)

\begin{tabular}{|c|c|c|c|}
\hline $\begin{array}{l}\text { Gil (1967) } \\
\underline{N}=5993\end{array}$ & 52.6 & 47.4 & \\
\hline $\begin{array}{l}\overline{\text { Gil }}(1968) \\
\mathrm{N}=6,617\end{array}$ & 51.2 & 51.2 & \\
\hline $\begin{array}{l}\text { Paulsen \& Blake } \\
N=96\end{array}$ & 55.0 & 45.0 & \\
\hline $\begin{array}{l}\text { Birrell (1968) } \\
\mathrm{N}=42\end{array}$ & 57.1 & 42.8 & \\
\hline $\begin{array}{l}\text { Silver } \\
\underline{N}=34\end{array}$ & 70.5 & 29.4 & \\
\hline $\begin{array}{l}\text { Terr }(1970) \\
N=10\end{array}$ & 50.0 & 50.0 & \\
\hline $\begin{array}{l}\text { Lauer } \\
N=130\end{array}$ & 55.0 & 45.0 & 56.0 male \\
\hline $\begin{array}{l}\overline{\bar{J}} \text { ohnson and Morse (1968) } \\
\mathrm{N}=101\end{array}$ & 50.0 & 50.0 & 50.0 male \\
\hline $\begin{array}{l}\bar{O}^{\prime} \text { Neill (1973) } \\
N=110 \\
\underline{\underline{n}}=11\end{array}$ & 61.8 & 38.2 & \\
\hline $\begin{array}{l}\overline{\bar{E}} \text { bbin et al (1969) } \\
\mathrm{N}=50\end{array}$ & 44.0 & 56.0 & 53.0 male \\
\hline $\begin{array}{l}\text { Burland et. al. (1969) } \\
\underline{N}=28\end{array}$ & 57.1 & 42.9 & \\
\hline $\begin{array}{l}\text { Coben (1966) } \\
\underline{N}=12\end{array}$ & 50.0 & 50.0 & \\
\hline $\begin{array}{l}\overline{\text { Glazier (1971) }} \\
\mathrm{N}=376\end{array}$ & 50.5 & 49.5 & \\
\hline $\begin{array}{l}\overline{\text { Ireland }(1966)} \\
\underline{N}=363\end{array}$ & 55.0 & 44.9 & \\
\hline $\begin{array}{l}\text { Skinner and Castle (1969) } \\
N=78\end{array}$ & 57.5 & 42.5 & \\
\hline $\begin{array}{l}\text { Fergusson et. al. (1972) } \\
\mathrm{N}=255\end{array}$ & 44.0 & 56.0 & 51.0 male \\
\hline $\begin{array}{l}\text { Oregon (1973) } \\
\underline{N}=353\end{array}$ & 52.0 & 48.0 & \\
\hline
\end{tabular}

a $\mathrm{p}$ at the .05 level 
small samples employed by many studies. For example, while Ebbin et al. (1969) reported that females (56\%) exceeded males (44\%) they determined that the difference was insignificant for the sample $(\underline{N}=50)$ when compared with the control population (53\% male). In addition it is entirely possible that the usual disproportion of males reflects the higher number of live male births (51. 3\% in the United States, $1968 ; 51 \%$ in New Zealand, 1967) coupled with the fact that younger children and infants run a higher risk of abuse. Since there is a larger pool of young male children and infants, it is expected that males would constitute a slightly higher proportion of abuse cases and, for that matter, a higher proportion of hospital admissions in general. In a controlled study, $(N=130)$, Lauer et al. (1974) confirmed that the sexual distribution of the abused population included slightly more males $(55 \%)$ but mirrored the general pediatric population (56\% male). In contrast, Fergusson et al. (1972) reported that $56 \%$ of their sample $(\underline{N}=255)$ were females and that a test for standard error of proportions (p less than .05) established a significant difference when compared with the total New Zealand population for the age range $0-16$ years. They point out that the overrepresentation of females finds explanation in the sexual distribution according to age.

While the distribution of male and female abuse victims is substantially even through the age of eleven, the number of adolescent females (13-17 years old) increases substantially. Although Gil (1970) 
reports a distribution by sex consistent with most other studies $-51.2 \%$ male in the 1968 study cohort $(\underline{N}=6,617)$ - he found similarly that while males outnumbered females for each age group through age eleven, the percentage of females older than eleven (63.8\%) exceeded males (36. $2 \%$ ) by nearly two to one. Gil (1970) explains this uneven distribution by sex with a hypothetical relationship between childhood development and culturally differentiated child-rearing practices for males and females. He suggests that girls are more quickly socialized than boys in accordance with their culturally assigned passive role and therefore, they are less often subject to severe physical punishment. Boys, on the other hand, are expected to engage in more aggressive behavior, control of which requires more physical force that, according to Gil, results in abuse. Gil believes, however, that the pattern is reversed at adolescense when less physical force is exerted on males primarily because they match or surpass the physical strength of the disciplining caretaker. Adolescent females, naturally involved in heterosexual relationships, become subject to increasing controls by parents which require more physical force.

However, Elmer (1967) contradicts Gil's description of the child-rearing pattern in reporting that girls are more consistently punished at an earlier age than boys. At nine months mothers reported that $31 \%$ of their girls but only $5 \%$ of their boys were punished; at eighteen months, $70 \%$ of the girls and $50 \%$ of the boys. Moreover, there is some 
evidence that tentatively suggests young female children are more severely punished. Both Lauer et al. (1974) and Glazier (1971) report that females sustained a significantly higher risk of fatality stemming from child abuse. It may be that since girls a re punished at an earlier age according to Elmer, they are more susceptible to serious injury resulting in fatality stemming from physical attack. Fergusson et al. (1972) extrapolates from Gil (1970) that the overrepresentation of abused female adolescents is accounted for by the fact that physical punishment of females is less socially acceptable than for males and that such assaults are more frequently reported. One would, however, expect that, therefore, females at each age groups would be overrepresented but most studies indicate otherwise. In any event, there is insufficient data to determine to what extent cultural attitudes regarding the physical punishment of males and females generate different reporting rates. The overrepresentation of abused female adolescents may find explanation in Steele and Pollock's (1968) position that actual child abuse and sexual abuse are etiologically distinct. Note that both Gil (1970) and Fergusson et al. (1972) include adolescents in their respective national surveys. Although Gil (1970) specifically excludes cases of primary sexual abuse where the motivation is self-gratification rather than intent to injure, it is possible that sexual conflicts that result in physical injury stem largely from unresolved Oedipal conflicts rather than from disciplinary measures as suggested by Gil. Simons et al. 
(1966) found that children were more frequently assaulted by the parent of the same sex. which suggests that sexual rilvary commencing at the puberty stage of development may underlie physical assaults. Moreover, reports of alleged physical child abuse can mask real incidents of sexual molestation. Consequently, some authors believe that perpetrators are more likely to abuse older children of the opposite sex. The only study that relates sex of the perpetrator and victim (Skinner and Castle, 1969) shows that fathers were less likely to abuse their daughter although the sample was too small to attach statistical significance to the difference. However, the children in the study were less than four years old which therefore does not permit testing the hypothesis that abuse among older female children is more frequently sexual molestation.

In sum, it appears that there is insufficient evidence to sustain any significant relationship between gender and child abuse although the uneven distribution by sex according to age requires an explanation which is not available given the present data.

\section{BIRTH HISTORY}

It is well established that abused children suffer a higher than a verage incidence of prematurity and/or complications stemming from birth.

A number of studies (TABLE V) indicate that abused children run a significantly higher risk of prematurity in birth weight, gestation 
or both. Simons et al. in their study of abuse in New York City, report that $20 \%$ of the abused children $(\underline{N}=313)$ had recorded birth weights below the international standard of 2500 grams, twice the rate for the city as a whole. However, that study sample included a much higher proportion of nonwhites compared with the racial distribution of New York City and it is suggested that nonwhites have a higher rate of prematurity in general. Elmer (1967) related premature, abused children to race and found that of her small sample $(\underline{N}=21) 27.2 \%$ of the abused children known to be premature were white whereas only $4.5 \%$ of the black abused children were premature. Nearly one-third of the total sample of abused children were premature. From a somewhat larger sample $(\underline{\mathrm{N}}=78)$ which included only $6 \%$ nonwhites, Skinner and Castle (1969) found that $13 \%$ of the abused children were premature compared with the national average of $6.5 \%$ in Great Britain. Similarly, McRae's (1973) study of abused children in Winnipeg, Canada showed that $12.5 \%$ of the abused children ( $N=132$ ) were premature although the study provides no data on an appropriate control population with which to make a comparison. However, in a study of 51 abused children conducted in Montreal, Canada, Klein and Stern (1971) compared the rate of prematurity of the abused children $(23.5 \%)$ with the average rate for the Quebec population in general $(7-8 \%)$. Unlike other studies cited above, Klein and Stern took into consideration that their sample was largely drawn from the lower socioeconomic strata which are 
TABLE V

\section{PREMATURE ABUSED CHILDREN}

Figures in percentages $(\%)$

\section{Abused Children Control Population}

Elmer (1967)

31.8

$\underline{N}=21$

Simons et al. (1966)

$\underline{N}=313$

20.0

10. 0 New York City

$\underline{\mathrm{T}} \mathrm{er}=\underset{10}{\mathrm{r}}(1970)$

20.0

McRae (1973)

12.0

$\underline{N}=132$

Lenoski (1974)

22. 0

10. 0 pediatric admis -

N-674

$$
\text { sions }
$$

Elmer (1970)

$\mathrm{N}=24$

37.0

Skinner and Castle (1969)

13. 0

6.5 Great Britain $\underline{N}=78$

Klein and Stern (1971)

23.5

10. 0 indigent population, Montreal 
predisposed to higher rates of prematurity due to the associated conditions of poverty. Klein and Stern compared their child abuse sample with rate for low birth weight for the indigent population of Montreal (9-10\%) and found, nevertheless, that the difference was significant at the .0014 level. Similarly, Lenoski (1974) compared a large sample of abusing families $(\underline{\mathbb{N}}=647)$ with a control population randomly selected from pediatric emergency admissions at the hospital where he conducted the study. He found that $22 \%$ of the abused children but only $10 \%$ of the nonabused children had a history of prematurity. It should be noted that the control population at that hospital has significantly more poor and nonwhite families than the area in general from which was drawn the child abuse sample.

In sum, the evidence strongly indicates that premature infants have a higher risk of abuse and consequently, prematurity must be considered a significant factor in child abuse.

Several early studies indicated a relationship between child abuse and illegtimacy. For example, Fontana (1963) found that nearly half the abused children in his original study of 115 families were premaritally conceived. Bryant et al. (1963) cited in Zalba (1966) reports the same rate of premarital conception in that study although neither Fontana or Bryant provide data on illegitimacy in appropriate control populations. Simons et al. (1966) determined that $32 \%$ of the abused children compared with $12 \%$ of the children in the general New York 
City population were born out-of-wedlock. However, nearly threefourths of the study sample were nonwhite and that group accounted for $65 \%$ of the illegitimate children. Simons et al. note that among nonwhite groups, rates of illegitimacy commonly equal or exceed $40 \%$ of the families and they suggest that the high rate of illegitimacy probably reflects the racial distribution of their study sample. In marked contrast, Lenoski (1974) reported that $90.3 \%$ of the abused children $(\underline{N}=674)$ but $60 \%$ of the control population $(\underline{N}=500)$ were legitimate. This finding is consistent with Lenoski's data about the higher rate of marriage among abusing families. Both findings may be explained, as noted elsewhere by the fact that the racial distribution of the sample and control groups was substantially different. When Johnson and Morse (1968) compared the abused children with their nonabused siblings in the 85 subject families, they found that $36 \%$ of the former but $40 \%$ of the latter were illegitimate. In other words, it appears that many abused children a re born out-of-wedlock but that comparable illegitimacy runs throughout their families and other families in the same racial and socioeconomic groups. In short illegitimacy is not a significant factor in child abuse.

\section{SIBSHIP}

A number of studies present data of variable quality on the number of children in the abusing family, the number of children abused 
and the ordinal position of the abused child in the family.

There is near complete consensus that abusing families have more than the average number of children. For example, Johnson and Morse (1968) reported that the mean number of children in the study families $(\underline{N}=85)$ was 3.1 compared with a national average of 2.3 . Elmer (1967) reports the ave rage number of children in her study of abusing families $(\underline{N}=11$ ) was 4.0. Similarly, Bennie and Sclare (1969) determined that one-third of their sample $(\underline{N}=9)$ were families with more than three children. Neither Johns on and Morse nor Elmer provide a relevant control population with which to compare their findings in view of the fact that both studies include a disproportionate number of nonwhite families which typically have larger families. For example, the U.S. census indicates that the proportion of nonwhite families with more than seven children is twice that for white families. However, in a study $(\underline{\mathrm{N}}=10)$ which matched study and control populations for race (all subjects were Black) and socioeconomic factors, Melnick and Hurley (1969) show that the mean number of children in the abusing family was 2.8 compared with 2.5 children in the control families. But all three of the studies cited above employed samples too small to avoid the possibility of chance sampling error.

However, Light presents a cross-cultural nationwide survey of the size of the abusing family accompanied by respective census figures (TABLE VI). 


\section{TABLE VI}

\section{NUMBER OF CHILDREN IN ABUSING FAMILIES}

Figures in percentages $(\%)$

\begin{tabular}{|c|c|c|c|}
\hline $\begin{array}{l}\text { Number of } \\
\text { Children } \\
\end{array}$ & $\begin{array}{l}\text { U.S. (1967)/ } \\
\text { Control } \\
\end{array}$ & $\begin{array}{l}\text { New Zealand/ } \\
\text { Control }\end{array}$ & $\begin{array}{l}\text { Great Britain/ } \\
\text { Control } \\
\end{array}$ \\
\hline 1 & $18.0 / 31.8$ & $13.5 / 33.2$ & $23.1 / 34.4$ \\
\hline 2 & $22.5 / 29.7$ & $19.2 / 30.8$ & $44.8 / 33.2$ \\
\hline 3 & $20.2 / 18.9$ & $20.8 / 21.9$ & $19.2 / 20.5$ \\
\hline 4 or more & $39.5 / 19.6$ & $46.5 / 14.1$ & $12.9 / 11.9$ \\
\hline
\end{tabular}

In both the United States and New Zealand, a family with four or more children significantly distinguishes abusing families. It should be taken into consideration that the United States data come from Gil's nationwide survey which included twice the proportion of nonwhite families as is in the country as a whole. Similarly, the New Zealand data come from the Fergusson et al. nationwide survey which includes a disproportionate number of Maori known to have larger families. However, separating out the Maori population, the mean number of children for non-Maori abusing families was 3.28 compared with a national average of 2.5 children per family. In sum, while it is possible that the overrepresentation of nonwhite families may inflate the average number of children per abusing family, there is enough reliable data to conclude that abusing families are larger than average and that size of family is a significant factor in child abuse. 
It might be expected that a family which uses inappropriate physical force in dealing with children would abuse more than one child given that a disproportionate number of abusing families have more than the average number of children. Unlike neglecting families which provide inadequate care for all their children, abusing families tend to single out one child for abuse. Steele and Pollock (1968) observe that "some children in a family are rather well treated, with a minimum of punitiveness, although another child in the same family is abused" (p. 123). Gil (1970) supplies some data to show that only one child is selected for abuse in multiparous families. In his 1968 survey, $65.3 \%$ of the child abuse incidents involved a single child (23.0\% unknown); in the 1967 sample cohort $(\underline{N}=1,380), 83.8 \%$ were cases involving one child. Yet, only $17.2 \%$ of the families in the sample cohort had only one child. Burland et al. (1972) also find a majority of the study families - most of had between three and six children - abused only one child. Although Lauer et al. (1974) reported 53\% $(\underline{N}=130)$ of the children in the study had siblings that were also mistreated, the sample included incidents of neglect which usually involve all the children in a family. However, Gil (1970) found that $26 \%$ of the siblings of the index child were also abused. Likewise, Simons et al. (1966) reported that $16 \%$ of the 239 subject families abused other children while Silver et al. (1969) reported that in more than half the families, siblings were abused. In the case of Simons the small number of multiple child abusing families may reflect the fact that some of the cases involved severe neglect. Both 
Gil and Silver et al. present data that differs from the "one child in a family" observation generally held by most authors - Merrill (1962), Zalba (1966), Boardman (1962), and as cited above, Gil (1970) found that in less than $10 \%$ of the abuse incidents was a sibling attacked at the same time. Silver et al. (1969) note that in about $60 \%$ of the cases, the index child had heen previously abused and that the incident had come to the attention of a hospital or agency. Gil (1970) reported that about one-third of the perpetrators were previously known to authorities for abusing their children. Perhaps in families where a perpetrator or victim of abuse has been identified by the authorities, siblings will be abused as well to avoid severely injuring one child. Consequently, less serious abuse to several children will go undetected and not reported as a child abuse incident.

Glazier's (1971) large study sample $(\underline{N}=376)$ revealed that $50 \%$ of the abused children were the only child or the oldest. Similarly, Elmer and Gregg (1967) reported that $37 \%$ of their sample of abused children $(\underline{N}=30)$ were first or second born. Burland et al. (1973) also found that $75 \%(\underline{N}=28)$ were first or second born in families with three to six children. The data appears to support Johnson and Morses' (1968) observation that the older rather than the younger children in the family are somewhat more likely to be injured, whereas middle children were least likely to be injured. The disproportion of only children is most easily explained by the simple statistical fact that the 
child is the only target for attack by the parent. More subtly, the large number of abused only children suggests that the parents are overwhelmed by the responsibility of one child and are not capable of having others. In many cases, the only child may be an unwanted child who is therefore subject to abuse. The overrepresentation of older children suggests that younger and more inexperienced parents place excessive and unrealistic demands on their first and second born, but learn by experience what the capacities of a child really are. Thus, younger children are less likely to be an object of disappointment. Moreover, the data indicate that one child is typically singled out for abuse and since older children are more likely to be abused, younger children have a smaller risk. However, Bennie and Sclare (1969) found that $80 \%$ of the abused children in their small sample $(\underline{N}=10)$ were either the only or youngest child in the family although the sample population is sus ceptible to random error. Elmer (1967) also indicated that the youngest child in the family ran a higher risk of abuse if the mother was pregnant at the time of abuse. Half of the abusing mothers in Bennie and Sclare's (1969) study had, in fact, been pregnant at the time of abuse.

In sum, although child abusing families have significantly more children than average, usually only one child is selected out for abuse and that child is more often than not the only, eldest, or youngest child in the family. The data conform to the general observation that families give most attention to oldest and youngest children. Moreover, the 
data appear to substantiate that abusing families as distinguished from neglecting families pay more and closer attention to their children.

\section{RACE}

Although only $15 \%$ of the children under eighteen living in the United States were nonwhite, about one-third of the abused children were nonwhite according to Gil's (1970) nationwide surveys in 1967 and 1968. Most studies (TABLE VII) concur with this finding which leads to the conclusion that race is significantly as sociated with child abuse. In assessing the validity of this relationship two possibilities must be considered:

1. The studies draw on biased samples.

2. There are specific characteristics about racial groups which produce different incidence rates of child abuse among them.

Each explanation will be tested against the available evidence to determine the extent to which it contributes to the statistical association between race and child abuse.

While a majority of surveys and clinical studies indicate that a disproportionate number of nonwhite children are abused, many of them draw upon nonrandom samples for reasons discussed generally in Chapter II. A review of the hospital and agency studies show that most report an overrepresentation ofmnwhites (mainly, Blacks) when compared to the racial distribution of the population of the city in which they 
are located. Without exception all are public facilities operating in the core area of major metropolitan areas. Since they are both urban and public, these hospitals and agencies serve that part of the population in the immediate vicinity and those people requiring free medical and welfare services. In cities like Los Angeles, Philadelphia, and Pittsburgh this means that the vast majority of this population is nonwhite. Consequently, the sample generated by most clinical studies - typically from pediatric and/or emergency room admissions - draws from a population which has a disproportionate number of nonwhites compared with the population for the entire city. Thus, the results of, for example, Paulsen and Blake's (1969) study must be interpreted in light of the fact that Los Angeles County General Hospital served a generally poor, nonwhite population although Los Angeles itself is predominantly white. The problem of nonrandom sampling is best illustrated by Glazier's (1971) survey of child abuse in Erie County, New York that reported $37 \%$ of the children were nonwhite. However, $74.1 \%$ of the total cases of abuse were reported in Buffalo, the major city which contains $93.2 \%$ of the nonwhite population for the entire county. Almost all the white children (96.8\%) live outside the city.

The difficulty of ascertaining whether the disproportion of nonwhite abused children is significant is compounded by the control population used to compare white and nonwhite percentages. Ebbin et al. (1969) discovered that $54 \%$ of the abused children compared with 
TABLE VII

CHILD ABUSE VICTIMS BY RACE

All figures in percentages (\%)

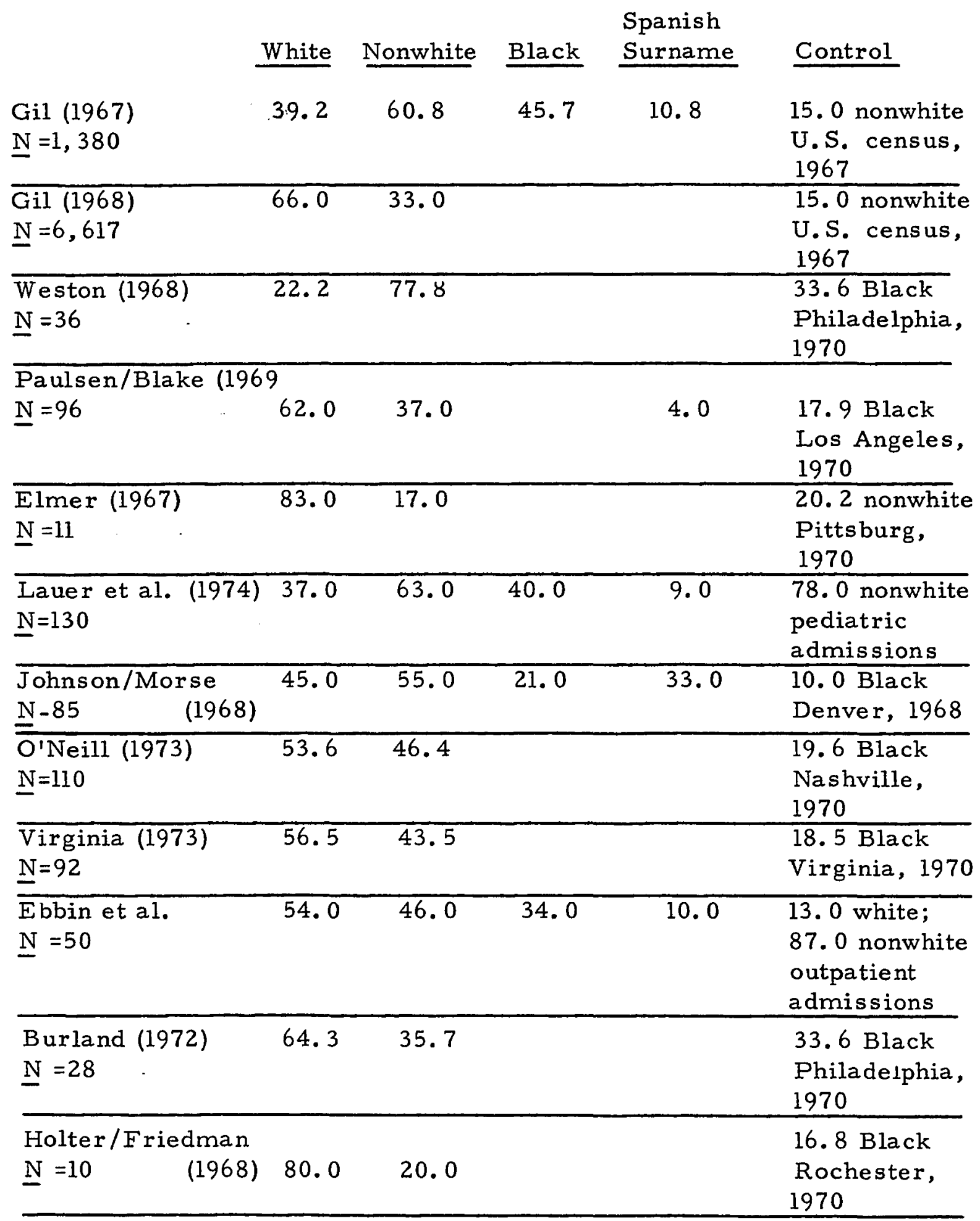


TABLE VII (continued)

CHILD ABUSE VICTIMS BY RACE

All figures in percentages $(\%)$

\begin{tabular}{|c|c|c|c|c|c|}
\hline & White & Nonwhite & Black & $\begin{array}{l}\text { Spanish } \\
\text { Surname }\end{array}$ & Control \\
\hline $\begin{array}{l}\text { Young (1967) } \\
N=300\end{array}$ & 79.0 & 21.0 & 18.0 & & $\begin{array}{l}15.0 \text { nonwhite } \\
\text { U.S. census, } \\
1967\end{array}$ \\
\hline $\begin{array}{l}\text { Glazier (1971) } \\
\underline{N}=376\end{array}$ & 63.0 & 37.0 & 32.0 & & $\begin{array}{l}20.4 \text { Black } \\
\text { Buffalo, } \\
1970\end{array}$ \\
\hline $\begin{array}{r}\text { Fergusson et al. } \\
(1972) .\end{array}$ & 60.0 & 40.0 & & & $\begin{array}{l}65.0 \text { nonwhite } \\
\text { pediatric } \\
\text { admissions }\end{array}$ \\
\hline $\begin{array}{l}\text { Elmer (1967) } \\
\underline{N}=31\end{array}$ & 73.0 & 27.0 & & & $\begin{array}{l}17.0 \text { nonwhite } \\
\text { Pitts burgh, } \\
1960\end{array}$ \\
\hline $\begin{array}{l}\text { Silver et al. (1971) } \\
\underline{N}=34\end{array}$ & 5.9 & & 94.1 & & $\begin{array}{l}71.1 \text { Black } \\
\text { Washington, D. C } \\
1970\end{array}$ \\
\hline $\begin{array}{l}\text { Simons et al. (1966) } \\
\mathrm{N}=313\end{array}$ & $\longdiv { 2 1 . 7 }$ & 74.8 & 48.3 & 26.5 & $\begin{array}{l}21.2 \text { Black } \\
\text { New York, } \\
1970\end{array}$ \\
\hline
\end{tabular}


$13 \%$ of the control population designated as the outpatient admissions were white. However, since Los Angeles County General Hospital now serves as the major center for all children's emergency medical services for the entire county, the control population was inappropriate and the results of the study are equivocal. Where clinical studies have compared the ratio of white and nonwhite abused generally with the racial distribution of the population actually served by the hospitals and agencies in which the studies are conducted, they (Elmer, 1967; O'Neill, 1973; and Silver et al., 1971) find no significant difference. In the one controlled study in which Lauer et al. (1974) matched abused children with nonabused children admitted to the same pediatric service, they found that $37 \%$ of the abused children but only $22 \%$ of the nonabused children were white.

Even surveys that ostensibly draw from a larger and more heterogeneous population select nonrandom samples skewed toward nonwhites. For example, Simons et al. (1966) found in their survey in New York City that "abuse was reported more than twice as often for nonwhites as for white children $\underline{\underline{N}}=293$ families/, whereas in the city as a whole, the ratio of white to nonwhite children under the age of fifteen is approximately four to one." However, the reporting source for $87.0 \%$ of the abusing families in that study came from hospitals of which half were public facilities. In contrast, only $2.4 \%$ of the families were reported by a private physician; only $1.0 \%$ of the families were reported by a proprietary hospital. Since the substantial majority of the popu- 
lation served by municipal and voluntary hospitals in New York City is poor and either Black or Puerto Rican, it becomes apparent that the sample is skewed and that comparisons with the racial distribution for the entire city are erroneous. Moreover, the balance of reporting sources in the Simons et al. study included a number of social welfare agencies eg. welfare examiner, day care center, police, which most frequently come into contact with nonwhite families. Similarly, Gil's (1970) cohort sample $(\underline{N}=1,380)$ drew $49.0 \%$ of its cases from hospitals and clinics, $23.2 \%$ from the police, and $7.0 \%$ from public social agencies. In addition the sample cohort involved thirty eight communities most of which contained high concentrations of Black and other nonwhite populations eg. New York City (21.2\% Black), Chicago $(32.7 \%$ Black), Detroit (43.7\% Black), St. Louis (40.3\% Black), Pittsburgh (20. 2\% Black), Los Angeles (17.9\% Black), and Baltimore (46. 4\% Black). These seven cities alone accounted for $71.89 \%$ of all the abuses cases in the 1967 cohort sample $(\underline{N}=1,380)$ which reported that $60.8 \%$ of the subjects were nonwhite. In general Gil (1970) found that whereas $67 \%$ of the population lived in the Standard Metropolitan Statistical Areas (SMSA's), $78.26 \%$ of the reports in 1968 came from SMSA's.

In sum, while most studies indicate an overrepresentation of nonwhite abused children, an analysis of their sample populations suggest they are subject to significant biases. For one thing, clinical studies draw no hospital populations located in la rge metropolitan areas with high concentrations of nonwhites. Moreover, the specific popula- 
tion served by these hospitals - primarily municipal or voluntary community facilities - are both poor and nonwhite. Even nationwide surveys like Gil (1970) or citywide surveys like Simons et al. (1966) draw most of their cases from sources eg. municipal hospitals, public welfare and law enforcements agencies which serve predominantly nonwhite populations. Whe re clinical studies have compared the proportion of white and nonwhite abused children with the racial distribution of the population served by the hospitals that conducted these studies, no significant difference is found. It appears that present studies do not adequately control for biased samples and consequently no definitive conclusion about the relationship between race and child abuse is possible at this time. It is nevertheless clear that a large number of nonwhite children are abused and there are several factors which may help explain this.

The relationship between race and socioeconomic status in this country is well established. On all measures of socioeconomic status, it appears that child abusing families are consistently low in achievement (see SOCIOECONOMIC FACTORS, Chapter IV). Clearly, a disproportionate number of nonwhites occupy the lowest socioeconomic classes. In addition the re is some evidence to suggest that within the context of a violence-prone society, minority groups tend to be particularly violent. Crime statistics, for example, or prison population distributions by race show that a disproportionate number of 
nonwhites are involved in criminal acts. Of course the very fact that they are minorities - very identifiable ones at that - immediately sug gests that they may be unusually susceptible to detection. But, perhaps as some authors suggest, there is within the minority group a value system which condones and even sanctions the use of physical force. Gil (1970) offers the explanation that the violence perpetrated against minorities in the country, in the subtle but pervasive form of discrimination following emancipation, is internalized by the se groups and reebacted upon the white society in the form of crime and upon themselves in the form of, for instance, child abuse. Although the theory has some merit insofar as it conforms to the dynamics of aggressive and violent behavior i.e. aggression in, aggression out or inverted, there is no independent way to determine to what, if any, extent nonwhites as a group of cultures are intrinsically more violent.

\section{INJURIES}

In presenting and evaluating the data on trauma sustained by abused children, it must be taken into consideration that the many studies report incomplete data due in large part to the frequent omission of a full report of the incidents. Naturally, many of the child abuse victims a re either unable or unwllling to explain the cause of their injuries. According to Fergusson et al. (1972), only $40 \%$ of the abused children $(\underline{N}=255)$ actually identified the perpetrator largely 
because they were too young or too frightened to talk. In addition, many studies report that the identity of a large percentage of the perpetrators is unknown McRae (1973) observes that even when the caretaker admits his role as abuser, he is reluctant to give a truthful account of the cause of the injury. Weston (1968) found that, for example, in nearly every case of abuse that resulted in a fatality, the alleged cause of injury - mainly, death by accidental fall - differed sharply from the confessed cause of injury following autopsy. Below is a discussion of the pattern of injury associated with child abuse including the way in which the assault was made, the type and frequency of the injuries sustained, and the effect of these injuries on the physical health of the child.

The principal modalities of assault are beating with hands, beating with instruments, and burning (TABLE VIII). It is significant that a large percentage of assaults employ weapons, mainly blunt instruments like a belt, strap, hairbrush, etc. particularly in view of the fact that most child abuse victims are quite young. Very few cases of child abuse (TABLE IX) involve poisoning, drowning, electrocution, etc. although assaults with deadly weapons, gassing, and strangulation a re the most frequent modalities of as sault in infanticide. The data suggest that these types of assaults may represent attempted but unsuccessful attempts to murder a child and should not be considered incidents of child abuse as defined in Chapter II. Naturally, the mod- 
ality of as sault is related to the type and frequency of injuries sustained by abused children.

\section{TABLE VIII}

MOST FREQUENT MEANS OF ATTACK

\begin{tabular}{lcccc} 
Modality & ${ }^{\mathrm{a}}$ Gil & $\begin{array}{l}\text { Paulsen and } \\
\text { Blake }\end{array}$ & ${ }^{\text {Johnson }}$ & Glazier \\
\hline $\begin{array}{l}\text { Beating with } \\
\text { instrument }\end{array}$ & $39.3 \%$ & $13.0 \%$ & $33.0 \%$ & $33.0 \%$ \\
$\begin{array}{l}\text { Beating with } \\
\text { hands }\end{array}$ & $44.2 \%$ & $41.0 \%$ & $50.0 \%$ & $39.0 \%$ \\
Burning & $9.1 \%$ & $10.0 \%$ & $5.9 \%$ & $15.0 \%$ \\
Unknown & $13.1 \%$ & $36.0 \%$ & $15.0 \%$ & $13.0 \%$
\end{tabular}

Indicates that study computes more than one mode of assault where appropriate

A comparison of the distribution of injuries in ten studies selected for the adequacy of their sample size and the relative precision of their data is presented in Table $\mathrm{X}$ accompanied by control data on childhood accidental injuries $(\underline{N}=29,762)$ provided by Lenoski (1974). It is immediately apparent that, as noted by Simons et al. (1966), there is no commonly recognized way of classifying the kinds of injuries which abused children suffer. The studies included in Table IX are placed in categories which are neither uniform or mutually exclusive. Note that many studies did not distinguish between and among "lacerations," "abrasions," and "contusions." Some aggre gated thrdr injuries as "bruises or welts" or "wounds and punctures" 
while others included a combination of all or some of these categories. Where categories are combined, the sum frequency is designated by pluses $(+)$ followed by the total for the aggregated categories. Where studies either list the same injury several times because categories overlap or where children sustained more than one injury, total injuries will exceed $100 \%$ and are designated with a notation (a).

Originally, Kempe et al. (1962) equated child abuse with the "battered child syndrome" a medical diagnosis which described a child with a subdural hematoma and/or multiple fractures of the long bones with accompanying soft tissue injuries. However, a review of the literature clearly indicates that superficial soft tissue injuries like bruises or welts are the most common type of trauma sustained by abused children. Gil (1970) found, for example, that only $13.6 \%$ of the total incidents in his nationwide survey of child abuse conformed to the "battered child syndrome" although Paulsen and Blake (1969) report that $90 \%$ of the 96 cases of physical abuse they studied fitted into the syndrome. The disparity may be explained the fact that in the latter study $60 \%$ of the subjects were less than three years old compared with $32.2 \%$ of the population in Gil's survey. Both Simons et al. (1966) and O'Neill (1973) observe that the incidence of the "battered child syndrome" is mainly confined to infants and children no older than two years. Moreover Paulsen and Blake's study drew its sample exclusively from cases treated at a hospital whereas Gil's sample included cases reported from 


\section{TABLE IX}

TYPE AND DISTRIBUTION OF PHYSICAL INJURIES SUSTAINED BY ABUSED CHILDREN

All figures in percentages $(\%)$

\begin{tabular}{|c|c|c|c|c|c|c|c|c|c|}
\hline Lenoski & ${ }^{a} \mathrm{Gil}$ & a Birrell & a Lauer & McRae & O'Neill & $a_{\text {Ebbin }}$ & Glazier & ${ }^{\mathrm{a}} \mathrm{Oregon}$ & ${ }^{a}$ Johnson \\
\hline Lacerations & & $8.3 \%$ & + & & + & & $36.2 \%$ & + & \\
\hline Abrasions & + & & + & & & & & $13.0 \%$ & \\
\hline Contusions & $32.3 \%$ & & + & & $63.0 \%$ & & & & \\
\hline Bruises, welts & $67.1 \%$ & $26.1 \%$ & $70.6 \%$ & $40.9 \%$ & $50.0 \%$ & $74.0 \%$ & $72.5 \%$ & $53.0 \%$ & $61.8 \%$ \\
\hline Wounds, punctures & $7.9 \%$ & $0.0 \%$ & & & & & & & $24.5 \%$ \\
\hline Head injuries & $9.8 \%$ & & & $9.7 \%$ & & & & & \\
\hline Subdural hematoma & $4.6 \%$ & $16.6 \%$ & $8.4 \%$ & $4.5 \%$ & $16.3 \%$ & & & & $4.9 \%$ \\
\hline Skull fractures & $3.7 \%$ & $28.5 \%$ & $22.3 \%$ & $9.0 \%$ & $13.6 \%$ & $12.0 \%$ & $22.4 \%$ & $2.0 \%$ & $7.9 \%$ \\
\hline Brain damage & & $1.5 \%$ & $23.8 \%$ & & & & & & \\
\hline Intercranial injury & & $33.3 \%$ & & & $29.0 \%$ & & & & \\
\hline Cerebral contusion & & & & $4.5 \%$ & & & & & \\
\hline Sprains, dislocations & & $1.9 \%$ & $4.7 \%$ & & & & & $0.0 \%$ & $\infty$ \\
\hline
\end{tabular}


TABLE IX (continued)

TYPE AND DISTRIBUTION OF PHYSICAL INJURIES SUSTAINED BY ABUSED CHILDREN All figures in percentages (\%)

\begin{tabular}{|c|c|c|c|c|c|c|c|c|c|c|}
\hline Injury & Lenoski & ${ }^{a} \mathrm{Gil}$ & a'Birrell & ${ }^{a}$ Lauer & McRae & O'Neill & ${ }^{a}$ Ebbin & Glazier & ${ }^{2}$ Oregon & a Johnson \\
\hline Fractures & $6.4 \%$ & & $40.4 \%$ & $14.6 \%$ & $28.7 \%$ & $30.9 \%$ & $42.0 \%$ & $10.0 \%$ & $3.0 \%$ & $10.0 \%$ \\
\hline Long bone & & $10.4 \%$ & & & $23.4 \%$ & & $8.0 \%$ & & & $5.4 \%$ \\
\hline Multiple & & & $33.3 \%$ & $11.5 \%$ & & $26.3 \%$ & $22.0 \%$ & & & \\
\hline Other & & $5.4 \%$ & & & & & & & & \\
\hline Malnutrition & & $4.2 \%$ & $30.9 \%$ & & & & & & $3.0 \%$ & \\
\hline Unknown & & $2.2 \%$ & $0.0 \%$ & & & & & & & \\
\hline Failure to thrive & & & & & $1.5 \%$ & & & & & \\
\hline Burns & $5.2 \%$ & $10.1 \%$ & $4.7 \%$ & $12.3 \%$ & $1.5 \%$ & & $14.0 \%$ & & $6.0 \%$ & \\
\hline Gunshot, stabbing & & & & $3.0 \%$ & $0.7 \%$ & $0.9 \%$ & & & & \\
\hline Internal & & $3.3 \%$ & & $2.3 \%$ & $2.2 \%$ & $8.1 \%$ & & & & \\
\hline Drowning & & & & $1.5 \%$ & & & & & & \\
\hline Poisoning & & $0.9 \%$ & $2.3 \%$ & $1.5 \%$ & $0.7 \%$ & $1.8 \%$ & $2.0 \%$ & & $0.0 \%$ & \\
\hline Electrocution & & & & & & $0.9 \%$ & & & & \\
\hline Hypothermia & & $0.1 \%$ & $0.0 \%$ & & $0.7 \%$ & $0.9 \%$ & & & & $\stackrel{\infty}{\infty}$ \\
\hline
\end{tabular}


a variety of sources. Since it is more likely that the most severe cases of abuse will be treated at a hospital, the frequency of the "battered child syndrome" is likely to be higher in clinical studies.

Holter and Friedman (1968) offer the hypothesis that the presenting type of injury defines the relative risk that a child has been abused. In particular the presence of head injuries, fractures and dislocations, limb injuries, burns, contusions, abrasions, welts, and the absence of lacerations or ingestions are injuries that distinguish child abuse victims. They present a comparison of injuries between abused children and children who sustained accidents in support of the hypothesis.

TABLE $X$

COMPARISON OF INJURIES SUSTAINED

BY ABUSED AND NONABUSED CHILDREN

\begin{tabular}{lcc} 
Injury & Abused $(\underline{N}=7)$ & Accidental $(\mathrm{N}=64)$ \\
\hline Lacerations & $0.0 \%$ & $44 \%$ \\
Ingestions & $0.0 \%$ & $32 \%$ \\
$\begin{array}{l}\text { Abrasions, contusions, } \\
\text { bruises }\end{array}$ & $37.5 \%$ & $0.0 \%$ \\
Fractures, dislocations & $50 \%$ & $6 \%$ \\
Burns & $25 \%$ & $0 \%$ \\
Limb injuries & $12.5 \%$ & $9 \%$ \\
Head injuries & $0 \%$ & $9 \%$
\end{tabular}

In general studies consistently indicate that the most frequent trauma sustained by abuse victims are bruises and welts followed by bone 
fractures, head injuries and burns. Comparing with Lenoski's (1974) data on injuries resulting from childhood accidents, it is clear that there is a disproportionate number of these kinds of injuries among abused children.

Determining the severity of injury to child abuse victims is accomplished by aggregating and comparing the incomplete and somewhat inconsistent data on the frequency and degree of severity rated by type of injury, type and duration of medical attention, and number of fatalities stemming from child abuse. Most studies show that the great majority of abuse incidents do not result in the death of the child (TAB LE XI) but that physical abuse to younger children and infants not unexpectedly is more likely to cause fatal injury. For example, Weston's (1968) study of fatalities $(\underline{N}=36)$ stemming from abuse revealed that the mean age of the subject was 1.5 years. The range $(1.5-60.0)$ of mortality rates for abused children among the studies is best explained by the samples upon which they drew. For example, the early study by Kempe et al. (1962) collected all cases of known abuse in the United States. Since the diagnosis of child abuse was not well established, only the most definitive and unequivocal cases were reported i.e. the most severe and the fatal cases resulting from nonaccidental injury. Bennie and Sclare (1969) reported that six of their very small sample of ten children died from inflicted injuries. However, at least three of the perpetrators "committed a catastrophic assault on the child" and had 
TABLE XI

FATALITIES RESULTING FROM CHILD ABUSE

\begin{tabular}{|c|c|c|}
\hline Study & $\underline{N}$ & Fatalities $(\%)$ \\
\hline Gil (1970) & 1,380 & 3.4 \\
\hline Fergusson et al. (1972) & 255 & 2.7 \\
\hline Skinner and Castle (1969) & 78 & 1.5 \\
\hline Kempe et al. (1962) & 749 & 10.4 \\
\hline American Humane Assoc. (1962) & 622 & 27.0 \\
\hline Rubin (1966) & 85 & 16.5 \\
\hline Elmer (1962) & 50 & 14.0 \\
\hline Simons et al. (1966) & 313 & 1.9 \\
\hline Bennie Sclare (1969) & 10 & 60.0 \\
\hline Lauer et al. (1974) & 130 & 4.6 \\
\hline McRae (1973) & 88 & 9.0 \\
\hline Gregg (1969) & 30 & 3.3 \\
\hline Johnson Morse (1968) & 101 & 1.9 \\
\hline O'Neill (1973) & 110 & 7.2 \\
\hline Virginia (1973) & 92 & 7.6 \\
\hline Ebbin et al. (1969) & 50 & 6.0 \\
\hline Schloesser (1964) & 85 & 16.5 \\
\hline Glazier (1971) & 376 & 2.1 \\
\hline
\end{tabular}


been diagnosed as severely mentally disturbed. Since the pattern of these cases resembles the pattern of infanticide - single, direct assault on a child by a psychotic parent - they may not belong to the category of child abuse defined in Chapter II. More generally, studies with higher mortality rates employ samples that drew from hospital populations a large proportion of severe and emergency cases and/or samples skewed toward younger children who are more susceptible to serious injury from physical assault.

Severity rated according to the type of injury as suggested by Fergusson et al. (1972) i.e. head injuries are more severe than fractures are more severe than burn is likewise related to sample biases. For example Gil (1970) and Fergusson et al. (1972) both show (TABLE XII) that most injuries to abused children are not serious in contrast to Ireland (1966) and Skinner and Castle (1969). However, the last study considered a sample of children no older than four years whereas both Gil and Fergusson et al. included children up to eighteen and sixteen respectively. Since severity of injury is clearly a function of age, the conclusions about the extent to which child abusers inflict severe injury depend mainly on the age range of the abuse victims.

Although Gil (1970) finds that a small percentage of injuries sustained by child abuse victims are serious, he also finds that at least $40 \%$ of his sample were hospitalized (TABLE XIII). Other nonclinical studies eg. Johnson and Morse (1968) and Simons et al. (1966) 
also report more than one third of their subjects were hospitalized implying that their injuries were serious. However, that latter points out that hospitalization may be required to insure protective custody where other remedies fail or are not available.

TABLE XII

SEVERITY OF CHILD ABUSE INJURIES

Figures in percentages $(\%)$

$\begin{array}{llll}\text { Gil (1970) } & \text { Fergusson } & \text { Ireland } & \text { Skinner and } \\ (\underline{N}=1,380 & \text { et al. (1972) } & (1966) & \text { Castle (1969) } \\ & (\underline{N}=255 & (\underline{N}=363) & (\underline{N}=78)\end{array}$

Very serious or

Permanent injury

$\begin{array}{lll}4.6 & 2.0 & 11.6\end{array}$

Serious

$36.5 \quad 11.8$

25. 5

73.0

Not Serious

53.3

71.4

44.6

25.5

No injury /

Unknown

12.2

19.8

TABLE XIII

HOSPITALIZED CHILD ABUSE VICTIMS

Study

Gil (1970)
N Percent

N Hospitalized Length of Stay

$1,380 \quad 40.0$ to 1 day: $4.7 \%$

2-7days: $10.6 \%$ $8-30$ days: $14.0 \%$ over 30 days: $7.3 \%$

\begin{tabular}{lccc}
\hline Fergusson et al. (1972) & 255 & 17.3 & \\
\hline Paulsen and Blake (196.9) & 64 & 33.0 & \\
\hline Simons et al. (1966) & 313 & 36.0 & \\
\hline Johnson and Morse (1968) & 101 & 44.6 & \\
\hline $\begin{array}{l}\text { Glazier (1971) } \\
\text { Birrell and Birrell (1968) }\end{array}$ & 363 & 15.7 & average stay: 22 \\
days & \\
\hline & & & $\begin{array}{r}\text { average stay: } 6-7 \\
\text { weeks }\end{array}$
\end{tabular}


Finally, Gil (1970) finds that nonwhite children suffer proportionally more severe injuries as do children whose family income is less than $3 ; 500$ dollars per year in 1967\%. Since Gil did not control for either race or income, given the fact that they are closely related, it seems likely that if there is a relationship between nonwhites and severity of injury, there will very likely be a congruent relationship between income and severity of injury. Moreover, poor nonwhites whose children receive severe injuries are most likely to go to public hospitals for treatment which are the most frequent and consistent sources of reporting for child abuse incidents. In any event, Fergusson et al. (1972) found that $16 \%$ of Europeans and $17 \%$ of non-Europeans were severely injured calling into question Gil's earlier results. These relationships require more study before any reasonable conclusion can be made.

In sum, it appears that injuries to abused children follow a pattern of high frequencies of welts and bruises, fractures, and head injuries, and lacerations. Compared with data on child victims of accidents, there is a disproportionate number of head injuries and fractures explained by the frequent beatings and use of blunt instruments used to exercise control over the child coupled with the fact that younger children and infants are more susceptible to serious injuries in view of their physical fragility and immobility. 


\section{PREVIOUS AND SUBSEQUENT ABUSE}

Researchers do not disagree that a high proportion of abused children have had a history of physical mistreatment and that, without effective intervention, they can expect a future of mistreatment. Studies differ according to what percent of the children suffered previous abuse (See TABLE XIV). Variations in rates of previous abuse are due largely to the different ways in which histories were determined and the completeness and accurateness of the data.

TABLE XIV

\section{PREVIOUSLY ABUSED CHILDREN}

Study

Simons et al. $(1968$

Morse (1970

Morse and Johnson (1968)

Lauer et al. (1974)

Ebbin et al. (1969)

Glazier (1971)

O'Neill (1973)

Terr (1970)

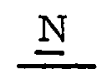

313

23

101

130

50

376

110

10
Previous abuse (\%)

33.0

35. 0

40.0

43.8

50.0

61. 3

80.0

80.0

Some studies eg. Weston (1968) relied on autopsies in the cases of fatalities stemming from abuse. The autopsies naturally revealed any internal injuries sustained previous to or concurrent with the fatal injury, although more superficial wounds which had completely healed were not recorded. Nevertheless, $64 \%$ of the physically abused children in the sample $(\underline{N}=36)$ displayed injuries superimposed on previous injuries indi cating the typical repetitive pattern of child abuse. 
Johnson and Morse (1968) determined the rate of previous abuse by computing the number of study children who had previously been reported to the Division of Services for Children and Youth for physical mistreatment. They found that $40 \%(\underline{N}=67)$ had been reported for prior physical injury. There is a strong possibility that a greater percentage of the children had been abused but had simply not come to the attention of the Division either because the previous incident had been misdiagnosed as an accident or the injury was not detected or reported. Gil (1970) determined that "at least half" of the abused children in his sample had suffered previous injury. He notes that information regard. ing the history of fully one quarter of the sample was lacking and he extrapolates the actual percentage of previous abuse at about $60 \%$. Fergusson et al. (1972) employed the most comprehensive approach in determining the rate of previous abuse and consequently present the most reliable data. Previous abuse was established if: at the time of the abuse incident under study the child displayed medical evidence of previous injuries; or it was established upon interrogation that a caretaker had inflicted previous injury; or the child had come to prior attention for suspected or alleged abuse. Their survey indicated that $73 \%$ of the sample subjects $(\underline{N}=255)$ had suffered previous abuse.

Given the repetitive pattern of child abuse, it is not unexpected that children previously identified as child abuse victims are nevertheless rembused. About two-thirds of the children originally diagnosed as abused by Holter and Friedman (1968) were returned to the hospital 
with new injuries. In a follow-up of the original study of 78 battered children, Skinner and Castle (1969) found that $60 \%$ of the identifiable cases $(\underline{N}=40)$ has been reabused. Martin (1972) citing Helfer asserted that "if an abused child is returned home with no intervention, he is exposed to a 20 to 50 percent risk of permanent injury" (p. 103). Finally, Silver et al. (1969) discovered that $34 \%(\underline{N}=34)$ of abused children referred to community services were nevertheless re-abused. In conclusion, repetitive injury is the significant pattern of child abuse.

\section{PAST AND PRESENT FUNCTIONING}

In attempting to gain a complete picture of the child abuse victim, it is important to explore the history of his physical, intellectual, social and psychological functioning. Unfortunately, the re is a paucity of documentation about these areas with respect to abused children for several reasons. For one thing, few researchers have the opportunity to obtain a complete medical and social history of the abused child. Many abused children, if not seriously injured, a re returned to their homes and not seen or heard about again since child abusing families appear to be especially mobile. Even when families remain in the area for follow-up interrogation, they are often uncooperative about disclosing information on themselves or their children. Also, record-keeping and record collection from the several sources which have had previous contact with the child abuse victim and his family 
are simply not adequate in most cases to develop and verify a full case history. Since many abuse victims tend to be younger children or infants, there is obvious difficulty in conducting intelligence or psychological tests. Naturally, the child has not established a record of performance, for instance, in school. Even when the child is old enough to undergo testing, often the emotional trauma surrounding the child abuse incident makes the child incapable of performing in a way that accurately reflects his actual level of development. Finally, the fact that a large percentage of abused children in study samples are nonwhite and concurrently from the lower socioeconomic stata will introduce the problem of interpreting the available data. It is well established that these populations exhibit a higher degree of intellectual, social and psychological dysfunction, at least at measured according to cultural norms in a predominantly white society. Taking these factors into consideration, the data will support the general conclusion that abused children suffer a higher degree of deviance in all areas of functioning although it can not be specified to what extent dysfunction may stem from early and continuous, but undisclosed mistreatment.

Physical Functioning

What is known about the birth history of abused children indicates that physical difficulties begin with delivery and continue. Elmer (1967) reports that one third of her abused population $(\underline{N}=22)$ and none of her nonabused group $(\underline{N}=4)$ had low birth weights although all 
seven of the abused children came from poverty environments. However, Lenoski (1974) provides a controlled study which compares a large sample of abusing families $(\underline{N}=674)$ with a group of nonabusing families $(\underline{N}=500)$ approximately matched for socioeconomic factors and racial distribution. As noted above, Lenoski found that twice as many abused compared to nonabused children had a history of premature birth. Moreover, he found that the abused children suffered twice as many complications in delivery and that $24 \%$ of them were deliveredby Caesarean section compared with $3.2 \%$ of the control population (both significant at the .05 level). It is well known that premature children run a higher than ave rage risk of child abuse although it is not clear that the physical immaturity per se predisposes a child to susceptibility to injury. Elmer (1967) observes that in her sample $(\underline{N}=7)$ the median age of abused children was 11 months which suggests that their physical development was equivilant to a full-term newborn. Similarly, Klein and Stern (1971) found that the mean age of the twelve abused children born prematurely was 22.0 months and that only one child was injured less than two months after birth. This corroborates Elmer's hypothesis that physical immaturity resulting from prematurity does not itself explain the disproportionate number of abused children that have a history of prematurity.

Klein and Stern (1969) also find that in addition to prematurity, a significant number of abused children suffered major neonatal problems 
which may increase their vulnerability. Finally, Birrell and Birrell (1968) reported that $26 \%$ of the abused children in their study $(\underline{N}=42)$ suffered congenital difficulties of one sort or another. What emerges from the fragmented data about the postnatal history of the abused child is a pattern of prematurity and/or other complications in delivery compounded by major early illnesses or disabilities. Since, for example, Paulsen and Blake (1967) regard the phenomenon of "failure to thrive" i.e. the inability of an infant to sustain normal development for reasons unknown as precursor to child abuse it should be noted that Koel (1969), Newberger (1973) and Van Stolk (1972) find that a number of the abused children in their sample exhibited failure to thrive.

Fergusson et al. (1972) produce some other measures of physical dysfunction which are consistent with the data on postnatal development and supplementary information about subsequent development from other studies. For example, they found that $18.3 \%$ of the abused children were rated as more physically unattractive than average perhaps reflecting a higher incidence of congenital abnormalities or constitutional weakness although the possibility of previous abuse or concurrent malnutrition is not unlikely. No unexpectedly, $23 \%$ of the child abuse victims were rated as unusually inactive or overactive, $36.9 \%$ evidenced some degree of poor physical or motor development for the appropriate age level. Morse (1970) states that of nineteen cases, ten ranked in the lowest category (bottom 10\%) for height 
according to age and nine children were in the lowest category for weight as well. Similarly, Ebbin et al. (1969) observed that $30 \%$ of the abused children $(\underline{N}=50)$ suffered some type of growth retardation. More generally, both Fergusson et al. (1972) and Klein and Stern (1974) find that about one-third of the abused children in their studies had a history of medical problems. In sum, the data presents a mosaic which indicates that abused children have unusual histories of medical problems, growth retardation or both.

\section{Intellectual Functioning}

Measurement of intelligence under optimal conditions is difficult and approximate at best. Determination of the intelligence of abused children, given the emotional trauma of the incident itself, a likely history of poor physical health or retarded growth, and compounded by the fact the samples often include a disproportionate number of poor and nonwhite subjects is almost useless. Nevertheless, what data is available given the constraints listed above suggests that a significantly higher proportion of abused children are intellectually impaired.

Upon observation only, raters in the Fergusson et al. (1972) study determined that $37.6 \%$ of the abused children $(\underline{N}=255)$ fell into the retarded or below average categories. Morse (1970) diagnosed mental retardation in $43 \%(\underline{N}=21)$ of the abuse cases while Elmer (1967) reported that fully $79 \%$ of the subject children $(\underline{N}=19)$ demonstrated 
early signs of mental retardation. Employing an intelligence test, Elmer (1967) determined that none of the nonabused children but all twelve abused children scored less than 80 . In a later study Gregg and Elmer (1969) determined that the I. Q. range for abused children to be between 52 and 103 and that half the children $(\underline{N}=20)$ scored below 80 . While acknowledging that lower class children performed less well on 1. Q. tests, Elmer observes that no where in the literature was the rate below a score of 80 as high as $50 \%$ as it was for her sample of abused children.

From the available evidence no conclusive determination can be made regarding the intellectual functioning of abused children. Although, given the large number of head injuries sustained by abused children particularly at an early age and the possibility of neurologic impairment stemming from cranial injuries, it would not be inconsistent that abused children are intellectually impaired even when race and socioeconomic factors were controlled.

Social and Psychological Functioning

Most difficult to determine is the extent to which abused children exhibit abnormal social and psychological functioning. Naturally, the young age of many victims and the generally brief contact made any meaningful assessment of behavior impossible. Moreover, the problem of distinguishing between dysfunction previous to the abuse incident and difficulties stemming from the incident is very great. 
Unfortunately, no studies exist that match abused children with an appropriate sample population to determine the extent to which socioeconomic factors, for example, affect the validity of the little data that exist about the behavior of abused children. What evidence is presented is substantially observational data about the children which indicates that they have many social and psychological problems.

Gil (1970) found that $20 \%$ of his survey population were deviant in social interaction and general functioning. Morse (1970) found that $29 \%$ of the abused children $(\underline{N}=21)$ were emotionally disturbed. Martin (1972) noted that $38 \%(\underline{N}-42)$ of the children evidenced language delay. Johnson and Morse (1968) comment that "less than half of these children $(\underline{N}=101)$ showed satisfactory mental and emotional development" (p. 9). Gregg and Elmer (1969) found, however that when they compared abused with nonabused infants the former "did not differ in mood or activity, but were more easily distracted making them somewhat easier babies" (p. 437). They add that "tempermentally, the abused babies were easier than the rest, but the outstanding baby characteristic was the developmental retardation of more than half of the group." (p. 437). Gil (1970) reported that $13 \%$ of the abused children were enrolled in classes below their age level and 3\% of the school-aged children never attended school. Young (1967) calculated that $41 \%$ $(\underline{N}=890)$ of her sample population were truant but her study included both abused and neglected children. Apart from truancy, $8 \%$ were 
labeled delinquent. Similarly, Gil (1970) reports that 5\% appeared in juvenile court for offenses other than traffic violations.

In sum, the literature is conspicuously incomplete regarding the behavioral in contrast to the demographic features of the child abuse victim. The pattern that emerges from the largely fragmented data is that abused children, as Gil contends, are unusually impaired in all categories of functioning. To what extent impairment results from previous abuse or is explained by other variables which predispose an abused child to physical, intellectual or social and psychological dys function awaits further and more refined study and analysis.

\section{CHAPTER SUMMARY}

The actual incidence of child abuse is extremely difficult to ascertain and is likely to remain unknown. Reported rates of incidence underestimate the real size of the universe of child abuse incidents because they rely on inaccurate and incomplete reporting. The best estimate of the incidence of child abuse in the United States is approximately 500,000 to $1,500,000$ annual occurences.

The demography of the child abuse victim is sufficiently established although data on the medical and especially, the social and psychological history of abused children are currently inadequate to formulate valid conclusions. The abused child is usually very young, typically below the age of three. Neither race nor gender a re specifically 
related to child abuse although there is an uneven distribution by sex according to the age of the victim. Abusing families tend to have more than the average number of children, but usually select only one child frequently, the eldest or the youngest - as the target for abuse. That child is likely to have been born prematurely and to have had more than the usual number of serious physical illnesses or disabilities throughout his life. In addition, a significant number of abused children display intellectual and social and psychological dysfunctions which may have resulted from injuries sustained from previous abuse. Most injuries stemming from child abuse fall into the general category of superficial bruises and welts although compared with accidental childhood injuries, there is a higher frequency of fractures and head injuries. The largest proportion of serious injuries - many characterized by multiple trauma are suffered by younger children and infants due in part to their physical immaturity and therefore greater susceptibility to physical injury from as sault. 


\section{CHAPTER IV}

\section{CHILD ABUSERS}

This chapter assembles all the available data on the actual perpetrator of child abuse as well as relevant data regarding the environment in which abuse occurs. As discussed in detail below (see IDENTITY OF ABUSER, below) the perpetrator of child abuse is nearly always the parent of the child, and consequently, the discussion will concentrate on the social, economic, and psychological features of the family of the child abuse victim.

\section{AGE}

Simons et al. (1966), Gil (1970), and Fergusson et al. (1972) provide age distributions of large samples of abusing parents as follows :

\section{TABLE XV-A}

AGE DISTRIBUTION OF ABUSING MOTHERS

All figures in percentages $(\%)$

\begin{tabular}{|c|c|c|c|}
\hline Age (yrs) & Simons et al. & Gil & Fergusso \\
\hline Under 20 & 9.20 & 9.29 & 6.25 \\
\hline $20-24$ & 26.60 & 26.20 & 18.1 \\
\hline $25-29$ & 56.41 & 20.94 & 27.1 \\
\hline $30-39$ & 7.80 & 24.10 & 31.3 \\
\hline $40-$ & $\ldots$ & 19.47 & 17.25 \\
\hline
\end{tabular}


TABLE XV - B

AGE DISTRIBUTION OF ABUSING FATHERS

All figures in percentages $(\%)$

Age (yrs.).

Under 20

$2-24$

25-29

$30-39$

$40-$ $\underline{\text { Gil }}$

2. 77

16.41

17. 44

32. 00

31.38
Fergusson et al.

2.1

6.4

21. 3 .

38.1

32.1

What emerges clearly from the data is that the majority of abusing parents range in age from twenty to thirty years old. Mothers tend to be somewhat younger than fathers but this is consistent with data on the general population. However, a composite of six clinical studies (TABLE XVI) indicates that the average ages of the abusing mother and father are respectively 20.0 and 22.5 years old. This finding may reflect the established fact that studies drawing on hospital admissions are skewed toward younger children who receive more serious physical injuries and require medical care. Lauer et al. (1974) reported that nearly $21 \%$ of the mothers $(\underline{N}=114)$ and $9 \%$ of the fathers $(\underline{N}=89)$ of abused children were nineteen or younger compared with $8 \%$ of the control mothers $(\underline{N}=114)$ and control fathers $(\underline{N}=91)$ and that the differences were statistically significant ( $p$ at the .05 and .001 levels respectively). The study also found that the abused children were compara-. tively younger (mean difference of 4 months) than the sample of nonabused children. However, Holter and Friedman (1968) also found that 
abusing parents were significantly younger than nonabusing parents but that all the children were approximately the same age. The relatively small difference in the mean ages of the abused and nonabused children in the Lauer et al. study coupled with Holter and Friedman's finding suggest that age of the child does not fully explain the slightly younger age of the abusing parent population.

The fact that abused children a re often first-born in the family and that mistreatment is frequently linked to the inexperience of parents suggests an alternative explanation. While chronological age is not equated with emotional maturity, it would seem likely that parents with no prior experience in raising children and/or a bad experience in their own child-rearing would be less able to deal effectively with their first child. In any event the data do not establish that the slightly younger age of child abusing parents is a significant factor in child abuse.

TABLE XVI

MEAN AGE OF ABUSING PARENTS

$\underline{\text { Study }}$

Bennie and Sclare (1969)

Lauer et al. (1974)

Lenoski (1974)

Holter and Friedman (1968)

Melnick and Hurley (1969)

Skinner and Castle (1969)
Mother/Control

25.8

$22.5 / 26.5$

$26.8 / 28.6$

$23.0 / 29.0$

$23.8 / 25.6$

22.0
Futher/Control

28.0

$25.2 / 29.0$

$30.2 / 31.6$

$26.5 / 30.0$

25.0

\section{IDENTITY OF ABUSER}

All studies (TABLE XVII) find that most child abuse is inflicted 
by parents of the victim. For example Gil (1970) reports that $86.8 \%$ of the abused children in his survey were injured by their natural parents or parent substitutes. Since, according to Gil (1970) $90 \%$ of child abuse occurs within the child's own home, it is not unexpected that child abuse is predominantly a household affatr. Yet, siblings accounted for only 1. $1 \%$ of the perpetrators in Ireland's (1966) study; $9 \%$ in Johns on and Morse (1968); 4.5\% in O'Neill (1973) and 0.7\% in Gil (1970). Babysitters were responsible for $2.7 \%$ of the abuse incidents according to $O^{\prime} \mathrm{Neill}$ (1973); 5.7\% in Ireland (1966); and 2.0\% in Oregon (1972). Moreover, Gil (1970) reports that only $4.3 \%$ of the known perpetrators were relatives outside the immediate family and that $6.5 \%$ of the child abuse was committed by persons unrelated to the family eg. boarders, day care persons, neighbors, etc. In short, child abusers are for all intents and purposes the parents of the victim.

Although, as Gelles (1973) suggests, the culturally determined passive role of women presumes that they would be less likely to physically abuse children, nearly all studies show that more mothers abuse their children than fathers. For one thing, mothers normally spend the most time with children, particularly infants and young children, in their culturally assigned caretaker role. Moreover, within the abuser population, Gil (1970) found, for example, that $29.5 \%$ of those families were fatherless households. Where the father is present and unemployed i.e. he has greater ontact with his children, Kempe 
TABLE XVII

IDENTITY OF THE CHILD ABUSER

\begin{tabular}{|c|c|c|c|c|}
\hline Study & $\underline{N}$ & Mothers (\%) & Fathers $(\%)$ & $\begin{array}{l}\text { Step- } \\
\text { parent }(\%)\end{array}$ \\
\hline De Francis (1963) & 622 & 28.86 & 38.25 & \\
\hline Simons et al. (1966) & 293 & 29.0 & 19.0 & \\
\hline $\operatorname{Terr}(1970)$ & 10 & 90.0 & 10.0 & \\
\hline Bennie and Sclare (1969) & 10 & 70.0 & 20.0 & \\
\hline McRae (1973) & 132 & 31.8 & 27.2 & \\
\hline Gregg (1969) & 30 & 20.0 & 16.6 & \\
\hline Johnson \& Morse (1968) & 101 & 31.6 & 29.7 & \\
\hline Oregon (1973) & 382 & 34.0 & 28.0 & 14.0 \\
\hline Virginia (1973) & 92 & 37.0 & 29.3 & \\
\hline Schloesser (1964) & 54 & 55.0 & & \\
\hline Ireland (1966) & 363 & 34.2 & 26.8 & \\
\hline Kroeger (1965) & -- & 21. 0 & 23.0 & \\
\hline Johnson (1965) & --- & 56.1 & 16.8 & \\
\hline Steele (1970) & 120 & 80.0 & 20.0 & \\
\hline Glazier (1971) & 251 & 32.3 & 44.2 & \\
\hline Gil (1970) & 1380 & 33.8 & 30.2 & 16.0 \\
\hline
\end{tabular}


TABLE XVII (continued)

\section{IDENTITY OF THE CHILD ABUSER}

Study

De Francis (1963)

Simons et al. (1966)

$\operatorname{Terr}(1970)$

Bennie and Sclare (1969)

McRae (1973)

Gregg (1969)

Johnson and Morse (1968)

Oregon (1972)

Virginia (1973)

Schloesser (1964)

Ireland (1966)

Kroeger (1965)

Johnson (1965)

Steele (1970)

Glazier (1971)

Gil (1970)
Siblings $(\%) \quad$ Other $(\%) \quad$ Unknown $(\%)$

32.89

14. 0

38.0

0.0

10.0

0.0

19. 0

22. 0

23.3

40.0

9.0

19.7

2. 0

12. 0

10.0

13.1

20.6

8.6

36.4

1. 1

24.7

13. 2

16. 0

30.0

18. 7

8. 4

0.0

6.8

16.7

6.8

12.1

1. 1 
and Schmidt (1974) state that the incidence rate differential between abusing mothers and fathers is eradicated. This is consistent with the finding that the father's unemployment is significantly related to child abuse (see Employment, SOCIOECONOMIC FACTORS, below). Several studies (Fergusson et al. 1972; Paulsen and Blake 1969) indicate that a significant number of abusers are parent substitutes. For example, Gil (1970) determined that $16 \%$ of the abuse perpetrated by parental figures was committed by someone other than the natural parents of the victims. However, Gil does not provide figures on what percentage of a comparable control population of nonabused children have parent substitutes. When Light (1973) reanalyzed Gil's data he found that "other" parents i.e. step-parents, adoptive parents and foster parents are "generally less likely to abuse when the perpetrator's sex is controlled as a third variable" (p.590). Since nearly every abusing parent substitute (89\%) was identified as male in Gil's (1970) survey, his finding merely reflects the fact that there are few abusing stepmothers simply because most children, according to custom, live with their natural mothers in the event of divorce or separation. Yet there appear to be intuitively a disproportionate number of substitute parents in child abusing families which partially reflects the general atmosphere of disruption and instability that surrounds these families (see FAMILY STRUCTURE, below). If controlled for fatherless households, sex of substitute parents, and contact hours, the data supports the conclusion 
that mothers and fathers are equally potential abusers.

Several authors eg. Johnson and Morse (1968) and De Francis (1963) cited in Silver (1968) attempt to establish a relationship between the sex of the perpetrator and the severity of injury sustained by the victim which indicates that mothers are more likely to seriously injure a child abuse victim. Johnson and Morse (1968) report that "injuries induced by the father typically consisted of bruises and welts. Wounds and fractures were more typical when the mother was the abuser" (p. 6). In his earlier review of the literature Silver (1968) determined that "mothers inflicted more serious injuries and were responsible for more fatalities" (p. 808). Gil (1970) likewise reported that women, particularly single women, inflict the most serious injuries. These data conform to the general observation that mothers are in closer and more frequent contact with their children, particularly infants and younger children. Since it is well known that immature children are especially susceptible to physical injury, it is expected that mothers are more likely to commit more severe and more frequent abuse. In fact Silver et al. (1971) discovered that for children under two years old, mothers were the abusers three times as frequently as fathers.

Simons et al. (1966) conclude that parents more readily abuse children of their own sex. No other study corrobates this information. In fact, the pattern of data suggests that the opposite is true i.e. mothers more often abuse sons and fathers more often abuse daughters. The 
evidence indicates that fathers tend to abuse older children which is consistent with the finding that they more often induce superficial bruises and welts. Given the general finding that a disproportionate number of abused older children and adolescents are female, it appears that fathers are more likely to abuse daughters. However, the problem of distinguishing between physical abuse and sexual molestation and/or injury stemming from sexual abuse makes this relationship tentative pending further study. Mothers are undoubtedly more likely to abuse male children primarily because there are more male live births and thus more males in the younger age range. Moreover, mothers are more likely to abuse younger children in the first instance so there is a natural association between female perpetrators and male victims. Thus far, the evidence does not establish a significant relationship between the sex of the perpetrator and of the victim.

While Gil (1970) determined in his 1967 survey that $95 \%$ of the recorded child abuse incidents were committed by one perpetrator; he also found that the incident "rarely took place in a diadic context" (1968, p. 19). In most cases, other individuals - notably, the other parent - were present in addition to the victim and perpetrator. The data coincides with Silver's (1968) observation that although one parent actually assaults the child, the other parent either overtly or covertly supports the attack. Brown and Daniels (1968) comment that "usually one of the spouses is responsible for the act and the other spouse, 
through having knowledge of the abuse, did nothing about it" (p. 90). As Elmer (1967) insightfully observes, inasmuch as the nonabusing spouse who fails to protect that victim against attack is equally accountable, the specific identity of a child abusing parent is ultimately of no great significance in understanding the etiology of child abuse.

In summary, most child abuse is committed by the parents or parent substitutes of the victim and it is rare that persons outside the family are involved. Although mothers are more likely to abuse their children, this finding is best explained by the simple fact that mothers are in greater contact with children. Although only one parent actually assaults the child, usually the other parent is overtly or covertly involved.

\section{FAMILY ENVIRONMENT}

In assessing the degree of stability in child abusing families one immediately encounters the usual difficulties of attempting to identify significant differences between child abusing families and the social, racial, and economic groups from which they are drawn. Indices such as the number of fatherless households or the number of families with both natural parents are standard measures of normative family structure for the nuclear family. To compare child abusing population composed of a disproportionate number of nonwhite families against those measures is to ignore the existence of the extended family 
structure that prevails among these groups. In short, the immediate assumption that a family without both natural parents is pathogenic and that children in these families are more likely to be abused can be a facile conclusion. On the other hand, the business of child-rearing is difficult in the best of material circumstances and family conditions. Where the re is a major disruption in the family caused by, for example, the departure of a parent or the separation of child from parent, the resulting stress may increase the potential for abuse. Although the evidence presented below is not conclusive, it is accurate to say that almost all indices of stress to families, taking into consideration ethnic or racial differences in viable family structures, distinguish the child abusing family.

One traditional index of family dis ruption is the number of single parent households among abusing families compared with nonabusing families. While Young (1967) found that a third of the subjects in her survey of neglecting and abusing families lacked one parent, she drew from a population with a disproportionate number of nonwhite families and she did not furnish control data with which to compare her findings. Likewise, Gil (1970) found that $29 \%$ of all the abusing families in his 1967 survey were without a father or father substitute. Specifically, he found that $37 \%$ of the Black families and $42 \%$ of the Puerto Rican families were fatherless compared with less than $20 \%$ of the white families. However, Simons et al. (1966) comment that "the 
marital situation among the abused families did not differ from that of the specific population groups from which these families come"! (p. 2786). Yet, when Ebbin et al. (1969) compared child abusing families $(\underline{N}=50)$ with nonabusing families drawn from the same population, they found while a high proportion of both abused children (50\%) and nonabused children (40\%) lived with their mothers only, the difference between the two groups was statistically significant at the .001 level. Moreover, the outpatient population contained a significantly high number of nonwhite families than the study sample which is strong evidence that abusing families are in fact less likely to have both parents living in the household.

Interestingly enough, the Ebbin et al. study shows that while $62 \%$ of the control population of families was married, only $33 \%$ of the abused white children and $18.1 \%$ of the abused nonwhite children lived in a household with married parents. Most other studies (Fergusson et al. 1972; Lenoski, 1974; and Simons et a1. 1966) found that a substantial majority of abusing parents were married. Most surprising is Lenoski's statistically significant finding that $96.7 \%$ of the parents of abused children ( $\underline{N}-674)$ but only $54.2 \%$ of the parents of the non abused children $(\underline{N}=500)$ were married (p at the .05 level). Curiously enough, his study was conducted at the same Los Angeles hospital during and subsequent to the Ebbin et al. study cited above. However, part of the discrepancy in the respective findings may be explained by the fact 
that sometime after the Ebbin et al. (1969) study Los Angeles County Hospital became the regional center for child abuse cases so that the nonwhite, lower socioeconomic population which lived near the hospital and served as the control group was significantly different from the largely white population of the whole county. Moreover, as Young (1967) discovered in her survey, abusing and neglecting parents remarried quickly. While the data show that most abusing parents are married and not distinguishable from the general population on that account, it is obvious as Simons et al. (1966) point out that marriage per se does not indicate family stability. They found that although two-thirds of the families $(\underline{N}=293)$ in their child abuse study were married, fully" one third of the families displayed evident discord or actual separation" (p. 2786). Similarly, Fergusson et al. (1972) reported that while $82 \%$ of the child abusing parents $(\underline{N}=255)$ were legally married, $43 \%$ of the marriages were characterized by severe problems and general disharmony.

Other indices of the family environment of abused children are furnished by Fergusson et al. (1972). They determined, for example that more than two-thirds of the abused children compared with one-half of the nonabused children experienced at least one major change during the course of their lives i.e. a change in a parent figure within the home or a change of homes. Only one-third of the abused children had lived with their natural parents their entire life. More importantly, $42 \%$ of the abused children had experienced a significant separation from their 
mothers during a part of the first three years of their lives. Not unexpectedly, Fergusson et al. discovered that significantly more mothers who had been separated from their children were the ones who actually abused their children.

Although, there is no conclusive data that establishes that single parent families, or commonlaw families particularly abuse children, the pattern of data indicates that a general theme of disruption and instability runs through the relationship between the abused child and his family. Obviously, the assumption that marriage per se indicates family cohesiveness which in turn means that children from married households are less susceptible to abuse is facile. However, on a number of indices that measured continuity in the family regardless of the kind of relationship between parents, it was clear that abusing families provide an unusually unstable environment for their children. Consequently, unfavorable family conditions as reflected by singleparent families, separations and divorces, etc. must be considered significant factors in child abuse.

\section{SOCIOECONOMIC STATUS}

Paulsen and Blake (1969) state that "although physical child abuse occurs in every strata $\overline{I s i c} /$ of society, there is more documented evidence of such abuse occurring more frequently in the lower socioeconomic levels" (p. 93). Nearly all studies demonstrate that on standard measures of socioeconomic status, child abusing families have low 
achievement. On the other hand, nearly all child abuse studies draw on a population in the lower socioeconomic strata primarily because child abuse is more easily detected and more frequently reported among these groups for reasons discussed in Chapter II. Generally, the data will not support the conclusion that the etiology of child abuse is poverty and its associated conditions because it is self-evident that not all poor people abuse children and it is sufficiently well established that some although how many is not likely to be documented - individuals in the upper-middle and upper socioeconomic classes physically abuse their children. What is significant is the interrelationship among poverty, inadequate housing, unemployment, etc. that creates a stressful environment which undoubtedly precipitates violence in the face of immense frustration and child abuse as a variant of that generalized violence.

\section{Employment}

Most studies clearly indicate that there is a high rate of unemployment or underemployment among abusing families although no study provides data on employment for comparable control populations. Intuitively, however, the rate of unemployment seems unusually high. For example Simons et al. (1966) reported that more than half the abusing families $(\underline{N}=275)$ were unemployed. Likewise, Holter and Friedman (1968) found that only about 55\% of the abusing families $(\underline{N}=10)$ were gainfully employed. In addition, Young (1967) showed that for $58 \%$ of the abusing and neglecting families $(\underline{N}=300)$ in her study, employment had 
not been continuous for more than two years. Although Young's study included neglecting families in which poverty is considered a direct cause of inadequate care, Johnson and Morse's (1968) study of exclusively abusing families $(\underline{N}=85)$ shows similarly that only "one-half of the fathers were working at capacity and only about one -third had substantial full-time employment" (p. 12). Galdston (1965) observed that among abusing families, it was not uncommon for husbands and wives to alternate employment so that the fathers were relegated to the care of the children a substantial part of the time. Gelles (1973) interprets this finding in light of the theory of intra-family violence posited by O'Brien (1971). He argues that violence will occur when the traditionally dominant member of the household (male-adult-husband-father) fails to maintain his status as the provider. However, Steele and Pollock (1968) found that on the basis of their admittedly small series $(\underline{N}=60)$, both employed and unemployed fathers assaulted their children. They concluded that "while the factors of employment and unemployment have some contributing effect on the presence or absence of child attack, they are certainly not crucial" (p. 107),

However, Gil (1970) found that "at the time of abuse, $11.8 \%$ of the fathers were unemployed at a rate about three times as high as the nationwide unemployment rate" at that time (p. 111). In re-analyzing Gil's (1970) data, Light (1973) determined that in fact, among child abusing families where the father was unemployed, "abuse was more 
likely to be directed against a very young child" (p. 587). Gil's finding that the more serious injuries occurred in families with an income less than $\$ 3,000$ is consistent with the general conclusion that the presence of the father in the household in a caretaking role resulting from unemployment is a situation that probably contributes to abuse of children, especially infants and younger children.

Income

Gil (1970) presents the most complete data (TABLE XVIII) on the income distribution of child abusing families $(\underline{N}=1,380)$ compared with the general population in the United States. It should be noted that the control population (approximately $15 \%$ nonwhite) does not match the racial distzibution of the sample study $(60.8 \%$ nonwhite $)$. The disproportionate number of nonwhites naturally skews the income distribution toward the lower incomes given the relationship between race and socioeconomic status in this country. Other studies which do not match for race also show that abusing families have comparatively low incomes. For example, Elmer (1967) reported that the median income of the eleven abusing families in her study was 310 dollars compared with 410 dollars for the city of Pitts burgh. However, her study contained about twice the percentage of nonwhite families as live in the city. Likewise, Johnson and Morse (1968) found that no more than one-third of the abusing families in their study $(\underline{N}=85)$ were "managing adequately with available income" (p. 12). Again, more than $40 \%$ of the families in that study were nonwhite. 
However, when Melnick and Hurley (1969) matched study sample and control populations $(\underline{N}=10)$ for race, they found that the weekly income of abusing mothers was 92.8 dollars and the income for nonabusing mothers was 93.8 dollars.

As might be expected from the data presented above, a substantial proportion of child abusing families receive public assistance. For example Gil (1970) records that $60 \%$ of the abusing families in his survey had received assistance during or prior to the year that the survey was conducted. Elmer (1962) on the basis of her small study $(\underline{N}=11)$ concluded that "child abuse mainly occurs among families on relief" (p. 21). Simons et al. (1966) also found that more than half of the abusing families $(\underline{N}=293)$ were on welfare. Interestingly enough they discovered that there were a number of families whose income level actually qualified them for welfare, but who did not avail themselves of public assistance. While all the studies cited above show that a substantial number of child abusing families are on welfare, this is not inconsistent with the established fact that the populations the samples are drawn from are skewed toward poverty families. In other words, a low level of income does not cause child abuse although abusing families are often in a state of financial need. But, as Johnson and Morse (1968) point out, and as the Simons' et al. data suggest, child abusing families may be distinguished by their inability to use what income is available. Further study and more precise data about the financial 
status of child abusing families is required in order to test their hypothesis.

\section{TABLE XVIII}

\section{INCOME DISTRIBUTION OF ABUSING FAMILIES \\ $1967-68$}

All figures in percentages $(\%)$

\begin{tabular}{lcr} 
Income (dollars) & Abusing Families & U.S. \\
\cline { 2 - 3 } Under 3,000 & 22.3 & 12.5 \\
$3,000-4,999$ & 26.1 & 12.8 \\
$5,000-6,999$ & 16.2 & 16.1 \\
$7,000-9,999$ & 12.7 & 24.3 \\
$10,000-14,999$ & 2.6 & 22.4 \\
$15,000-. .-$ & 0.4 & 12.0 \\
Unknown & 19.8 & 0.0
\end{tabular}

\section{Occupation}

Gil (1970, p. 111) confirms the established relationship that

"the occupational status of parents of the sample cohort corresponded to their low educational status" in presenting the occupa tional distribution of abusing parents (TABLE XIX). Most other studies are consistent with Gil's findings since these studies similarly draw on populations in the lower socioeconomic strata for reasons discussed in Chapter II. For instance, Johnson and Morse (1968) found that among abusing families $(\underline{N}=85) 30 \%$ of the providers were employed in unskilled occupations, $50 \%$ in skilled or semi-skilled occupations and very few in professional or managerial positions. Likewise, Schloesser (1964) reported that the majority of wage earners in the abusing families $(\underline{N}=36)$ were 
common laborers. While none of the studies cited above compared the occupations of abusing parents with nonabusing parents from the same socioeconomic group. Paulsen and Blake (1967) determined that although none of the abusing fathers $(\underline{N}=47)$ in their study was employed as a professional or semi-professional, that pattern was consistent with the general population from which the abusing families were drawn. Moreover, Steele and Pollock (1968) reported that their sample of child abusers (1968) included individuals employed as professionals in industry, business, and finance. The data reflect the interrelationships among education, income, and occupation and the fact that most child abuse studies employ a population from the lower socioeconomic strata. Consequently, there appears to be no significant relationship between occupation and child abuse given that the type of employment among child abusing families reflects occupational distribution of the social, economic, and racial groups to which they belong.

TABLE XIX

OCCUPATIONS OF ABUSING PARENTS

All figures in percentages $(\%)$

Category

Clerical

Laborers

Operatives

Craftsmen, foremen

Service workers

Electrical workers

Professional, technical

Managerial workers

Sales

Students

Private household workers

Unknown
Fathers

24.5

21.5

15.8

10.8

4.3

6.6

2. 4

0.5

13.5
Mothers

16. 4

3.2

11.2

0.9

31. 2

6.0

4. 7

0.4

6.3

19. 0 
Educátion

The general relationships between and among socioeconomic status, race, and educational achievement demonstrated by Jencks et al. (1972) is reflected in the data on the educational achievement of abusing parents (see TABLE XX) presented by Gil (1970). In general, most studies indicate that abusing parents have a lower than average educational achievement measure in years of schooling compared with the nation as a whole but not significantly different from the social, racial, and economic groups to which the parents belong. For example, Glazier (1971) found that $28 \%$ of the mothers and fathers of abusing children $(\underline{N}=334)$ had a high school education. Given that a third of the sample was Black and that the majority of subjects had low incomes, the number of high school graduates is consistent with the educational achievement for these groups according to the national census. Melnick and Hurley (1969) matched abusing and nonabusing mothers $(\underline{N}=10)$ for race and socioeconomic status and found that the difference in years of schooling was not significant. Holter and Friedman (1968) compared abusing ( $\underline{N}=10)$ and nonabusing families $(\underline{N}=34)$ on the extent of post-high school education and found that none of the parents in the former group, but $27 \%$ of the parents in the latter group received some higher education. However, the size of the abusing sample is too small to establish any meaningful conclusion. Lenoski (1974), however, reported that $9 \%$ of the parents of abused children $(\underline{N}=674)$ and $7 \%$ of the parents of nonabused children $(\underline{N}=500)$ were college educated. Steel and Pollock (1968, p. 107) found that'educational 
achievement ranged from partial grade school up to advanced postgraduate degrees" among their sample of child abusing parents $(\underline{N}=60)$. In sum, the data indicate, as expected, the child abusing parents have low educational achievements which is consistent with the social, economic, and racial groups to which they belong. Education is not a signïficant factor in child abuse.

TABLE XX

\section{EDUCATIONAL ACHIEVEMENT OF ABUSING PARENTS}

All figures in percentages $(\%)$

Schooling

No school

Less than 9 years

9 - 12 years

High school graduate

Some college

College graduate

Not Stated
Mother

0.4

24. 0

40.6

16.7

4. 4

0.4

13.5
Father

0.3

23.5

16.8

16.8

6.4

1. 3

34.9

Religion

The data established that all religions are represented among child abusing families. A comparison among selected child abuse studies (TABLE XXI) shows that, by and large, the religious distribution of abusing families is not especially different from the general population. Lenoski (1974) reported that $80.1 \%$ of the abusing families $(\underline{N}=674)$ but only $61.5 \%$ of the nonabusing families $(\underline{N}=500)$ expressed a religious affliation. Similarly, Young (1967) found that among severe and moderate abusing and neglecting families $(\underline{N}=300)$, the severely abusive families most 
frequently stated a religion. Yet, Lenoski (1974) and others (Elmer, 1967, 1972; Currie, 1970; Holter and Friedman, 1968) find that abusing families characteristically avoid outside contacts. The apparent conflict in these findings may be harmonized by Young's (1967) observation that because abusing families "are outwardly well organized and conforming to community standards, it is quite possible that they would more often have some religious affliation" (p. 176). In other words, few abusing families are actively involved in their religions. In the few cases where child abusers were actively involved in their religion, Steele and Pollock (1968) found that the parents belonged to fundamentalist denominations. In general, religious preference is not a significant factor in child abuse.

TABLE XXI

RELIGIOUS AFFILIATION OF CHILD ABUSERS

All figures in percentages (\%)

\begin{tabular}{lcccr} 
Religion & $\begin{array}{c}\text { Gil } \\
(N=1,380)\end{array}$ & $\begin{array}{c}\text { Paulsen } \\
(\underline{N}=96)\end{array}$ & $\begin{array}{c}\text { Ebbin } \\
(\underline{N}=50)\end{array}$ & U.S. \\
\hline Protestant & 62.0 & 45.0 & 48.0 & 66.0 \\
Roman Catholic & 25.5 & 26.0 & 20.0 & 26.0 \\
Jewish & 0.7 & 1.0 & 14.0 & 3.0 \\
Other & 1.8 & 3.0 & --- & 1.5 \\
Mixed & ---0 & ---- & 18.0 & ---- \\
Not stated & 10.0 & 26.0 & 0.0 & 3.5
\end{tabular}

Mobility

Schloesser (1964) observes that one distinguishing characteristic of abusing families is their high mobility. Gil (1967) found that nearly half the families $(\underline{N}=1,380)$ had been "living one year or less in 
the homes they occupied at the time of the incident, about one quarter had been in their homes from 1 to 3 years, and about $27 \%$ had lived in their homes for 3 years or longer"' (p. 113). Johnson and Morse (1968) likewise report that most of the abusing families in their study $(\underline{N}=85)$ had moved at least once in the previous year. In an attempt to follow up the abused children in their study, Birrelland Birrell (1968) discovered that $33 \%$ of the children $(\underline{N}=42)$ could not be located five years subsequent to their initial hospitalization. Since the studies cited above draw substantially from the lower socioeconomic stata where mobility rates are higher, the results may reflect this fact. However, in a study controlled for socioeconomic status, Lauer et al. (1974) found that $66 \%$ of the abusing families $(\underline{N}=130)$ "had been at their last addresses less than ten months compared with $42 \%$ of the controls" (p. 69). Only 5\% of the abusing families occupied the same premises for more than thirty months compared with $20 \%$ of the control population ( $p$ at the .01 level). Lauer et al. conclude that despite the fact that Americans are characteristically mobile, the "study families were considerably more nomadic" than a nationwide estimate $(20 \%)$ or the study control population (p. 70$). "$ This conclusion is consistent with other findings that few abusing families tend to remain detached from the community. The data strongly suggest that child abusing families a re unusually mobile.

\section{Housing}

With the single exception of Elmer (1967) whose small study 
sample $(\underline{N}=11)$ is subject to random error, all studies have reported that the substantial majority of child abusing families live in rented housing. Naturally, the predominance of urban and poor families in child abuse study populations would predict that fewer families would live in privately owned housing. However, Holter and Friedman (1968) reported that $89 \%$ of the children hospitalized for abuse $(\underline{N}=10)$ but only $11 \%$ of the children hospitalized for accidental injuries $(\underline{N}=34)$ lived with families that rented apartments. Moreover, Light (1973) determined that abusing families were more likely to live in apartment houses than comparable nonabusing families even when the employment of the father is controlled. Curiously enough, both Gil (1970) and Morse and Johnson (1968) found that despite the general poverty of abusing families, relatively few of these families lived in publicly subsidized housing. Moreover, Holter and Friedman (1968) reported that $30 \%$ of the children sustaining accidental injuries compared with $70 \%$ of the abused children lived in substandard neighborhoods. Likewise, Young (1967) found that only $21 \%$ of the abused and neglected children $(\underline{N}=300)$ lived in adequate housing.

The data appears to conform to a pattern of living that distinguishes child abusing families from nonabusing families of a comparable socioeconomic class. Although fewer families in the lower socioeconomic strata are likely to own private homes - especially, urban nonwhite families subject to housing discrimination - child abusing families are even less likely to live in their own home. Moreover, these families 
seem to avoid availing themselves of public housing even when they are eligible. They more frequently live in substandard housing. However, the precise relationship between housing and child abuse can not be established in view of the limited available data.

\section{Section Summary}

For all standard measures of socioeconomic status, the data show that a majority of child abusing families have low achievement. However, when compared with appropriate central populations, most socioeconomic indices of status do not distinguish that child abusing family.

Only two significant findings emerge from the mass of data. It appears that unemployment is significantly related to child abuse to the extent that it increases the likelihood that the father will commit abuse. Indication of social isolation eg. high mobility, lack of religious involvement is the most consistent factor that distinguishes the abusing family.

\section{INTELLECTUAL, SOCIAL, AND PSYCHIATRIC FUNCTIONING}

From a view of the literature emerges a major problem in assessing the significance of the past and present functioning of parents who who abuse their children. As Caffey (1972b) suggests, it must be determined whether or not "perpetrators of child abuse are characteristically of normal intelligence. - and suffer from the same neuroses, the same emotional and character problems in the same range as any 
randomly selected group of the same milieu and size" (p. 16I).

Immediately, there is the difficulty of obtaining complete and accurate information about the past and present intellectual, social, and psychiatric functioning of the child abuser. While most states now maintain centralized records of child abuse, they generally contain only demographic data on the child abuse victim, and to some extent, the child abuse perpetrator. Most child abuse studies focus attention on the abused child and do not provide detailed information about the perpetrator. On one hand, for obvious reasons, child abusers are frequently uncooperative with investigators seeking personal information. On the other hand, prolonged contact with child abusing families is atypical due in large part to the unusual transience of these families. Determination of the past and present functioning of child abusers relies on an aggregation of data gathered from studies employing different indices of measurement. For example, the intelligence of the perpetrator was ascertained by a combination of standa rdized tests and simple appraisal after interview. For the most part, social functioning was determined by the known previous and current institutionalizations and contacts with public social welfare and law enforcement agencies. The analysis of psychiatric functioning rests on some diagnostic personality testing, clinical interviews, and general observation of the perpetrators. In general, few studies attempt to measure the extent to which the deviance found among child abusers 
is significantly greater than that found among the social, economic and racial groups to which they belong. Consequently, while the data will show that child abusers exhibit an apparently high degree of deviance in all areas of functioning, the evidence will not indicate that intellectual, social, and psychiatric functioning especially distinguishes child abusers.

\section{Intellectual Functioning}

The early data on child abuse indicated that perpetrators exhibited low intelligence. In 1961 the Journal of the American Medical Association cited in Paulsen and Blake (1967) stated that the incidence of abuse varied inversely with the intelligence of the parents. Sheridan (1965) had reported that $70 \%$ of the criminally neglectful mothers $(\underline{N}=100)$ i. e. purposefully inadequate care resulting in physical injury scored in the "mental defective to dull/normal range" on intelligence tests. How these results compared, for example, with the balance of the population of the prison in which the study was conducted is not established. Bennie and Sclare (1969) presented the following distribution of intelligence forten abusing parents: Mentally deficient - 5; Dull - 1; Low average - 1; Above average - 3. While the data indicate a disproportionate number of intellectually dysfunctional subjects, the small size of the study sample does not preclude random error. Moreover, the a uthors did not state on what basis they made a determination of the perpetrator's intelligence. Gil (1967) provided a considerably larger sample $(\underline{N}=1,380)$ and found that $10.4 \%$ of the mothers and $6.9 \%$ of the 
fathers of abused children were intellectually deviant although Gil does not explain either what deviance means or on what basis that determination was made. Neither study cited above supplied a matched control population with which to compare results. For example, in the case of Gil's survey which included a disproportionate number of nonwhites from the lower socioeconomic strata, that possibility exists that socioeconomic class and race may be intervening variables in the relationship between child abuse and intellectual deviance.

However Smith et al. (1973) recently measured the intelligence of his sample of thirty-five parents who abused their children and ascertained that about $25 \%$ of the subjects scored in the "subnormal" range on the Weschler Adult Intelligence Scale. In addition, they found that $23 \%$ of the subjects demonstrated abnormal electro-encephalograms and on the basis of these findings suggest that there is a significant relationship between intellectual dysfunction and child abuse. But, Smith et al. provided no data on the demographic characteristics of the abusing parents nor a control population on which to adequately assess the results of their study. Although their sample $(\underline{N}=201)^{\prime}$ consisted of a disproportionate number of child abusing parents from the lower socioeconomic strata, Fergusson et al. (1972) found that the subjects were generally of average intelligence and did not differ significantly from comparable nonabusing parents. However, the assessment of intelligence was made solely on the evaluation of the investigator during 
the interview with the abusing parents. Steele and Pollock (1968) conducted standardized intelligence tests on their subjects $(\underline{N}=60)$ which comprised a heterogeneous sample according to race and socioeconomic class. They found that most of the subjects were of average intelligence, scoring in the 90 to 110 category (range: 73-130). On the basis of these results, they concluded that "there is no evidence of a significant relationship between intelligence as measured by intelligence tests and abuse" (p. 135).

In sum, what little data available is not sufficiently refined to establish any significant difference between the intellectual capacity of abusing and nonabusing parents.

\section{Social Functioning}

As noted above, the determination of the social functioning of child abusers relies mainly on the known past or present institutionalization and/or contact with social and law enforcement agencies. Naturally, there is substantial difficulty in aggregating the relevant material eg. records from schools, courts, penal institutions, public agencies, etc. In spite of the paucity of data, a composite of studies indicates that child abusing parents have a consistent history of antisocial behavior.

For example Young (1967) found that $37 \%$ of the abusing and neglecting parents in her survey $(\underline{N}=300)$ had a criminal record although the nature of the conviction was not stated. Naturally, there exists the 
possibility that a number of these parents may have been convicted. for mistreating a child. Fergusson et al. (1972) reported similarly that $32 \%$ of the abusing parents $(\underline{N}=238)$ were convicted of a crime previous to the child abuse incident. Moreover, only about $3.6 \%$ of these parents were convicted for the mistreatment of children. Gil (1970) found that 4. $7 \%$ of the abusing mothers but that almost $16 \%$ of the father had a criminal record. Likewise, Bennie and Sclare (1969) indicated that all three of the male abusers $(\underline{N}=10)$ had previous criminal records although the small sample size makes the finding unrepresentative. However, Fergusson et al. (1972) also show that male abusers are much more likely to have criminal records than the female abusers. They reported findings consistent with Gil's proportional distribution cited above $57.4 \%$ of the abusing fathers but only $15.3 \%$ of the abusing mothers had previous convictions. They explain the disproportion of male to female abusers (4:1) with criminal records by the fact that the conviction rate is 9.6 times greater for males than females. More than $50 \%$ of the male parents of abusing families compared with $41 \%$ of the nonabusing male parents $(\underline{N}=213)$ were subject to a previous criminal prosecution. However, both abusing and nonabusing females $(\underline{N}=228)$ had nearly the same rate of previous prosecution. In other words, the data indicate the male abusers have an unusual criminal record even when compared with an appropriate control population. The data suggest that males with previous criminal records are more likely to abuse children 
despite the fact that males in general are more frequently convicted than females. Moreover, Fergusson et al. show that of the fathers of abused children with criminal records, $58 \%$ were actually responsible for the physical attack against the child. In sum, prior criminal activity, at least for males, may be a significant factor in child abuse. Other evidence relating to the social functioning of abusing parents comes in the form of a curious paradox. On one hand, the studies cited below indicate that abusing parents as children and as adults have a substantial history of contact with the courts and welfare and protective services. On the other hand, few child abusing families maintain contact with voluntary community and social organizations. For example, Gil (1970) found that $6.5 \%$ of the abusing parents in his survey had appeared as children in juvenile court and that $7.8 \%$ had been in foster care at some point in their childhood. Fergusson et al. (1972) found that about $22 \%$ of the abusing parents $(\underline{N}=238)$ had themselves come to the notice of a child welfare agency as children or adolescents compared with only $13 \%$ of the nonabusing parents. As adults, more than $70 \%$ of the parents had come to the attention of the child welfare agencies for reasons other than the mistreatment of children compared with about half of the control population. In sum the available evidence demonstrates that abusing parents have a history of contacts with public agencies that manifest maladaptive behavior.

In contrast, social contact with and participation in community 
activities among abusing families is extremely limited. For example, Holter and Friedman (1968) observed that whereas over half the abusing families in their study were known to community agencies i.e. welfare, police, courts, emergency rooms, only two of the ten families were known to have contact with social groups such as the church, PTA, unions, etc. Elmer (1972) stated that the most significant feature about child abusing parents was the extent to which they maintained no associations outside the home. Lenoski (1974) provides two meaningful and related measures of self-isolation. He found that $81 \%$ of the abusing parents $(\underline{N}=674)$ compared with $43 \%$ of the nonabusing parents $(\underline{N}=500)$ expressed a preference to resolve problems by themselves. He also found that only $10 \%$ of the former group, but $88 \%$ of the latter group publicly listed their telephone numbers. Steele and Pollock (1968) comment only half-facetiously that within a home with the shades drawn in broad daylight and an unlist ed phone number, "the chances are high that the inhabitants abuse their children" (p. 106). Another indication of the isolationary behavior of abusing parents is Helfer's (1973) observation that child abusing parents are both incapable of asking for help when they are in trouble and actively resist offers of help when they are available. Although a substantial percentage of his survey sample was poor, Gil (1968) found that less than $13 \%$ of the child abusing families received services from voluntary social agencies during or prior to the study year. Young (1967) discovered that what particularly distinguished severely abusing parents in her survey was their con- 
sistent refusal to cooperate with social agencies in providing care and/ or in permitting foster placement for their children. Morris and Gould (1963) provide an accurate summary of the findings when they conclude that "child abusing parents are isolates, belong to no organizations, and have few bridges to society. They do not seek help and are rarely known to voluntary social agencies" (p. 46).

\section{Psychiatric Functioning}

Evaluating the data on the psychiatric functioning of child abusing parents encounters two major problems. On one hand, less is known and more is disputed about this area of lluman activity than any other. Consequently, there is wide variation in the way psychiatric functioning is assessed and the interpretation of what constitutes deviance. Moreover, as Gelles (1973) points out, the determination of psychological problems in child abusing parents involves the possible fallacy of ex post facto diagnosis discussed generally in Chapter II. Bennie and Sclare (1969) furnish a specific example when they found that all their child abusing patients had personality disorders characterized by impulsive behavion. Diagnosed after the child abuse incident, it is self-evident that a parent who severely injures or kills his child displays impulsive behavior. In Gelles (1973) words, "this type of a nalysis does not distinguish the behavior in question from the explanation." Assuming that this fallacy can be overcome by relying on diagnostic data generated independently from that generated from the abuse 
incident, the re remains the problem of determining whether the incidence of psychiatric dysfunction is significantly and specifically related to child abuse. Friedman (1972) states that "when suggesting etiological implications, one must always compare the incidence of psychological problems in abusive parents to the occurence of similar problems in other groups" (p. 81).

For example, alcoholism, according to Wertham (1972), is often unrecognized as a casual or contributing factor in child abuse. Young (1967) determined that $12 \%$ of both neglecting and abusing parents in her survey $(\underline{N}=300)$ were severe and chronic drinkers. Both Birrell and Birrell (1968) and Johns on and Morse (1968) found that alcoholism was a problem in about $20 \%$ of the child abusing families $(\underline{N}=124)$. None of these studies provided data on the rate of alcoholism among the social, economic; and racial/ethnic groups to which the child abusers belonged nor do they determine whether the perpetrator was actually intoxicated at the time of the attack. Although Simons et al. (1966) found similarly that $20 \%$ of the abusing parents $(\underline{N}=293)$ were alcoholics or drug addicts, they implied that this percentage was not inconsistent with the comparable population in general. Steele and Pollock (1968) found only one case $(\underline{N}=60)$ of true alcoholism in their heterogeneous sample and determined that while "drinking was occasionally a source of marital conflict $[$ it $/$ bore no significant, direct relationship to episodes of child beating" (p. 93). However, Gil (1970) reported that in $12.9 \%$ of 
the incidents of child abuse recorded in his sample $(\underline{N}=1,380)$ the perpetrator of the attack against the child was intoxicated, although again he provides no data on the extent of alcoholism in a control population matched for race and socioeconomic status. Fergusson et al. (1972) furnishes the most complete and reliable data on the relationship between alcoholism and child abuse. He compared the drinking habits of abusing mothers $(\underline{N}=228)$ and fathers $(\underline{N}=213)$ with a comparable population of nonabusing mothers $(\underline{N}=81)$ and fathers $(\underline{N}=74)$. The drinking pattern of the two groups of mothers as about the same, $35 \%$ of the abusing fathers and $28 \%$ of the nonabusing were classified as heavy drinkers. However, almost half the heavily drinking fathers were personally responsible for injuring the child. However, the Fergusson et al. study fails to determine whether the assailant was intoxicated at the time of the abuse incident. In sum, the data indicate that a significant number of child abusing parents have alcoholic problems which may contribute to child abuse but the evidence does not establish that a significant number of parents are actually intoxicated at the time of the abuse incident.

There is substantial disagreement among authors about the extent to which parents who abuse children suffer mental illness and/or psychological problems. Defined as psychosis or acute neurosis, mental illness among child abusing families is found to be relatively rare according to most studies including Steele (1970), Caffee (1972), Kempe (1973) and others. They estimate that approximately no more than $10 \%$ 
of the child abusers fall into discrete, nosological categories of mental illness: Birrell and Birrell (1968), 7.6\%; Delsordo (1963), 5\%; Johnson and Morse (1968), 4.7\%. Likewise, few child abusers were diagnosed as mentally retarded eg. O'Neill (1973), 2.7\%. Mental illness indicated by admission to a mental institution was present in about $6.6 \%$ of the abusing mothers and $4.4 \%$ of the abusing fathers. $(\underline{N}=1,380)$ according to Gil (1970), although he provides no data on the admissions rate for a comparable control population. However, Fergusson et al. (1972) calculated the expected and observed incidence of mental institution admissions for abusing parents $(\underline{N}=238)$ in their survey. They found that rate of admission for abusing fathers (3. $2 \%$ ) was not significantly different from the general population but that the incidence of admissions for abusing mothers $(9.0 \%)$ was statistically significant ( $\mathrm{p}$ at the .01 level). More generally, Fergusson et al. found that $30 \%$ of the abusing mothers but only $13 \%$ of the abusing fathers displayed indications of mental illness measured by admissions to a psychiatric hospital or medical diagnosis of mental illness or serious problems. In sum, most child abusers are not mentally ill according to conventional diagnoses nor do the ones who are diagnosed as mentally ill fall into a particular nosological category. However, the re is some evidence to suggest that more mothers than fathers of abused children suffer mental illness. Although, as Birrell and Birrell (1968) note, abusing parents represent the full spectrum of psychological functioning that includes psychopathic as well as normal states, several studies indicate that 
many abusing parents share common psychological characteristics. Johnson and Morse (1968) found that the abusing parents in their study were beset by anxiety, hostility, and depression as well as being evasive and resistant. However, given the context of the study, it is likely that this description represents a typical reaction of the parents under the circumstances. Several authors (Cohen, 1966; Steel and Pollack, 1968; Bennie and Sclare, 1969) agree that many abusing parents suffer from inadequate personalities characterized by unmet dependency needs and lack of identity. Kempe (1973) stated that almost all the child abusers in his experience were "dependent, inadequate, yearning people" (p. 803). Steele and Pollock (1968) administered a battery of diagnostic tests Rorchach, Thematic Apperception Test (TAT), Sentence Completion Test, and Figure Drawing - to the sixty subjects in their study. They state that:

The test reports specifically mention strong oral-dependent needs as significant intrapsychic areas of difficulty for every patient tested. In four-fifths of the patients, unresolved identity conflicts were cited as major determinants of their behavior, and in nearly as many, depressive trends and/or noteworthy feelings of worthlessness were noted. (122).

These common features of the abusing parent are confirmed. in Melnick and Hurley's (1969) study of abusing mothers ( $\underline{N}=10)$ who were tested with the California Test of Personality, Manifest Rejection index, Family Concept Inventory, and the TAT. Between and among all four tests, the interscorer reliability exceeded .80 using the product-moment correlation. Comparing results with a group of ten mothers matched 
for race and socioeconomic status, the authors found that the tests indicated that the abusing women "showed both marked dependency and feelings of being unable to cope with the responsibilities of life. . (p. 747). In addition, the abusing mothers expressed a higher level of need frustration and a lower need to be nuturant compared with the nonabusing mothers. These differences were statistically significant at the .05 level. The data indicate that the abusing mother have on one hand, strong personal needs that go unmet or unsatisfied and, on the other hand, "have a deficient capacity for empathizing with and administering to children's needs" (p. 747). Melnick and Hurley (1968) note that the se conclusions must be weighed in light of the small sample as well as the low socioeconomic status and race (all subjects were Black) of the study sample.

Section Summary

Given the limitations on the reliability and validity of the data, the general pattern that emerges is one of substantial social and psychological dysfunction among child abusing parents. Specifically, there is significant evidence of a history of anti-social and abnormal behavior among abusers perhaps reflecting a disruptive and abusive environment in their own childhood. Moreover, although no one basic personality structure describes all abusing parents there appears to be a pattern of features - strong unmet dependency needs, lack of identity, inability to be nuturant - that are common to child abusers. 


\section{CHAPTER SUMMARY.}

Nearly all child abuse is committed by parental figures most of whom are the natural mothers and fathers of the abused children. Most abusing parents are around 25 years old reflecting the fact that the majority of abuse victims are infants and younger children. Mothers are the most frequent child abusers largely because they have the most contact with children and almost always care for their children in the event of separation or divorce from the father. Although one parent actually attacks the abuse victim, generally speaking, the other parent is overtly, or at least covertly involved in abusing the child. Abusing parents are characterized by a history of anti-social and abnormal behavior. Although no one basic personality structure describes all abusing parents, there appears to be a pattern of features that are common to child abusers. A general atmosphere of instability and disruption surrounds the child abusing family indicated by frequent discord among married couples, separations, and single-parent families. Moreover, on all measures of socioeconomic status, child abusing families have low achievement and suffer the stresses of poverty and its associated conditions. Even where assistance is available, abusing families fail to seek help and actively refuse help when it is offered. These families are often transient and maintain little social contact with the community and limited affiliation with social organizations. 


\section{CHAPTER V}

\section{EVALUATION OF CHILD ABUSE THEORIES}

In Chapter I two major theories of child abuse were outlined to provide a theoretical framework for the presentation and analysis of the literature. Chapter II introduced and discussed the methodological problems encountered in a review of the child abuse literature. In Chapters III and IV, child abuse studies were compared and contrasted in an effort to determine what were significant factors in child abuse. Chapter $\mathrm{V}$ attempts to evaluate the respective theories of Gil and Steele and Pollock in light of the findings as a way of relating and summarizing what has been learned about child abuse in the course of this review.

As was suggested at the end of Chapter I, neither Gil's sociocultural theory nor Steele and Pollock's psychodynamic theory provides a complete and coherent explanation of the relationships between and among the factors determined to be significant to child abuse. Any other outcome would have been unexpected. Both theories predicted findings that in fact turned out to be significant. Each theory made predictions that were in conflict with the findings. Moreover, both theories failed to predict some factors that are significantly related to child abuse. An evaluation of each theory is presented in light of the major findings of this review and according to the analytical framework set forth 
directly above.

I. EVALUATION OF THEORIES ACCORDING TO SIGNIFICANT FACTORS ABOUT THE CHILD ABUSE VICTIM

Incidence

Since both theories relate child abuse to the widespread use of physical force in contemporary child-rearing practices, both theories imply that the incidence of child abuse is high. Gil's original estimate modified by Light's corrections indicate the re are about one million incidents of child abuse in America each year. Compared with other childhood problems eg. sexual molestation, or cancer, child abuse does not constitute a numerically significant problem. This does not mean that child abuse is not a problem worthy of serious attention and action, but only that relatively few families physically abuse their children.

Age

One of the very few unequivocal findings that emerges from the review of the literature is that child abuse victims are more than likely to be infants or younger children. Since the sociocultural theory assumes that any child can be attacked given the combination of environmental stresses which precipitate abuse, the theory predicts an even distribution of abuse victims according to age. This part of the theory is not supported by the finding. Psychodynamic theory states that child abure stems from a primitive expression of disappointment over the inability of a 
child to respond to excessive demands. Since infants and younger children are least able to respond to demands and moreover, impose demands upon the parent, the theory predicts that they are most likely to be abused. This part of Steele and Pollock's theory is consistent with the finding.

\section{Gender}

Neither theory establishes a relationship between gender and child abuse. Gil's theory simply posits that child abuse is randomly perpetrated on victims given the necessary circumstances. Steele and Pollock locate the genesis of child abuse at a developmental stage prior to sexual differentiation according to psychoanalytic theory. The common prediction is consistent with the finding that the gender of the victim or the perpetrator is not a significant factor in child abuse.

\section{Birth History}

Since neither theory emphasizes the role of the victim in the explanation of child abuse, prematurity, serious neonatal illnesses and illegitimacy are not regarded as primary causes of child abuse. The analysis of the data indicates that whereas illegitimacy is not specifically related to child abuse, premature children and children who had serious illnesses after birth run a significantly higher risk of being abused. These findings are consistent with, but not predicted by, both theories. On one hand Gil's theory designates environmental stress as a major casual component of child abuse. The financial and emotional strains 
involved in caring for a "special" child create stresses that can precipitate abuse. On the other hand Steele and Pollock's theory suggests that the identification with the "sick" child by the parent may cause an abusive response. Despite the burdens on parents imposed by premature or seriously ill children, the psychodynamic theory does not regard this factor as an adequate cause of child abuse.

Since illegitimacy is linked to socioeconomic status, Gil's theory would predict a high rate of illegitimacy among abused children as an artifact of the primary relationship between child abuse and socioeconomic class. However, premarital conception may reflect an unwanted pregnancy which imposes stress on a large family or an impoverished family or both. Since, as discussed below, child abuse, according to the psychodynamic theory, is not significantly related to socioeconomic factors, the legal status of a child would not be significantly related to child abuse.

Sibship

The data supports the conclusion that abusing families have more than average number of children even when controlled for race and socioeconomic class. Since Steele and Pollock's emphasis on a specific abusing relationship patterned after the relationship between the perpetrator as a child and his parent predicts that the child who most closely fits the pattern will be abused. In contrast, Gil's theory suggests that the victim of abuse is often selected by the circumstances that precipi- 
tated the attack. The finding that only one child in a multiparous family is typically abused contradicts the expected finding of the latter theory. Again, the sociocultural theory posits that any child, regardless of age, gender, or position in the family is susceptible to being abused given the necessary circumstances. The psychodynamic theory which attaches great significance to the relationship between the age of the child and physical abuse would predict that the youngest child runs the highest risk of abuse. The finding that the youngest and oldest children are most likely to be abused does not conform to either explanation.

Injuries

Both theories relate child abuse to the inappropriate and unusually severe use of physical force in disciplining children among abusing families. The finding that a substantial number of the assaults against children were committed with blunt instruments lends support to both theories. While bruises and welts constitute the most frequent child abuse injuries, neither theory specifically predicts the type of injury sustained by abused children. Nor does either theory explain the prevalence of head injuries and bone fractures except by implication, in the case of Steele and Pollock, who accurately predict that abuse victims are more likely to be infants and younger children. Since the susceptibility to fracture is greater in the early development of children when tissue is soft, the findings a re not inconsistent with, but not predicted by the psychodynamic theory. 
Since both theories relate child abuse to the reliance on the use of physical force in abusing families, both would predict that abuse victims were and will be subject to repeated assault. The finding that repetitive injury is a significant feature of child abuse lends substantiation to both theories.

\section{Past and Present Functioning}

The pattern that emerges from the data indicates that abused children are unusually impaired in intellectual, social, and psychological functioning. Gil's theory includes dysfunctional behavior as a predisposing cause of child abuse whereas Steele and Pollock's theory considers dysfunction as a contributing not a primary factor in child abuse. Consequently, the finding is crucial to Gil's theory but not a necessary ingredient for the Steele and Pollock explanation.

II. EVALUATION OF THEORIES ACCORDING TO SIGNIFICANT FACTORS ABOUT THE CHILD ABUSE PERPETRATOR

Age

Quite simply, neither theory relates the age of the perpetrator to child abuse and the data confirm that age is not a significant factor in child abuse.

Identity of the Abuser

Since Steele and Pollock's theory rests on the relationship between a parent and a child, the theory necessarily predicts that the 
perpetrators of child abuse are the parents of the victim. Gil's theory makes no prediction about the identity of the abuser. The finding that child abusers are almost always the parents of the abused child does not contradict either theory.

Although Steele and Pollock regard the breakdown in mothering as a major part of the explanation of child abuse, they acknowledge that the mothering function is not restricted to maternal figures. Gil's theory attaches no significance to the identity of the perpetrator and consequently neither theory predicted the finding that mothers are the most frequent perpetrators of abuse.

Family Environment

The pattern that emerged from the data characterized the abusing household as an unstable and disruptive environment. Naturally, Gil's theory which relates environmental stress to child abuse strongly predicts that abusing families are more than likely to face stresses from unfavorable family conditions including marital discord, separations, and divorces. Steele and Pollock's theory establishes no special relationship between family environment and child abuse.

\section{Socioeconomic Status}

Steele and Pollock state unequivocally that child abuse is not related to socioeconomic factors whereas Gil maintains that these factors play a significant role in child abuse. On nearly all measures of 
socioeconomic status, child abusing families fell into the lower strata. However, when compared with appropriate control populations no socioeconomic factors except the father's employment status and the family's mobility distinguished abusing households. The general finding supports the psychodynamic theory, but destroys a major component of the sociocultural theory.

The specific finding that unemployment is significantly related to child abuse, however, is predicted by Gil's theory and not predicted as consequential by Steele and Pollock who consider unemployment as a contributing factor only. Curiously enough, neither theory specifically predicted what emerges as one of the clearest and most consistent factors that distinguishes the child abusing family. On every index of social relations eg. mobility, religious involvement, community activity affiliation, unlisted telephone numbers, etc. child abusing families displayed a significant lack of community contact and a pattern of self-isolation.

\section{Past and Present Functioning}

Both theories are supported by the general finding that child abusing parents have a substantial history of anti-social behavior and psychiatric dysfunction. Specifically, pattern of psychological features that begin to emerge from the data support the dynamics of dependency and lack of mothering which largely explain child abuse according to Steele and Pollock. However, the finding, based on limited available 
data, that some but not all or most abusing parents report being abused as children gives only partial support to the core of the psychodynamic theory. Gil's theory regards dysfunctional behavior particularly reflecting violent tendencies as predisposing perpetrators to attack children and to that extent, the general finding is consistent with the sociocultural theory.

\section{CHAPTER SUMMARY AND CONCLUSION}

Neither Gil's sociocultural theory nor Steele and Pollock's psychodynamic theory provides a comprehensive explanation for the findings about child abuse identified in this review. Many factors determined to be significantly related to child abuse were not predicted by one or both of the theories. Specifically, neither theory addresses itself to an explanation of the role of the victim in child abuse. For example, neither theory establishes a causal connection between prematurity and child abuse.

More or less, Gil's sociocultural theory adequately identifies and relates some of the environmental stresses which precipitate child abuse incidents. However, to attribute child abuse to predominantly environmental stresses including and emphasizing socioeconomic, racial, and chance factors ignores the self-evident observation that most families in the lower socioeconomic strata, and most nonwhite families do not abuse their children. Moreover, the theory does little to explain 
why families in the middle and upper classes abuse their children. In other words, the sociocultural theory does not take account of the pattern that emerges from a review of the literature. In brief, child abuse does not appear to be a random phenomenon in the sense that any and all children are susceptible to injury from a physical assault and/ or that all families under adverse conditions will attack their children.

Steele and Pollock's theory provides a historical explanation of why a parent abuses his child, but much of that theory is not verified by the data usually generated by child abuse studies to date. Further research is required, including longitudinal studies of abused children, to determine in what ways and by what mechanisms a parent's own childhood experiences are transformed into an abusing relationship with his child. Although many of the socioeconomic factors do not distinguish child abusing families from the social, economic, and racial groups to which they belong, Steele and Pollock's theory does not go far in relating the distinct social behavior of the family to child abuse. For example, the clear finding that abusing families remain isolated from contact with the community is not adequately related to an abusing parent's childhood experiences by the psychodynamic theory.

What ultimately emerges from an analysis of the two theories is that anothe $r$ theory is required to coherently explain all the factors dete rmined to be significantly related to child abuse. Helfer (1973) initiates a fruitful approach to the formulation of an etiology of child 
abuse when he suggests that it is best explained by the relationships between and among the parent, the environment, and the child himself. The task of reformulating a child abuse theory incorporating these components and evaluating it against the present and future findings awaits the next generation of students of child abuse. 


\section{SELECTED BIBLIOGRAPHY}

Adelson, Lester. "Slaughter of the Innocents." New England Journal of Medicine, 264:26 (June 1961), 1345.

Adelson, Lester. "The Battering Child." Journal of the American Medical Association, 222 (October 1972), 159-161.

American Humane Association. Children's Division. "Protecting the Battered Child." Denver, Colorado: American Humane Association, 1962.

Asch, Stewart and Rubin, Lowell. "Postpartum Reactions: Some Unrecognized Variations." . American Journal of Psychiatry, $131(8)(1974), 870-874$.

Bakan, David. Slaughter of the Innocents: A Study of the Battered Child Phenomenon. San Francisco: Jossey-Bass, 1971.

Baron, Michael A., et al. "Neurologic Manifestations of the Battered Child Syndrome." Pediatrics, 45 (6) (1970), 1003-1007.

Bennie, E. and Sclare, A. "The Battered Child Syndrome." American Journal of Psychiatry, 125 (7) (1969), 975-979.

Birrell, R. G., and Birrell, J.H.W. "The Maltreatment Syndrome in Children: A Hospital Survey." The Medical Journal of Australia, 2 (December, 1968), 1023-1029.

Bloch, H. "Dilemma of 'Battered Child' and 'Battered Children'." New York State Journal of Medicine, 73 (March, 1973), 799-801.

Blumberg, M. "When Parents Hit Out." Twentieth Century, 173 (Winter, 1964), 39-44.

Boisvert, J. "Battered Child Syndrome." Social Casework (October, $1972), 475-480$.

Brown, John A. and Daniels, Robert. "Some Observations on Abusive Parents." Child Welfare, XLVII, No. 2 (1968), 89-94. 
Bryant, Harold D. et al. "Physical Abuse of Children in an Agency Study." Child Welfare, 42 (March, 1953), 125-130.

Burland, Alexis J. et al. "Child Abuse: One Tree in the Forest." Child Welfare, LII, 9 (November, 1973), 585-592.

Caffey, John. "Multiple Fractures in Infants Suffering From Subdural Hematoma." American Journal of Roentology, Radium Therapy and Nuclear Medicine 56 (1946), 163-173.

Caffey, John. "Some Traumatic Lesions in Growing Bones Other Than Fractures and Dislocations - - Clinically Radiological Features." British Journal of Radiology; 30 (1957), 225-238.

Caffey, John. "The Parent-Infant Traumatic Stress Syndrome; (CaffeyKempe Syndrome), (Battered Babe Syndrome)." American Journal of Roentgenology, Radium Therapy, and Nuclear Medicine, 114 (February, 1972a), 218-229.

Caffey, John. "On the Theory and Practice of Shaking Infants." American Journal of Diseases of Children, 124 (Augest, 1972b). 161-169.

Chesser, E. Cruelty to Children. New York: Philosophical Library, Inc., 1952.

Child Abuse in Oregon, 1972 and 1973. Family and Child Services. Salem, Oregon: Child Services Division, 1973.

Child Abuse. Virginia Health Bulletin, Richmond, Virginia: State Department of Health, vol. 26, series no. 2, (October-November-December, 1973).

Cohen, M. "Psychologic Aspects of the Maltreatment Syndrome of Childhood." Journal of Pediatrics, vol. 69, no. 2 (August, 1966), $279-284$.

Court, Joan. "The Battered Child." Medical Social Work, vol. 22, no. 1 (April, 1969) Reprint.

Currie, J. R. B. et al. "A Psychiatric Assessment of the Battered Child Syndrome." South African Medical Journal, (May 30, 1970), 635-639. 
Davoren, Elizabeth. The Battered Child in California. San Francisco: San Francisco Consortium, 1973.

De Francis, Vincent, Child Abuse - Preview of a Nationwide Survey. Denver: American Humane As sociation, 1963.

De Francis, Vincent. Child Abuse Legislation in the 1970's. Denver: American Humane Association, 1970.

Delsordo, James D. "Protective Casework for Abused Children." Children 10:6 (November/December, 1963), 213-17.

Ebbin, Allan J. et al. "Battered Child Syndrome at the Los Angeles County General Hospital." American Journal of Diseases of the Child, 118 (October, 1969). 660-666.

Elmer, Elizabeth. "Hazards in Determining Child Abuse." Child Welfare (January, 1966), 28-33.

Elmer, Elizabeth. "Child Abuse: A Symptom of Family Crises." in Billingsley, Andrew, and Giovannoni, Jeanne M. Children of the Storm. New York: Harcourt Brace and Jovanovitch, 1972 .

Elmer, Elizabeth. Children in Jeopardy: A Study of Abused Minors and Their Families. Pittsburgh, Pa.: University of Pittsburgh Press, 1967.

Elmer, Elizabeth and Gregg, G. "Developmental Characteristics of Abused Children." Pediatrics, 40 (October, 1967), 596-602.

Fanaroff, Avroy A. "Follow-Up of Low Birth Weight Infants - The Predicative Value of Maternal Visiting Patterns." Pediatrics, 49 (February, 1972), 287-90.

Fergusson, David M. et al. Child Abuse in New Zealand. Wellington, New Zealand: A. R. Shearer, 1972.

Ferry, Peggy. "Child Abuse 1974: A Continuing Medical-Legal Challenge." Oregon State Bulletin, (March, 1974), 5-9.

Finestone, Samuel. "Issues Involved in Developing Diagnostic Classifications for Casework." Casework Papers, New York: Family Service Association of America, 1960. 
Fischoff, Joseph et al. "A Psychiatric Study of Mothers of Infants in the Growth Failure Secondary to Maternal Deprivation." Pediatrics, $79(2)$ (August, 1971), 209-215.

Flynn, William R. "Frontier Justice: A Contribution to the Theory of Child Battery." American Journal of Psychiatry, 127 (3) (1970), 375-379.

Fontana, Vincent. The Maltreated Child: The Maltreatment Syndrome in Children. 2nd ed. Springfield, Illinois: Charles C. Thomas, 1963.

Fontana, Vincent. "The Neglect and Abuse of Children." New York Journal of Medicine, 64 (1964), 215-224.

Fontana, Vincent. "Physical Abuse of Children." (Letter) Pediatrics, 45 (March, 1970), 509-510.

Fontana, Vincent J. Somewhere a Child is Crying: Maltreatment Causes and Prevention. New York: Macmillan, 1973a.

Fontana, Vincent J. "The Diagnosis of the Maltreatment Syndrome in Children." Pediatrics, 51, Supplement 4 (April, 1973b), $780-782$.

Friedman, Stanford B. "The Need for Intensive Follow-Up of Abused Children." in Kempe, C. Henry and Helfer, Ray E. eds., Helping the Battered Child and His Family. Philadelphia: Lippincott, 1972, pp. 79-92.

Gladston, R. "Observations of Children Who Have Been Physically Abused by Their Parents." American Journal of Psychiatry. 122 (4) (1965), 440-443.

Gelles, Richard J. "Child Abuse as Psychopathology: A Sociological Critique and Reformulation." American Journal of OrthoPsychiatry, 43 (4) (July, 1973), 611-621.

George, J.E. "Spare the Rod: A Survey of the Battered-Child Syndrome." Forensic Science, 2 (May, 1973), 129-267.

Gil, David and Nobel, John. "Public Knowledge, Attitudes and Opinions About Physical Child Abuse in the U.S." Papers in Social Welfare. Watham, Mass.: Brandeis University Press, 1967. 
Gil, David G. Nationwide Survey of Legally Reported Physical Abuse of Children. Boston: Brandeis University, Florence Heller Graduate School for Advanced Studies in Social Welfare, 1968a.

Gil, David G. "California Pilot Study of the Battered Child." in Helfer, Ray E. and Kempe, C. Henry eds. The Battered Child.

Chicago: Chicago Univiv. Press, 1968b, Appendix "A", pp.' 215-225.

Gil, David G. "Incidence of Child Abuse and Demographic Characteristics of Persons Involved. "in Helfer, Ray E. and Kempe, C. Henry eds. The Battered Child, Chicago: Chicago Univ. Press, 1968 c, pp. $19-39$.

Gil, David G. "Physical Abuse of Children: Findings and Implications of a Nationwide Survey." Pediatrics, 44 (Suppl.) (November, 1969), 857-864.

Gil, DavidG. Violence Against Children: Physical Child Abuse in the United States. Cambridge, Mass.: Harvard University Press, 1970.

Gil, David G. "Violence Against Children." Journal of Marriage and and the Family, (November, 1971), 637-648.

Gil, David G. "Violence Against Children." (Letter) Pediatrics; 49 (April, 1972), 641.

Giovannoni, Jeanne M. and Billingsley, Andrew. "Child Neglect Among the Poor: A Study of Parental Adequacy in Families of Three Ethnic Groups." Child Welfare, XLIX, no. 4 (April 1970), $198-204$.

Giovannoni, Jeanne M. "Parental Mistreatment: Perpetrators and Victims." Journal of Marriage and the Family, 33 (November, 1971), 649-657.

Glazier, Alice, ed. Child Abuse: A Community Challenge. Buffalo, N. Y.: Henry Stewart, Inc., 1971.

Goode, W. "Force and Violence in the Family," Journal of Marriage and the Family, 33 (November, 1971), 624-636.

Gregg, Grace S. and Elmer, Elizabeth. "Infant Injuries or Abuse?" Pediatrics, 44, no. 3 (September, 1969), 434-439. 
Helfer, Ray E. and Kempe C. Henry. ed. The Battered Child. 1st ed. Chicago: University of Chicago Press, 1968..

Helfer, Ray E. "The Child's Need for Early Recognition, Immediate Care, and Protection." in Kempe C. Henry and Helfer, Ray E. eds. Helping the Battered Child and His Family. Philadelphia: Lippincott, 1972, pp. 69-78.

Helfer, Ray. "The Etiology of Child Abuse." Pediatrics (Suppl.) 51, No. 4 (April, 1973), 777-779.

Helfer, Ray. "A Plan for Protection: The Child Abuse Center." Child Welfare, vol. XLIX, No. 9 (November, 1974a).

Helfer, Ray E. and Kempe C. Henry. eds. The Battered Child 2nd. ed. Chicago: Univ, of Chicago Press, 1974b.

Holter, J. C. and Friedman, S.B. "Child Abuse: Early Case Findings in the Emergency Department." Pediatrics (1968), 42-128.

Ireland, William H. "A Registry on Child Abuse." Children, 13 (May/ June, 1966), 313.

Issacs, S. "Neglect, Cruelty and Battering." British Medical Journal, $3(1972), 224-226$.

Jencks, Christopher. Inequality: Reassessment of the Effect of Family and Schooling in America. New York: Basic Books Inc, 1972.

Johnson, Betty and Morse, Harold. The Battered Child: A Study of Children with Inflicted Injuries.: Denver: Denver Department of Welfare, 1968.

Kadushin, Alfred. Child Welfare Service. New York: MacMillan, 1967.

Kempe, C. Henry. "The Battered Child Syndrome." The Journal of the American Medical Association, 181 (July, 1962), 17-24.

Kempe, C. Henry. "The Battered Child and the Hospital." Hospital Practice (October, 1969), 44-57.

Kempe, C. Henry and Helfer, Ray E. Helping the Battered Child and and His Family. Philadelphia: J. B. Lippincott, 1972. 
Kempe, C. Henry. "A Practical Approach to the Protection of the Abused Child and Rehabilitation of the Abusing Parent." Pediatrics, 51:4 Part II, (April, 1973), 8044-8812.

Klein, Michael, and Stern, Leo. "Low Birth Weight and the Battered Child Syndrome." American Journal of Diseases of Children, 122 (July, 1971), 15-18.

Koel, Bertram S. "Failure to Thrive and Fetal Injury as a Continuum." American Journal of Diseases of Children, 118 (October, 1969), $565-567$.

Lauer, Brian et al. "Battered Child Syndrome: Review of 130 Patients with Controls." Pediatrics; 54:1 (July, 1974), 67-76.

Lenoski, Edward F. "Translating Injury Data Into Preventative and Health Care Services - Physical Child Abuse." (Draft) Univ. of Southern Calif., School of Medicine, Los Angeles, 1974.

Light, Richard J. "Abused and Neglected Children in America: A Study of Alternative Policies," Harvard Educational Review, (November, 1973) 557-598.

Martin, Harold. "The Child and His Development" in Kempe, C. Henry and Helfer, Ray E. Helping the Battered Child and His Family. Philadelphia: Lippincott, 1972, pp. 93-114.

McRae, K. N. et al. "The Battered Child Syndrome." Canadian Medical Association Journal, 108, (April, 1973), 859-860.

Melnick, Barry and Hurley, John R. "Distinctive Personality Attributes of Child-Abusing Mothers." Journal of Consulting and and Clinical Psychology, 33 (6), 1969, 746-749.

Milowe, Irvin D, and Louire, Reginald S. "The Child's Role in the Battered Child Syndrome." Journal of Pediatrics, 65 (December, 1964), 1079-1081.

Morse, Carol W. et al. "A Three-Year Follow-Up Study of Abused and Neglected Children." American Journal of Diseases of Children, 120 (November, 1970), 439-446.

Morris, M. and Gould, R. "Role Reversal: A Necessary Concept in Dealing with the 'Battered Child Syndrome'." American Journal of Orthopsychiatry:, 33 (1963), 298-299. 
Morris, Marian G. and Gould, Robert W. "Role Reversal: A Concept in Dealing with the Neglected/Battered-Child Syndrome." in The Neglected/Battered Child Syndrome. New York: CW LA, 1963, pp. 29-49.

Myers, Steven A. "Maternal Filicide." American Journal of Diseases of Children, 120 (December, 1970), 534-536.

Newberger et al. "Child Abuse in Massachusetts." Massachusetts Physician, 32:1 (January, 1973), 31-38.

Newson, Elizabeth. Four Years Old in an Urban Community. Chicago: Aldine Publishing Co., 1968.

Newson, John and Elizabeth. Infant Care in an Urban Community. New York: International Universities Press, Inc., 1963.

Normura, F. M. "The Battered Child Syndrome: A Review." Hawaii Medical Journal. 25: (May-June, 1966), 387-50.

O'Brien, J. "Violence in Divorce Prone Families." Journal of Marriage and the Family, 33 (November, 1971), 692-698.

Oliver, J.E., and Taylor, Audrey. "Five Generations of Ill-Treated Children in One Family Pedigree." British Journal of Psychiatry, 119 (1971), 473-480.

O'Neill, N.A. et al. "Patterns on Injury in the Battered Child Syndrome." Journal of Trauma, 13 (April, 1973), 332-339.

Paulsen, Morris J. and Blake, Phillip R. "The Abused, Battered, and Maltreated Child: A Review." Trauma, 9 (1967), 1-136.

Paulsen, Morris J. and Blake, Phillip R. "The Physically Abused Child: A Focus on Prevention." Child Welfare, vol. XLVIII, no. 2 (February, 1969).

Platou, R. V. et. al. "Battery." Bulletin of Tulane Medical Faculty, 25, (May; 1964), 151-167.

Radbill, Samuel X. "A History of Child Abuse and Infanticide." in Helfer, Ray E. and Kempe, C. Henry, eds., The Battered Child. Chicago: Univ. of Chicago Press, 1974. pp. 3-21. 
Resnick, Phillip J. "Child Murder by Parents: A Psychiatric Review of Filicide." American Journal of Psychiatry, 126:3 (September, 1969), 325-35.

Rycroft, C. "Non-accidental Injuries." Review of: The Battered Child, Helfer, R. E. and Kempe, C. H. eds., New Society, June 20, $1968,221$.

Sargent, D. "Children Who Kill: A Family Conspiracy?" Social Work, 7 (1962), 35-42.

Schloesser, P.T. "The Abused Child." Bul, Menniger Clin., 28 (September, 1964), 260-269.

Silver, Larry B. "Child Abuse Syndrome: A Review." Medical Times, 96 (1968), 803-818.

Silver, Larry B. et al. "Does Violence Breed Violence?: Contributions from a Study of the Child Abuse Syndrome." American Journal of Psychiatry, 126 (1969), 404-407.

Silver, Larry B. et al. "Agency Action and Interaction in Cases of Child Abuse." Social Casework, 52 (3) (1971), 164-171.

Silverman, Broderic N. "Unrecognized Trauma in Infants, the Battered Child Syndrome, and the Syndrome of Ambroise Tardieu." Radiology, 104 (August, 1972), 337-353.

Siverman, F.N. "The Roentgen Manifestations of Unrecognized Skeletal Trauma in Infants." American Journal of Roentgenology, Radium Therapy, and Nuclear Medicine, 69 (1953), 413-427.

Simons, Betty et al. "Child Abuse: Epidemiologic Study of Medically Reported Cases." New York State Journal of Medicine, 5 (November, 1966), 2783-2788.

Skinner, Angela E. and Castle, Raymond L. Seventy-Eight Battered Children: A Retrospective Study. National Society for the Prevention of Cruelty to Children. Hoddesdon, England: Thomas Knight and Co., 1969.

Smith, S. M., et al. "E. E. G. and Personality Factors in Baby Batterers." British Medical Journal, 3 (July, 1973), 20-22.

Solomon, T. "History and Demography of Child Abuse." Pediatrics, Suppl. 51, 4 (April, 1973), 773-776. 
Spinetta, J. and Rigler, D. "The Child Abusing Parent: A Psychological Review." Psychological Bulletin, 77 (April, 1972), 296 304.

Steele, Brandt F. "Violence in Our Society." Pharos (April, 1970a), $42-48$.

Steele, Brandt and Pollock, Carl. "A Psychiatric Study of Parents Who Abuse Infants and Small Children." In Helfer, Ray E. and Kempe, C. Henry. eds. The Battered Child. 1st ed. Chicago: Univ. of Chicago Press, 1968, pp. 103-148.

Steele, Brandt F. "Parental Abuse of Infants and Small Children." Parenthood, Its Psychology and Psychopathology, eds. Anthony, E. James, and Benedel, Theresa. Boston: Little, Brown, 1970b.

Terr, Lenore C. "A Family Study of Child Abuse." American Journal of Psychiatry, 127:5 (November, 1970), 663-671.

Terr, Lenore, and Watson, Andrew. "The Battered Child Rebrutalized: Ten Cases of Medi-Legal Confusion." American Journal of Psychiatry, 124 (1968), 1432-1439.

Togut, Myra R. et al. "A Psychological Exploration of the Nonorganic Failure-To-Thrive Syndrome." Developmental Medicine and Child Neurology, 11 (1969), 601-606.

Van Stolk, Mary. The Battered Child in Canada. Toronto: McClleland \& Stewart Ltd., 1972.

Wasserman, S. "The Abused Parent of the Abused Child." Children, 14 (Sept. - Oct. , 1967), 175-179.

Wertham, Fredrick. 'Battered Children and Baffled Parents." Bulletin of the N. Y. Academy of Medicine, 48 (August, 1972), 887-898.

Weston, J.T. "The Pathology of Child Abuse" in Helfer, Ray E. and Kempe, C. Henry, eds. The Battered Child. 2nd ed. Chicago: Univ. of Chicago Press, 1974.

Wooley, P.V. and Evans, W. A。 "Significance of Skeletal Lesions in Infants Resembling Those of Traumatic Origin." Journal of the American Medical Association, 158 (1955), 539-543. 
Young, Leotyne. Wednesday's Child: A Study of Child Neglect and Abuse. New York: McGraw Hill, 1967.

Zalba, Serapio. "The Abused Child: I. A Survey of the Problem." Social Work (October, 1966), 3-16.

Zalba, Serapio. "The Abused Child: II. A Typology for Classification and Treatment." Social Work, XII, no. 1 (1967), 70-79.

Zalba, Serapio. "Battered Children." Transaction, 8 (July-August, $58-71$. 